\title{
Bridging the gap between coastal engineering and nature conservation?
}

\section{A review of coastal ecosystems as nature-based solutions for coastal protection}

\author{
Philipp Jordan ${ }^{1}\left[\right.$. Peter Fröhle ${ }^{1}$
}

Received: 11 August 2021 / Revised: 28 October 2021 / Accepted: 11 December 2021 / Published online: 23 February 2022

(c) The Author(s) 2022

\begin{abstract}
Under the umbrella term of Nature-based Solutions ( $\mathrm{NbS}$ ) fall measures from a wide range of disciplines. With regard to coastal protection, coastal ecosystems represent possible and promising NbS to coastal threats such as storm surges or erosion. Around the globe, the looming climate change and related developments in the coastal landscapes as well as a paradigm shift in societal views shifted the focus of decision-makers and researchers onto $\mathrm{NbS}$ for coastal protection, driving the need for a comprehensive up-to-date review of coastal ecosystems like salt marshes, mangroves, seagrass meadows, beaches, dunes, coral, and shellfish/oyster reefs and their benefits for Water, Nature and People alike. While existing reviews of NbS have mainly focused on the idea of softer coastal protection in general and constraints regarding management and regulations, this study reviews not only the characteristics, features and needs of the coastal ecosystems under consideration but also examines the ecosystems' potential and related processes for coastal protection, their ecological as well as their societal benefits. This review paper is based on an extensive literature review and analysis of scientific publications, books and book sections, guidelines, reports, policy recommendations and strategies. In order to create a basis for the selection of site-suitable adaptation measures for local coastal challenges and questions, this study compiles the coastal ecosystems' key features and elaborates the provided ecosystem services for protective, ecological and societal needs. The highlighted diversity of processes within ecosystems that directly cause or support coastal protection, in combination with the multiple ecological services and societal benefits, underlines the great potential of coastal ecosystems to bridge the gap between coastal engineering and nature conservation. In combination with existing coastal protection, coastal ecosystems as NbS can serve both disciplines equally and provide an integral, sustainable element in the adaptation of coastal protection to climate change.
\end{abstract}

Keywords Nature-based solutions $\cdot$ Coastal ecosystems $\cdot$ Coastal protection $\cdot$ Ecosystem services $\cdot$ Multiple benefits

\section{Introduction}

Sandy coasts are exposed to the forces of the sea, engaging constant wave action under varying water levels and occasional storm surges which causes permanent change and adaptation of the coastal environment and which may destabilise or erode the coast over time. Around the globe, coastal protection structures, strategies and concepts are and were build or put into action to counteract these natural processes

Philipp Jordan

philipp.jordan@tuhh.de

1 Institute of River and Coastal Engineering, Hamburg University of Technology, Hamburg, Germany which are often seen as threats to humans and human activities in coastal areas. Coastal protection enables humans to make a living on the coast by providing a certain level of safety and protection. For a long time, interests of engineers working in coastal protections and interests of conservationists working on the preservation of coastal ecosystems and the natural environment have been conflicting and a source of conflict, for some actors seemingly impossible to combine. Nowadays, a recent paradigm shift in societal views shifted the spotlight of general perception and therefore also of the political will towards solutions that are more environmentally friendly - softer, multifunctional and interdisciplinary solutions that include protective and ecological functions while at the same time benefiting societal needs (cf. 
Briere et al. 2018), i.e. serving Water, Nature and People. The knowledge that climate change will affect coastal safety (IPCC 2019) - but to what extent and with what certainty? - has also shifted the focus in coastal protection towards adaptive measures. In this field of tension between multiple concerns and uncertainties, the area of Nature-based Solutions $(\mathrm{NbS})$ offers promising options for reconciling different interests and remaining adaptable to change.

The question remains, however, which features, properties or measures help to mitigate or adapt to increased storminess, rising sea-levels or coastal erosion? This is, of course, highly site-specific. For sandy coasts in general, water level buffers or floodplains, created for example through the opening of formerly diked polders, have hardly any or no effect on local water levels (cf. Hofstede 2019), as the the oceans are merely too big and the effect of such areas therefore negligible. Hence, wave energy dissipation or attenuation as well as sediment accumulation appear to be the decisive influences regarding coastal adaptation - combined with the already existing and for now well functioning coastal protection infrastructure.

Within the scope of this review paper, seven coastal ecosystems have been identified as potentially promising $\mathrm{NbS}$ approaches for coastal protection in combination with nature conservation and social concerns. In order to create a basis for decision-making to be able to select site-suitable adaptation measures for local problems, these ecosystems grouped into wetland (salt marsh, mangrove and seagrass), beach (beach and dune) and reef ecosystems (coral and shellfish/oyster) - are being assessed against the following research question:

1. Where and under what conditions do natural coastal ecosystems thrive?

2. Which processes within or provided by the ecosystems protect and stabilise sandy coasts?

3. Which further benefits do the coastal ecosystems provide, promoting and covering ecological and societal needs?

4. Do coastal ecosystems as NbS in addition to the existing coastal protection offer a chance to bridge the gap between coastal protection and nature conservation in the land-sea transition zone?

\section{Methods}

To assess the potential of coastal ecosystems as $\mathrm{NbS}$ approaches bridging the gap between coastal protection and nature conservation, while also benefiting societal needs, a comprehensive literature review was conducted. The review procedure is divided into the steps of (i) data collection, (ii) initial screening and finally an (iii) in-depth analysis of the selected literature.

(i) As search engines for data collection Google Scholar and Scopus databases were chosen. The search was conducted with the search terms 'nature-based solutions', 'coastal protection', 'salt marsh', 'mangrove', 'seagrass', 'beach', 'dune', 'coral reef', 'shellfish reef', and 'oyster reef', as well as all relevant combinations. For this literature review scientific publications such as peer-reviewed journal articles or conference proceedings were considered along with books and book sections, guidelines, reports, policy recommendations or strategies.

(ii) During the initial screening process, literature that was neither relevant to coastal protection nor to ecological or societal benefits of the coastal ecosystems under consideration was eliminated.

(iii) In the final in-depth analysis the selected literature was analysed and summarised based on the overarching and comparable subjects

- general characteristics of the ecosystem,

- natural (and anthropogenically triggered) development,

- natural distribution,

- distinctive feature (regarding the ecosystem's survival in the land-sea transition zone,

- zonation,

- threats,

- coastal protection processes, and

- ecological and societal benefits

for each of the examined coastal ecosystems.

\section{Terminology}

When discussing 'Nature-based Solutions' a variety of different definitions and terminologies arise and one can easily get confused by the range of wordings or branding used in scientific publications as well as in policy documents and recommendations. To structure the concept and to define a clear terminology for this work, the term 'Nature-based Solution' was identified as the main caption for the measures investigated in this work. Regarding the meaning of the individual words of which the term is made up, Albert et al. (2019) point out the descriptive part of the first term ('nature-based'), which suggest the essential role of natural or self-regulating ecosystem processes. Secondly, the word 'solution' implies that a predefined challenge should be solved, hence the ecosystem processes are evaluated against their contribution to problem-solving. 
Fig. 1 Overview of the evolution of the term 'Nature-based Solutions' and associated terms focusing on arising new definitions; new colour-bar indicates the arising of a new or adapted definition of the same term (cf. Table 1)

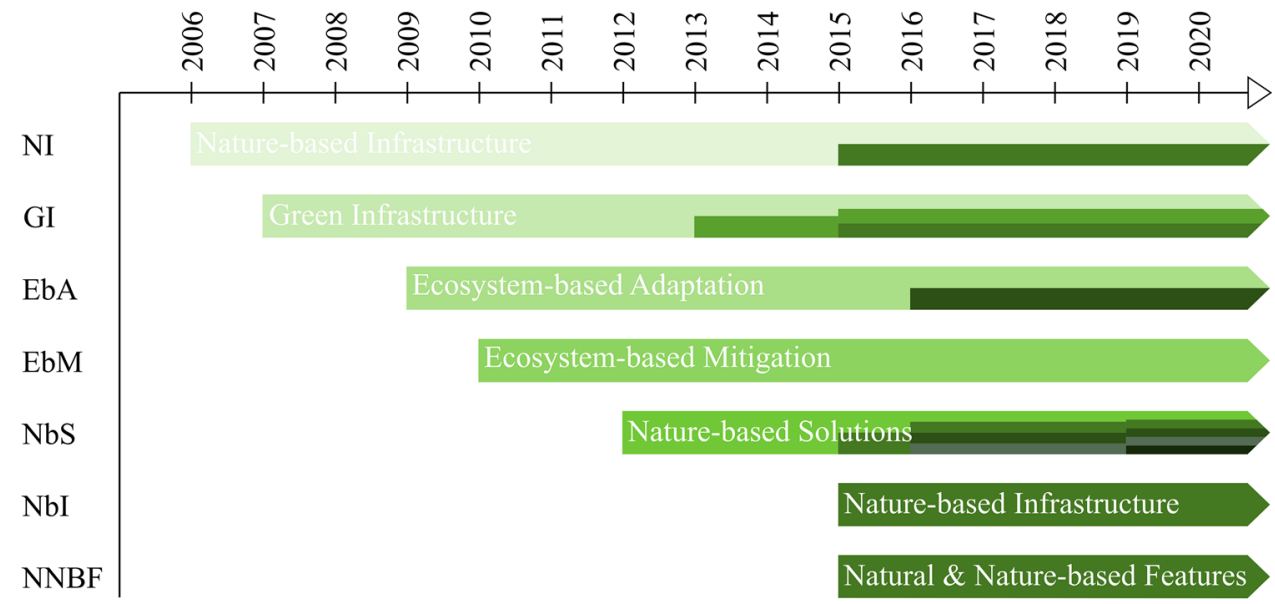

Bearing this in mind, the evolution of the definition of Nature-based Solutions can be investigated. A brief overview of the terms' evolution is depicted in Fig. 1. While terms such as 'Natural Infrastructure' (Benedict and McMahon 2006), 'Green Infrastructure' (Tzoulas et al. 2007) or 'Ecosystem-based Adaptation and Mitigation' (CBD 2009, 2010) arose earlier, today they can be regarded as subsets of $\mathrm{NbS}$. An overview of the key aspects of the different terms associated with and definitions of Nature-based Solutions can be seen in Table 1.

A first and widely accepted definition for NbS by IUCN (2012) briefly describes NbS as a concept to actively promote nature for climate mitigation and adaptation purposes. According to the European Commission (2015) NbS 'aim to help societies address a variety of environmental, social and economic challenges in sustainable ways. They are actions inspired by, supported by or copied from nature; both using and enhancing existing solutions to challenges, as well as exploring more novel solutions. Nature-based solutions use the features and complex system processes of nature (...) in order to achieve desired outcomes, such as reduced disaster risk and an environment that improves human wellbeing and socially inclusive green growth'. Building on this, the IUCN's definition was refined, emphasising the multibenefit character of $\mathrm{NbS}$, which are defined as actions to protect, sustainably manage and restore natural and modified ecosystems that address societal challenges effectively and adaptively, simultaneously providing human well-being and biodiversity benefits' (Cohen-Shacham 2016). Lately, Albert et al. (2019) included a policy perspective into the definition of $\mathrm{NbS}$, stressing the importance that $\mathrm{NbS}$ are 'embedded within viable governance or business models for implementation'.

The terms 'Nature-based Infrastructure' (Bridges et al. 2015) and 'Natural and Nature-based Feature' (Bridges et al. 2015) can also be regarded as a subset or respectively a mechanism of $\mathrm{NbS}$.
Within the scope of this review paper Nature-based Solutions are defined as measures that use characteristics and effects of natural features like coastal ecosystems for climate adaptation and to promote nature, while simultaneously providing protective, ecological and societal functions or benefits.

With a focus on flood protection and coastal risk reduction various frameworks or concepts exist, that deal with $\mathrm{NbS}$. The common goal is to use natural processes to serve the fields of Water, Nature and People - thus facilitate societal, economic and ecological benefits. The most prominent national and international frameworks are listed below.

- Building with Nature, BwN (Netherlands): The BwN concept develops multi-functional solutions through the use of natural processes and ensures that they are 'aligned with the interests of both nature and stakeholder' (Vriend and van Koningsveld 2012).

- Ecological Engineering: Ecological Engineering is defined as 'the design of sustainable ecosystems that integrate human society with its natural environment for the benefit of both' (Mitsch and Jørgensen 2003).

- Engineering With Nature, EWN (USA): The USACE's concept of EWN is based on the 'intentional alignment of natural and engineering processes to efficiently and sustainably deliver economic, environmental and social benefits through collaborative processes' (USACE 2012).

- Living Shorelines (USA): The Living Shorelines framework pursues several goals, such as shoreline stabilisation, ecosystem services provision or interconnections between land and water ecosystems (SAGE 2015).

- Soft Engineering: 'Soft engineering aims to work with nature by manipulating natural systems which can adjust to the energy of the waves and tides to good effect and has the potential for achieving econo-mies whilst minimising the environmental impact of traditional engineering structures' (Pethick and Burd 1993). 
Table 1 Key aspects of the different terms associated with and definitions of 'Nature-based Solutions'

\begin{tabular}{|c|c|}
\hline Term & Key Aspects \\
\hline Ecosystem-based Adaptation, EbA (CBD 2009) & $\begin{array}{l}\text { - use of biodiversity and ecosystem services } \\
\text { - adapt to the adverse effects of climate change }\end{array}$ \\
\hline Ecosystem-based Mitigation, EbM (CBD 2010) & $\begin{array}{l}\text { - enhance benefits for biodiversity } \\
\text { - conservation, sustainable use and restoration }\end{array}$ \\
\hline Green Infrastructure, GI (Tzoulas et al. 2007) & $\begin{array}{l}\text { - all natural, semi-natural and artificial networks of multifunctional ecological } \\
\text { systems } \\
\text { - multifunctional role, and the importance of interconnections between habitats }\end{array}$ \\
\hline Green Infrastructure, GI (EuropeanCommission 2013) & $\begin{array}{l}\text { - semi-natural areas with other environmental features } \\
\text { - designed and managed to deliver a wide range of ecosystem services }\end{array}$ \\
\hline Green Infrastructure, GI (Palmer et al. 2015) & $\begin{array}{l}\text { - a network of natural or semi-natural features } \\
\text { - same objectives as grey (built) infrastructure }\end{array}$ \\
\hline Natural and Nature-based Features, NNBF (Bridges et al. 2015) & $\begin{array}{l}\text { - Natural: created by physical, geological, biological and chemical processes } \\
\text { over time } \\
\text { - Nature-based: created by human design, engineering, and construction to } \\
\text { provide specific services }\end{array}$ \\
\hline Natural Infrastructure, NI (Benedict and McMahon 2006) & $\begin{array}{l}\text { - strategically planned and managed network of natural lands } \\
\text { - conserves or enhances ecosystem values and functions and provides associ- } \\
\text { ated benefits }\end{array}$ \\
\hline Nature-based Infrastructure (Bridges et al. 2015) & $\begin{array}{l}\text { - mimics characteristics of natural infrastructure } \\
\text { - created by human design, engineering, and construction to provide specific } \\
\text { services }\end{array}$ \\
\hline Nature-based Solutions, NbS (IUCN 2012) & $\begin{array}{l}\text { - promote nature } \\
\text { - climate mitigation and adaptation }\end{array}$ \\
\hline Nature-based Solutions, NbS (EuropeanCommission 2015) & $\begin{array}{l}\text { - address environmental, social and economic challenges } \\
\text { - inspired by, supported by or copied from nature }\end{array}$ \\
\hline Nature-based Solutions, NbS (Cohen-Shacham 2016) & $\begin{array}{l}\text { - address societal challenges } \\
\text { - human well-being and biodiversity benefits }\end{array}$ \\
\hline Nature-based Solutions, NbS (EuropeanCommission 2016) & $\begin{array}{l}\text { - address societal challenges } \\
\text { - inspired and supported by nature } \\
\text { - environmental, social and economic benefits }\end{array}$ \\
\hline Nature-based Solutions, NbS (Albert et al. 2019) & $\begin{array}{l}\text { - challenge-orientation } \\
\text { - ecosystem processes utilization } \\
\text { - practical viability }\end{array}$ \\
\hline
\end{tabular}

- Working with Nature, WwN (PIANC, worldwide): PIANC's WwN concept is centred around the identification and exploitation of 'win-win solutions which respect nature and are acceptable to both project proponents and environmental stakeholders' (PIANC 2011).

\section{Coastal ecosystems as Nature-based Solutions}

In light of the terminology described above, as well as the definitions and the various subsets of $\mathrm{NbS}$, natural and semi-natural ecosystems are to be considered the most pristine NbS. As per definition by the Millennium Ecosystem Assessment Board, 'an ecosystem is a dynamic complex of plant, animal, and microorganism communities and the nonliving environment, interacting as a functional unit', including humans as an integral part of many ecosystems (Watson and Zakri (Eds.) 2003). Intact ecosystems naturally provide diverse benefits to humans and nature equally. These benefits, that people obtain from ecosystems are called ecosystem goods and services (Watson and Zakri (Eds.) 2003), hereafter collectively referred to as ecosystem services. Displayed in Table 2 grouped after their function, these include selected provisioning, regulating, cultural and supporting services, which, as the name suggests, are the basis for the provision of all other ecosystem services. As ecosystems offer a wide range of services, not all can be mentioned and listed here.

Since the focus of this work is on sandy coasts and their protection and preservation, the most significant coastal ecosystems with benefit for this purpose, hence ecosystems 
Table 2 Ecosystem services - functional groupings as supporting, provisioning, regulating and cultural services according to the Millennium Ecosystem Assessment (Watson and Zakri (Eds.) 2003)

\begin{tabular}{lll}
\hline Provisioning Services & Regulating Services & Cultural Services \\
\hline Food and fibre & Air quality maintenance & Cultural diversity \\
Fuel & Climate regulation & Spiritual and religious \\
Genetic resources & Water regulation & Knowledge systems \\
Biochemicals & Erosion control & Educational \\
Ornamental resources & Water purification & Inspiration \\
Fresh water & Waste treatment & Aesthetic \\
& Disease regulation & Social relations \\
& Biological control & Sense of place \\
& Pollination & Cultural heritage \\
Supporting Services & Storm protection & Recreational and ecotourism \\
Soil formation & & \\
\hline
\end{tabular}

that represent possible $\mathrm{NbS}$ to coastal threats like storms or erosion, are presented in the following sub-chapters.

Regarding the scale of this investigation, featured ecosystems include wetland (salt marshes, mangroves and seagrass meadows), beach (beaches and dunes), and reef ecosystems (coral and shellfish/oyster). Offshore islands or barrier islands, that border many sandy shorelines sheltering wetlands, bays and the mainland coast from direct offshore impacts - thus fulfilling an outstanding function for coastal protection - can be considered separate ecosystems themselves (cf. Feagin et al. 2010). They are, however, to be assigned to a broader scale of investigation, as they are essentially composed of many of the aforementioned basic coastal ecosystems of finer scale examined below. Therefore, offshore and barrier islands are not studied further within the scope of this review paper or listed as a separate ecosystems. In the following, the different coastal ecosystems are defined and their most prominent characteristics, their formation, natural distribution and existing threats are described.

Besides flood and storm protection and erosion control, which are considered regulating services according to the Millennium Ecosystem Assessment (Watson and Zakri (Eds.) 2003), coastal ecosystems provide a number of other important ecosystem services, which benefit nature and people. These ecosystem services constitute the ecological and societal value of coastal ecosystems. Both coastal protection processes and effects provided by the coastal ecosystems as well as their ecological and societal value are explained in the following. It should be mentioned, that the quantification of these processes and benefits is possible but, nevertheless, highly complex, requires in-depth studies and usually is highly site-specific and difficult to transfer to other locations.

\section{Wetland ecosystems}

Wetland ecosystems such as salt marshes, mangroves and seagrass meadows serve as buffers for storms and extreme events while also providing important coastal habitats for a variety of different plant an animal species.

\section{Salt marshes}

At the coasts of the seas, the salt marsh zone begins above the line to which the tide rises on average, which is therefore only flooded at irregular intervals. This zone can be characterised as amphibious, i.e. at least occasionally under water, and by a strongly fluctuating salinity. In temperate climates, salt-tolerant herbaceous plants typically colonise such sites, which are then collectively referred to as salt marshes (Zerbe and Wiegleb 2009). Salt marshes are intertidal ecosystems that form in shallow, low-energy, wave-protected shorelines under continuous sedimentation. They are characterised by a sharp vegetation zonation and rather low species diversity, but a high primary and secondary productivity (Barbier et al. 2011; Rupprecht 2015). Bio-geomorphic feedback processes between plant growth, water flow and sediment transport and deposition as well as anthropogenic impacts and global change make up the dynamics in salt marsh formation and stability, which enable salt marshes to inhabit these harsh coastal environments (Rupprecht 2015).

Salt marshes can develop naturally on shallow sandy or muddy coasts, where sediments are eroded with each tide and redeposited in areas of low current speed and wave height. Over time, this creates areas along the coast that are flooded less and less frequently. Here, the first pioneer plants can spread, such as the glasswort (Salicornia) in case of the North Sea Region, which can tolerate very high salinity levels. Young shoots and dead parts of the plants promote sedimentation on the surface. They act like a filter, retaining the sediment on the surface at low tide. This positive feedback accelerates the growth of the area accordingly. With an extensive pioneer population, the land is already high enough to no longer be flooded with every tide. Now, other plants such as common saltmarsh-grass (Puccinellia 


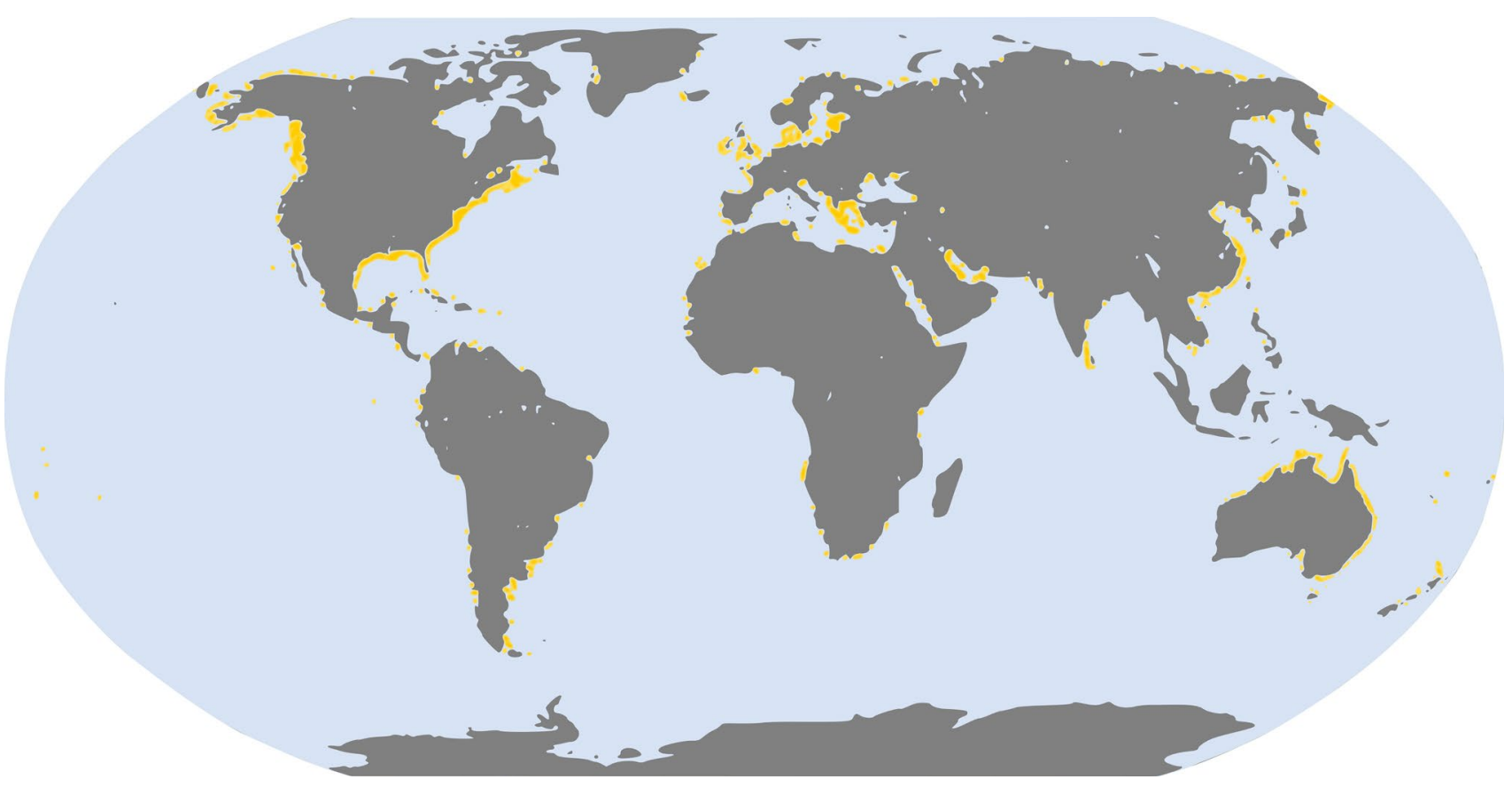

Fig. 2 Global distribution of salt marshes in yellow after Mcowen et al. (2017)

maritima) can spread, which, for example, additionally stabilises the young salt marsh through its root formation and leaves lying close to the ground. Especially where the first plants grow, debris and sediment are more strongly retained. At the beginning, the vegetation is therefore not yet evenly distributed, but in patches over the entire area (Küster 2015). Currents tend to concentrate around these patches of salt marsh vegetation, which can lead to the formation of tidal creeks or channels, through which the salt marsh is drained from this point onwards (Best et al. 2018). The salt marsh continues to grow in its further evolution with each flooding and more plant species settle. As the sea-ward edge of the salt marsh is flooded more frequently by the tide, over time it grows faster than the areas further in-land, forming so-called bank ridges (Küster 2015).

Many salt marshes that can be found along the coasts today are actually not naturally grown ecosystems but their development was once triggered and promoted by man-made interventions in the coastal landscape. In the South-Eastern North Sea region for example, salt marshes are created with the use of sedimentation fields, brushwood groyne fields, in which low hydrodynamic energy conditions enable sediment deposition. Artificial creeks and channels enhance the drainage of the area and therefore accelerate marsh formation. For decades or even centuries, until the mid- $20^{\text {th }}$ century, land reclamation measures were implemented to create arable land for cattle or sheep grazing or mowing (Thorenz 2014). Thus, the majority of today's salt marshes in the foreland of the dikes in the North Sea Region thrive on sites that in many places could only be developed with human support under the protection of brushwood groynes (Stock et al. 2012). In many man-made marshes, however, artificial drainage systems persist even decades after their abandonment and the well drained conditions are related to shifts in vegetation cover such as the formation of rather homogeneous plant populations, which on the one hand alter the stability of the marsh and on the other hand provide less suitable habitats for breeding birds (Rupprecht 2015; WWF Deutschland (Ed.) 2018).

Salt marshes can be found throughout the world in midelevation coastal zone in temperate regions, while in the subtropics and tropics mangroves widely occur in similar environments (Gutiérrez et al. 2011; Nolte et al. 2013; United Nations 2016). As depicted in Fig. 2, salt marshes can be found on every continent except Antarctica and cover an estimate of 22,000 to $400,000 \mathrm{~km}^{2}$ worldwide (Mcleod et al. 2011).

The natural composition of vegetation in salt marshes is determined by both abiotic factors as well as biotic processes. Decisive abiotic factors are elevation, salinity, flooding and nutrient availability. Relevant biotic processes are competition and facilitation among flora and fauna (Rupprecht 2015). Salt marshes are semi-terrestrial habitats. Trees cannot thrive in this environment, but vascular plants, so-called halophytes, which are adapted to the conditions, can. These plant species have developed various strategies against the high salinity, including amongst others ion barriers on roots (e.g. Puccinellia maritima), salt glands (e.g. 
Fig. 3 Patches of European glasswort (Salicornia europaea) in the pioneer zone of a salt marsh in Westerhever, Germany
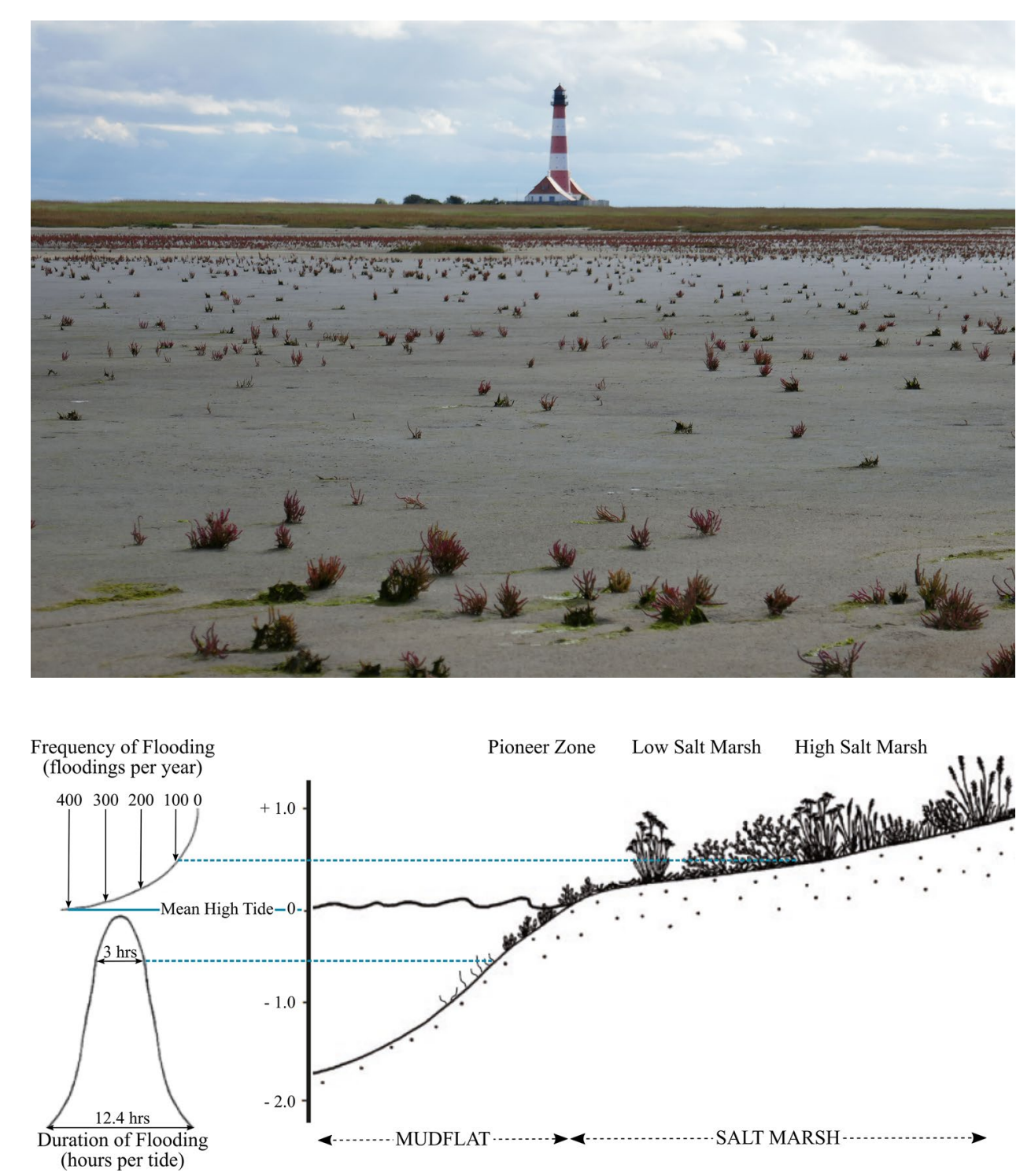

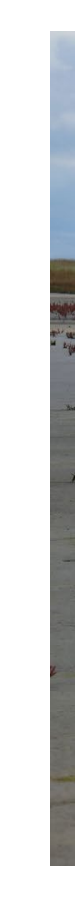

Fig. 4 Vegetation zonation in salt marshes depending on frequency and duration of flooding after Erchinger et al. (1985) and Kollmann et al. (2019)
Armeria maritima) or desalination hairs (e.g. Atriplex portulacoides). Some species compensate for the high salinity levels by taking up additional water (e.g. Salicornia europaea). Further inland, beyond the transition to the terrestrial, hence no longer intermittently flooded area, the salt-tolerant halophytes are increasingly supplanted by the non-salt-tolerant glycophytes (Kollmann et al. 2019).

A characteristic feature of the salt marsh habitat is the vegetation zonation caused by its marginal location at the sea. The high tide line, as the extreme of the living conditions in the transition zone between land and sea, represents an important boundary line from which the number of species of plants and animals settling both above and below it increases (Stock et al. 2012). Depending on the elevation above sea level, and thus also the frequency of flooding and the salinity, three typical vegetation zones emerge (see
Fig. 4), which are subject to succession (Kollmann et al. 2019; Stock et al. 2012; Zerbe and Wiegleb 2009).

- Pioneer Zone: The pioneer zone begins approximately $40 \mathrm{~cm}$ below the mean high tide line and extends up to just above it. On average, this zone is still flooded daily. Here mostly annual glasswort communities can be found (e.g. Fig. 3).

- Low Salt Marsh: The low marsh ends approximately $35 \mathrm{~cm}$ above the mean high tide line and is therefore, depending on the elevation, flooded between 100 to 400 times per year. Species-poor dominant populations, such as common saltmarsh-grass communities, form the predominant vegetation here.

- High Salt Marsh: The high or upper marsh succeeds the low marsh. Situated above the spring high tide line this 
zone is only flooded between 40 to 70 times per year. The predominant vegetation are species-poor dominant populations like red fescue communities (Festuca rubra).

The three zones are not to be understood as clearly defined sectors. The transitions between the zones are smooth and vary from site to site. Thus, species of the lower salt marsh occur in the pioneer zone and typical species of the upper salt marsh in the lower marsh. Grazing on salt marshes also leads to a shift in vegetation zonation.

Salt marshes are intertidal ecosystems. Therefore, they are subject to and, if healthy and undisturbed, can tolerate and resist frequent flooding with saline water as well as mechanical stresses induced by currents, waves or sometimes ice scour (Rupprecht 2015). Nevertheless, salt marshes range among the most heavily used and therefore threatened ecosystems on earth (Kirwan et al. 2013), which are degrading at an estimated global loss rate of $1-2 \% \mathrm{yr}^{-1}$ over the last decades (Duarte et al. 2008). The reasons for these losses are manifold. Natural extremes - in coastal areas mainly extreme storm events - can be the cause for salt marsh losses, as was e.g. historically the case with the first 'Grote Mandränke' in 1362 (Bose et al. 2018), one of the first well documented devastating storm surges in the North Sea that caused severe loss of life, property and land in the area. Most threats however, are caused by human-induced alterations to the ecosystem itself or the surrounding landscape. Elevated atmospheric $\mathrm{CO}_{2}$ concentrations, increased temperatures and eutrophication represent negative indirect human impacts or threats. Direct human modifications, which pose threats to salt marshes, are shoreline development and embankment of salt marshes to gain arable land. Historically, activities like peat cutting also resulted in the loss of many salt marsh communities, for example along the South-Eastern North Sea coast. Hydrological alterations in salt marshes like ditching for soil drainage may threaten the ecosystems' stability as well (Rupprecht 2015).

Assessing a salt marsh's sensitivity to such threats is highly complicated, because salt marshes like many other coastal ecosystems show an 'alternative stable state behaviour'. They can in fact exist in various different stable states, but once a certain threshold is passed, may collapse entirely (Rupprecht 2015). Depending on sea level rise projections and available suspended sediment concentrations, salt marshes are estimated to be resilient to sea level rise. They can either migrate landward where sufficient space is available or keep up with sea level rise by sediment accretion. If sediment is not sufficiently available, and landward migration is hindered by man-made structures, salt marsh ecosystems can drown, marking the transition to subtidal landscape. Besides, under the accelerated rise in sea level, there most probably is a critical stability threshold below which salt marsh ecosystems can survive and above which they drown. Thus, sea level rise poses the major threats to salt marsh stability and survival (Best et al. 2018; Bouma et al. 2014; Kirwan et al. 2010; Marijnissen et al. 2020). Depending on emission scenarios, the IPCC (2019) is projecting a global wetland loss of $20-90 \%$ by the end of the century. This includes salt marsh ecosystems as well as mangroves and seagrass meadows. At a local scale, total losses of wetland ecosystems are projected under the RCP8.5 emission scenario with medium confidence.

Coastal protection processes Salt marshes, like several other wetland ecosystems, can make an important contribution to coastal protection. For example, when Hurricane Sandy struck the North-Eastern US coast in 2012 including the heavily urbanized coastlines of New York and New Jersey, it is estimated that temperate coastal wetlands like salt marshes reduced property damages by more than $10 \%$ on average and damage reduction benefits reached as high as $29 \%$ in case of Maryland (Narayan et al. 2016). Processes within salt marshes ecosystems that provide coastal protection can be divided into direct and indirect mechanisms (Gedan et al. 2011) and either have an impact on the reduction of hydrodynamic loads, shoreline stabilisation and erosion control or water retention.

Salt marshes can effectively attenuate wave energy and current flow through wave breaking caused by limited water depth and damping as well as plant-flow interactions (Frohlich and Rosner 2015; Narayan et al. 2016; Rupprecht 2015; Sutton-Grier et al. 2018), though the effect of friction on wave characteristics is very small compared to the limitation of water depth. The main, indirect mechanisms that causes wave attenuation and affects wave propagation in the salt marsh therefore is the marsh's ability to built up peat and soil, thus altering the bathymetry (Gedan et al. 2011). This causes wave dampening through changes in water depth. In addition, the salt marsh vegetation has a direct impact on the dampening of wave energy and, hence, wave height through friction between water and vegetation (Narayan et al. 2016). This process, the dissipation of waves by vegetation, is very complex and variable (Rupprecht 2015), and depends on a number of different biophysical and hydrodynamic characteristics or factors. Standing biomass, buoyancy, vegetation density, high of the canopy and width of the marsh are important vegetation characteristics to be considered (Anderson et al. 2011; Bouma et al. 2014; Shepard et al. 2011). The vegetation property of primary interest is the plants flexibility (Anderson et al. 2011), as it defines the amount of flow resistance plants provide. Important hydrodynamic conditions are water depth or inundation height of the plants and the incident wave characteristics such as wave height and length (Anderson et al. 2011; Shepard et al. 2011). Although wave attenuation generally is greater, the larger the salt marsh is, even short marsh transects of less 
than $10 \mathrm{~m}$ width can show significant wave attenuation (Shepard et al. 2011). According to a meta-analysis of sixtynine scientific studies by Narayan et al. (2016), salt marshes can reduce wave heights by $72 \%$ (95\% CI: 62-79\%).

A comprehensive review on wave dissipation by coastal vegetation in general - not only salt marshes - is provided by Anderson et al. (2011). They identify Dean's approach (Dean 1978), which later on was further developed by Knutson et al. (1982) to better describe the response of plants to wave forcing (e.g. swaying), as one of the first hydrodynamic models for wave attenuation. Although these first advances to calculate, hence quantify the wave attenuating effects of coastal vegetation have been published almost 40 years ago, the complex behaviour of different plant species still is not fully incorporated into wave attenuation formulas and there still is research to be done to accomplish this goal. As a current example the work by Zhang et al. (2020) on smooth cordgrass (Spartina alterniflora) can be mentioned. They worked with the wave decay rate by Dalrymple et al. (1984), which assumes that linear wave theory is valid and wave energy dissipation occurs only due to the plants, and which was later extended to random waves by Mendez and Losada (2004). Representing the single plants as rigid cylinders the wave decay rate according to Dalrymple et al. (1984) is

$\frac{H_{x}}{H_{0}}=\frac{1}{1+\alpha x}$,

where $H_{x}$ and $H_{0}$ are the wave heights at the reference point 0 and at the distance $\mathrm{x}$ from the reference point in the direction of wave propagation, and $\alpha$ is a wave damping factor theoretically defined by Dalrymple et al. (1984) and later extended by Mendez and Losada (2004). The accuracy of the wave damping factor $\alpha$ largely relies on a proper estimation of the vegetation-specific bulk drag coefficient $C_{D}$, for which Zhang et al. (2020) developed a new formula valid for flexible plants, thus better accounting for the actual plant behaviour when exposed to hydrodynamic forcing. They validated their approach in a field survey in a Chinese salt marsh dominated by smooth cordgrass.

Bouma et al. (2014) developed a strongly simplified and partly measurement-based formula to estimate habitat dimensions needed to significantly contribute to wave attenuation. Their method is valid for areas with shallow to intermediate foreshore slopes, where wave attenuation mainly occurs due to friction and not breaking. Under the assumption of the decrease in wave height roughly following an exponential decay, with the main modifiers being crossshore length $L[\mathrm{~m}]$ of the habitat and the water depth $h$, the wave height after attenuation by the coastal habitat $\left(H_{L}\right)$ can be estimated as

$H_{L}=H_{0} e^{-K L}$, with $H_{0}$ being the incoming wave height and $K$ the decay coefficient. The decay coefficient $K$ after Bouma et al. (2014) is

$K=k_{\text {habitat }} \frac{B}{B_{\max }} e^{-d h}$,

with $k_{\text {habitat }}\left[\mathrm{m}^{-1}\right]$ being the habitat-specific, measurementbased decay constant -0.01 to 0.05 for salt marshes $-B$ and $B_{\max }$ being the (maximum) percentage coverage ratio of biota along the coastal habitat's cross-shore length, and $d$ being a measurement-based decay coefficient for the loss of friction with water depth. When deriving the significant wave height by

$H_{0}=0.3 h$

based on the depth-limitation of incoming waves in shallow waters and following the estimation of $d=1.5$ by Bouma et al. (2014) based on measurements in salt marshes, the wave height after maximum attenuation by a salt marsh habitat (thus maximum coverage, $B=B_{\max }$, and $k_{\text {saltmarsh }}=k_{\text {saltmarsh, } \max }=0.05$ ) can be approximated by

$H_{L, \text { saltmarsh }}=0.3 h e^{-\left(0.05 e^{-1.5 h}\right) L}$

Shoreline stabilisation or erosion protection is provided through various processes and characteristics of salt marsh ecosystems by either changes in the ground structure or the lowering of hydrodynamic loads (Baptist et al. 2019; Fröhlich and Rösner 2015; Gedan et al. 2011; Sutton-Grier et al. 2015). Aboveground biomass, i.e. branches, stems and leaves, have a direct effect on hydrodynamic loads from currents and waves and can thus promote sedimentation (Baptist et al. 2019). In case of a typical salt marsh canopy, the vegetation exerts a drag force counter the direction of water movement and therefore causes a reduction in turbulence, a deceleration of the flow velocity of the water and a reduction in shear stresses near the seabed (Gedan et al. 2011). Direct effects below ground are caused by the plants' roots. They stabilise the soil and slow erosion rates by enhancing cohesion and tensile strength of the surrounding soil substrate they are growing in, which in turn causes an increase of the soil's shear strength. Furthermore, roots can act as a physical barrier between open water and soil, e.g. along tidal creeks or channels in the marsh (Gedan et al. 2011; Möller et al. 2014). Even after larger storm events, which cause breakage of vegetation stems, the stabilising function of the root system is maintained and and resistance to surface erosion is kept up (Möller et al. 2014). Indirectly, the belowground biomass in the form of decaying roots has a positive effect on erosion stability through the build-up of humus, which is rich in organic material. Compared to typical mineral soils, this type of soil is considerably more resistant to erosion (Gedan et al. 2011). 
Fig. 5 A flock of Eurasian oystercatchers at a drainage creek in a salt marsh on the island of Föhr, Germany

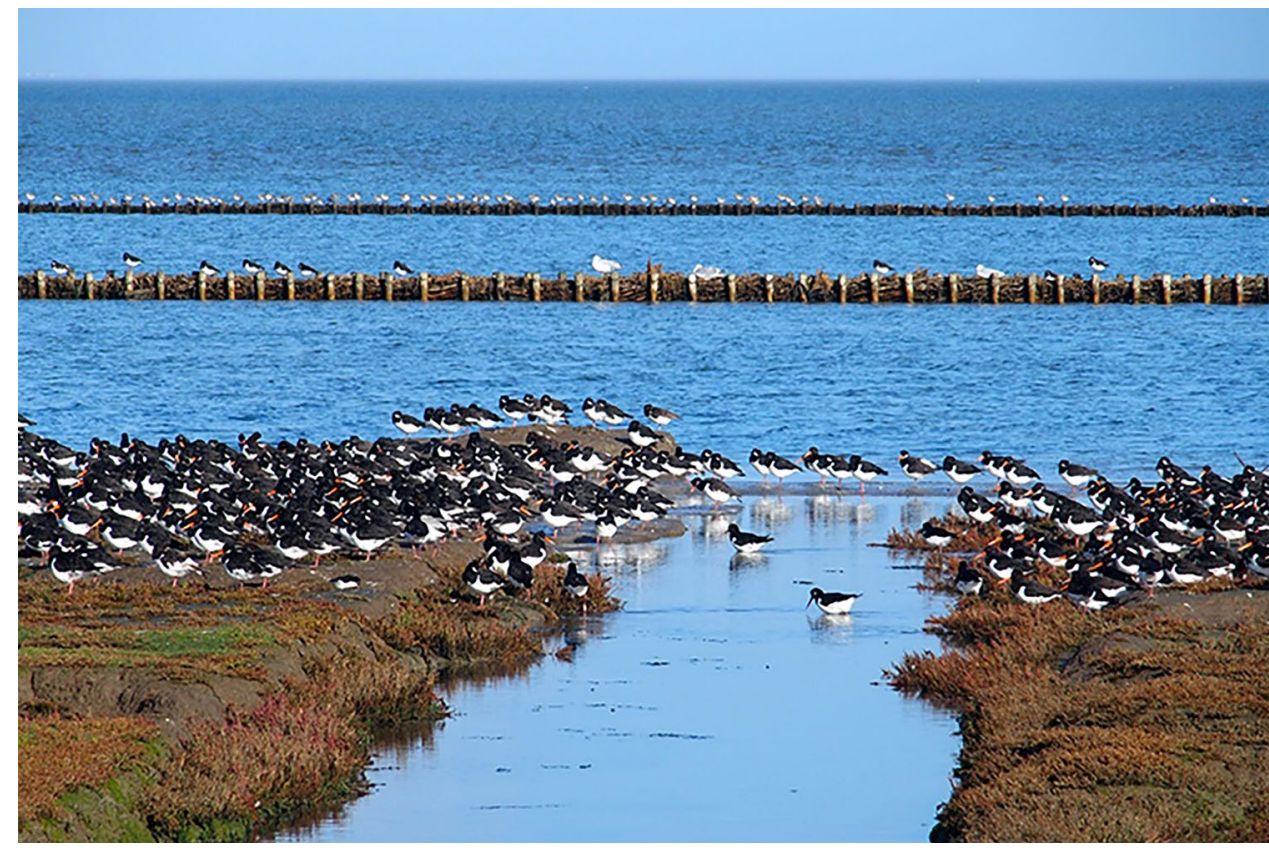

Besides wave attenuation and shoreline stabilisation, salt marshes have a large water retaining capacity. They can mitigate coastal flooding by reducing storm surge duration and flood peaks through water uptake and holding capacity (Barbier et al. 2011; Shepard et al. 2011). In the event of a dike breach for example, this capacity can also limit the amount of water flooding the hinterland. Additionally, salt marshes secure the base of a dike against the permanent influence of the tide and thus make a dike foot revetment dispensable (Thorenz 2014).

Ecological and Societal Value In a study by Costanza et al. (1998), which attempted to estimate the value of the world's ecosystems by assigning values to different ecosystem services they provide, coastal wetlands like salt marshes were rated among the most valuable ecosystems on earth. In addition to regulating services like coastal protection and erosion control as described above, salt marshes provide a number of other ecosystem services, which benefit humans and nature. Salt marshes represent important linkages between marine, coastal and onshore ecosystems and the services they provide. Supporting services by salt marshes include the high rate of primary production and nutrient cycling within the marsh. Furthermore, they allocate habitat for a large number of flora and fauna, equipped to the specific and harsh conditions (Hassan et al. (Eds.) 2005).

Due to the salt marshes' limited accessibility, provisioning services of coastal marshes include the allocation of important nursery grounds for young fish as well as shrimp and shellfish (Barbier et al. 2011; Kirwan et al. 2016). For a large number of bird species salt marshes are essential for breeding, foraging and resting, as depicted in Fig. 5 (Hassan et al. (Eds.) 2005; Rupprecht 2015).

Important regulating services are the improvement of water quality (Kirwan et al. 2016) as well as carbon sequestration (Kirwan et al. 2016; Mcleod et al. 2011; Siemes et al. 2020). Salt marshes sequestrate carbon with an average rate of $210 \mathrm{~g} \mathrm{~m}^{-2} \mathrm{yr}^{-1}$ (Chmura et al. 2003).

Cultural ecosystem services are provided by the landscape and, e.g., the bird life in salt marshes in the form of aesthetic ecological values. Birds also serve as important indicators of ecosystem conditions (Hassan et al. (Eds.) 2005). Tourism and recreation constitute further cultural services that are directly related to the landscape and nature.

\section{Mangroves}

The term mangrove describes both the ecosystem as well as the plant families (Barbier et al. 2011). According to FAO (FAO 2007) there are 50 to 70 different species that are considered to be mangrove-type vegetation. The species richness in one location largely depends on the prevalent wave load, the range of air and water temperatures, the tidal amplitude, mineral nutrients, light, rainfall variation and the frequency of tropical storms (Augustinus 1995). In Asia conditions seem to be especially favourable, as the highest species diversity can be found here, followed by Eastern Africa (FAO 2007). Mangroves are perfectly adopted to loose and wet soils, periodic tidal submergence and saline to brackish waters. They fringe the shorelines or the intertidal zone of estuaries, occupying the waterlogged and anoxic soils (Gutiérrez et al. 2011). Mangroves are often falsely 


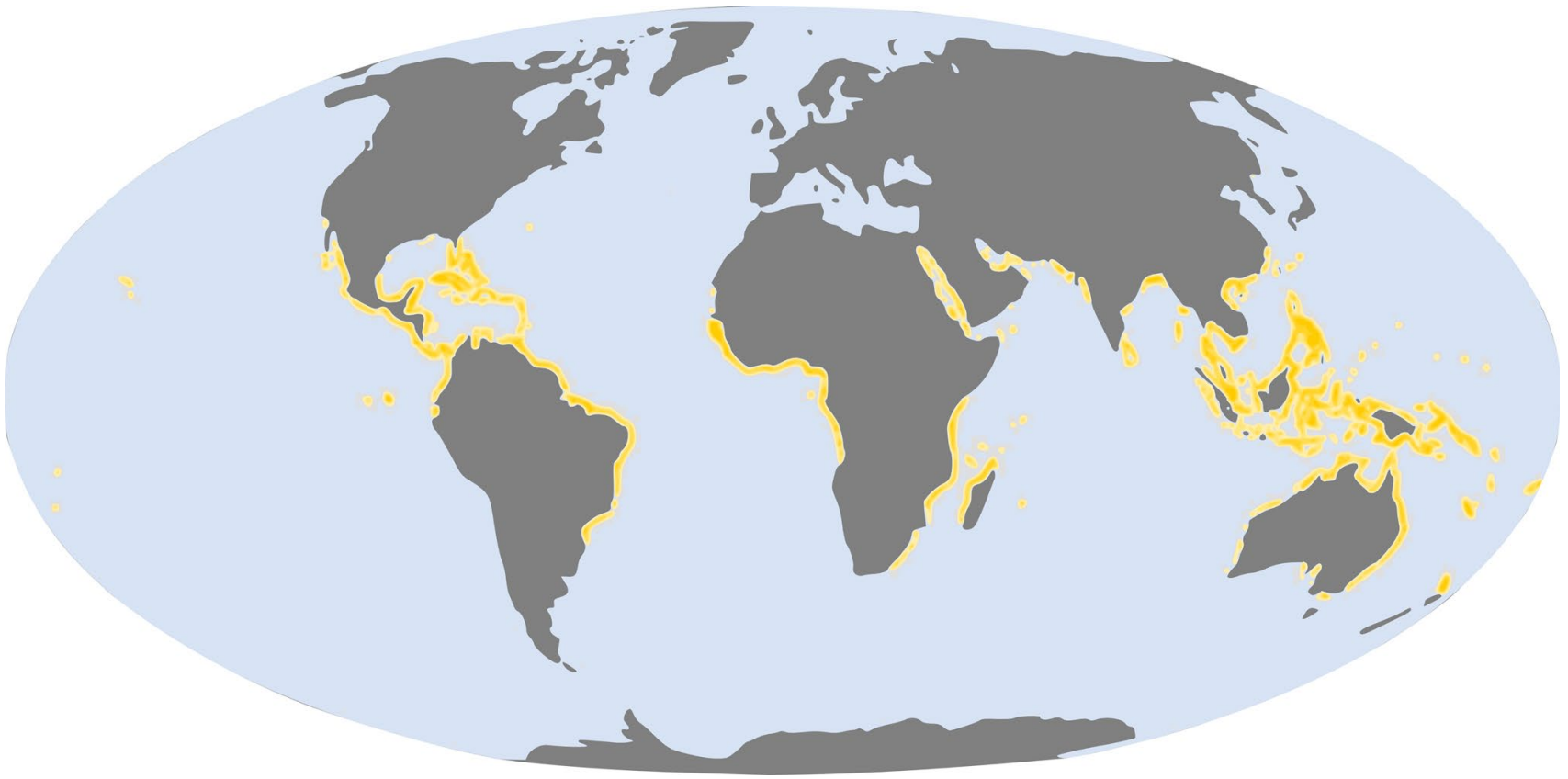

Fig. 6 Global distribution of mangroves in yellow after Spalding et al. (2010)

regarded as merely the tropical equivalent of salt marshes, although they differ from salt marsh ecosystems in two defining aspects. Instead of herbs, their vegetation structure is composed of trees and shrubs, and, with respect to their position to the mean high water line, they can grow in lower areas than salt marshes, due to their rooting system (Augustinus 1995).

Where mangroves develop, they are often pioneers to the area, e.g. colonizing newly formed mudflats (Alongi et al. 2008). As an adaptation to the tidal conditions, some mangrove species produce viviparous seedlings (e.g. Rhizophoraceae or Avicenniaceae). Compared to regular seeds, the propagules have the advantage that they can take root faster when they touch the ground, since they do not have to germinate first (Augustinus 1995). Mangrove development or successful establishment is characterised by three threshold stages as described by (Balke et al. 2011).

1. Anchorage: After stranding on a mudflat, mangrove propagules require a minimum inundation-free period to anchor in the soil. Seeds need to germinate first and therefore require more time.

2. Growth: In order to be able to withstand hydrodynamic disturbances by waves and currents, the seedlings' roots need to exceed a minimum length.

3. Resistance: To resist further disturbances, e.g. from removal of sediment around the seedling, the mangroves' roots need to grow to a sufficient length.
Of course there are no exact values that can be regarded as sufficient root length, as hydrodynamic disturbances as well as boundary conditions such as the soil composition are highly site specific.

In mid-elevation coastal zones, which are home to salt marshes in temperate region of the world, mangroves thrive in the tropics and subtropics (Gutiérrez et al. 2011; QuangBao 2011; Stock et al. 2012), as shown in Fig. 6. Globally, mangrove forests cover an estimated area of around 138,000 to $152,000 \mathrm{~km}^{2}$ (World Bank Group 2016); Mcleod et al. 2011) and can be found in 123 countries (World Bank Group 2016). $75 \%$ of the world's mangroves are concentrated in just 15 of these 123 countries, of which Indonesia has by far the largest mangrove population, accounting for $22.4 \%$ of the global total. When comparing the continents, the largest extent of mangroves can be found in Asia with $42 \%$ of the global total, followed by Africa with $20 \%$ (Giri et al. 2011).

The most noticeable and well-known aspect of mangroves is their aerial rooting system. mangrove roots are completely or partly exposed to the atmosphere at least part of the day, when not covered by water during high tide (FAO 2007). The above-ground parts allow gas exchange with the belowground parts through air holes or lenticels, while the belowground parts are in charge of anchorage in the muddy oil as well as the absorption of nutrients (Augustinus 1995; FAO 2007; Marchand 2008). The different typical rooting systems, e.g. of three main mangrove species (Avicennia, Rhizophora and Bruguiera) depicted in Fig. 7, allow easy differentiation of species. The Avicennia type has a star-shaped 

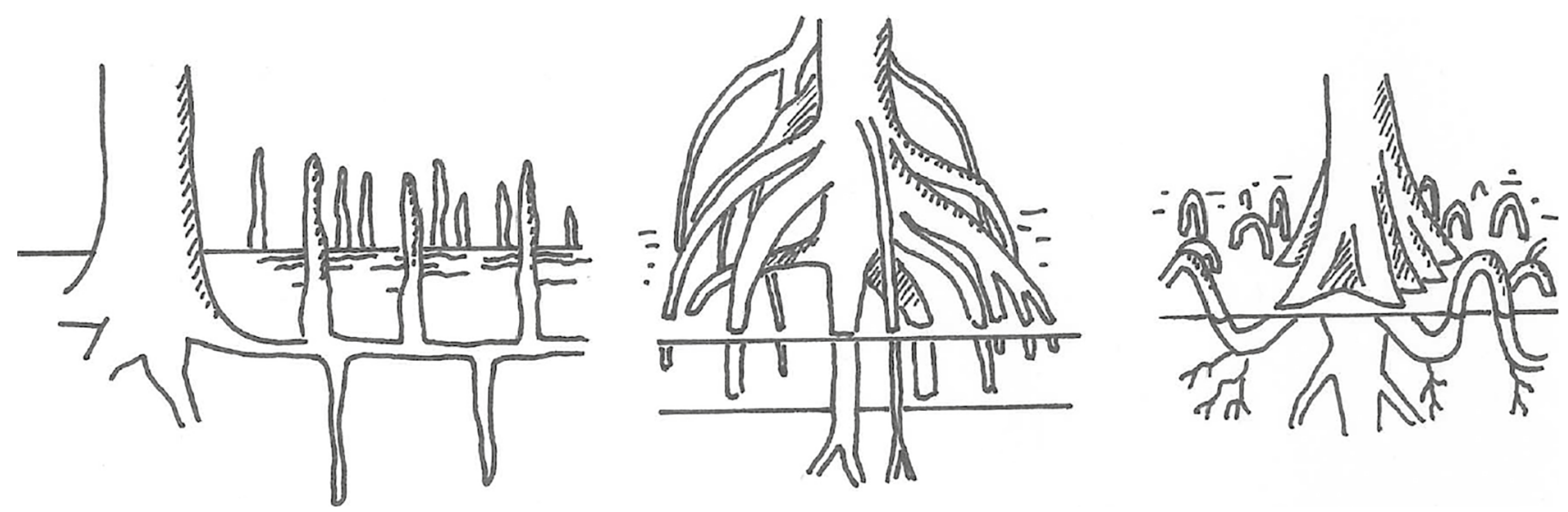

Fig. 7 Drawings of mangrove rooting systems of Avicennia, Rhizophora and Bruguiera, from left to right, after Marchand (2008)

network of cable roots radiating out from the trunk. From these cable roots, anchor roots are shooting downwards and aerial roots, so-called pneumatophores, are shooting upwards. Rhizophora-type mangroves are characterised by a system of prop roots, which arch out from the trunk and anchor the mangrove plant in the soil. The roots of the Bruguiera type radiate out from the bottom of the trunk growing alternating above and below the surface (Augustinus 1995).

Despite the area they inhabit, mangroves are actually not very fond of saline water, as it poses a physiological stress factor to them (Marchand 2008). Nevertheless, they are able to tolerate a broad range of salinities from 0 up to $90 \%$ (upper salinity limits occurring in warm and dry tidal areas which are only inundated a few times per year) (Augustinus 1995), with the usual upper boundary ranking around 2.5 times the salinity of seawater (Hassan et al. (Eds.) 2005). The plants expose themselves to the saltwater-induced stress and compensate for it through various mechanisms, as it gives them a key competitive advantage over other, higher-growing plants that cannot grow in this area under these conditions (Augustinus 1995; Marchand 2008). In general, mangrove forests show zonation, with mono-specific zones succeeding one after the other from the waterline going landward (Augustinus 1995). These zones form due to the varying tolerances of the different mangrove species to the changing boundary conditions.

Comparable to salt marshes, mangroves also range among the most exploited and therefore threatened ecosystems on our planet (Kirwan et al. 2013), and are degrading at an estimated global loss rate of 1-3 \% $\mathrm{yr}^{-1}$ over the last decades (Duarte et al. 2008). Changes in the ecosystem that lead to its degradation may be based on natural processes, such as land subsidence or the reduction of fluvial sediment (Alongi et al. 2008; Nguyen et al. 2015). Natural weather extremes like e.g. the Indian Ocean Tsunami of 2004 also bear the potential to destroy mangroves with a single event. However, most threats to mangrove ecosystems are of anthropological origin. Indirect human impacts are industrial development and excessive pollution (Hassan et al. (Eds.) 2005; Nguyen et al. 2015), pressure from the expansion of the tourism industry (Nguyen et al. 2015) and climate change related phenomena like a rise in atmospheric $\mathrm{CO}_{2}$ concentrations, increasing air and water temperatures, changes in precipitation (Alongi et al. 2008), as well as hydrological changes like an increase in wave energy or the intensity and frequency of storms (Hassan et al. (Eds.) 2005; Nguyen et al. 2015). Human-induced land use changes, thus direct human impacts, account for the major part of mangrove losses worldwide. The removal or cutting of trees for firewood and construction material and the conversion of mangrove-covered land to allow for agriculture and aquaculture (Hassan et al. (Eds.) 2005) leave behind fragmented mangrove patches and damaged trees and shrubs, unable to offer sufficient resistance to the attacks of the sea and thus break away and erode as can be seen in Fig. 8. According to Barbier et al. (2011), shrimp farming alone accounts for 38 $\%$ of global mangrove loss (aquaculture in total accounts for $52 \%$ ) and the use of mangrove wood is responsible for $26 \%$ of mangrove loss globally.

Sea level rise is also a major threat to mangroves (Alongi et al. 2008; Hassan et al. (Eds.) 2005). Where landward progression of mangrove forests is hindered by structures, industry or settlements, the ecosystems only have two options. Depending on the limitation of sediment resources, they either outgrow sea level rise by sufficient sediment accretion or they will slowly erode, starting at the seaward margin. Strongly depending on the different location variables, e.g. on the available sediment supply, threshold rates are likely to exist, beyond which mangrove forests can no longer keep up with sea level rise through sediment accretion and might ultimately drown (World Bank Group 2016), as projected by the IPCC (2019) for 20-90 \% of the world's wetland ecosystems by 2100 , depending on emission scenarios. 
Fig. 8 Patches of heavily damaged mangrove forest through overexploitation at the West coast of Cà Mau Province in southern Vietnam, damages from cutting and fragmentation

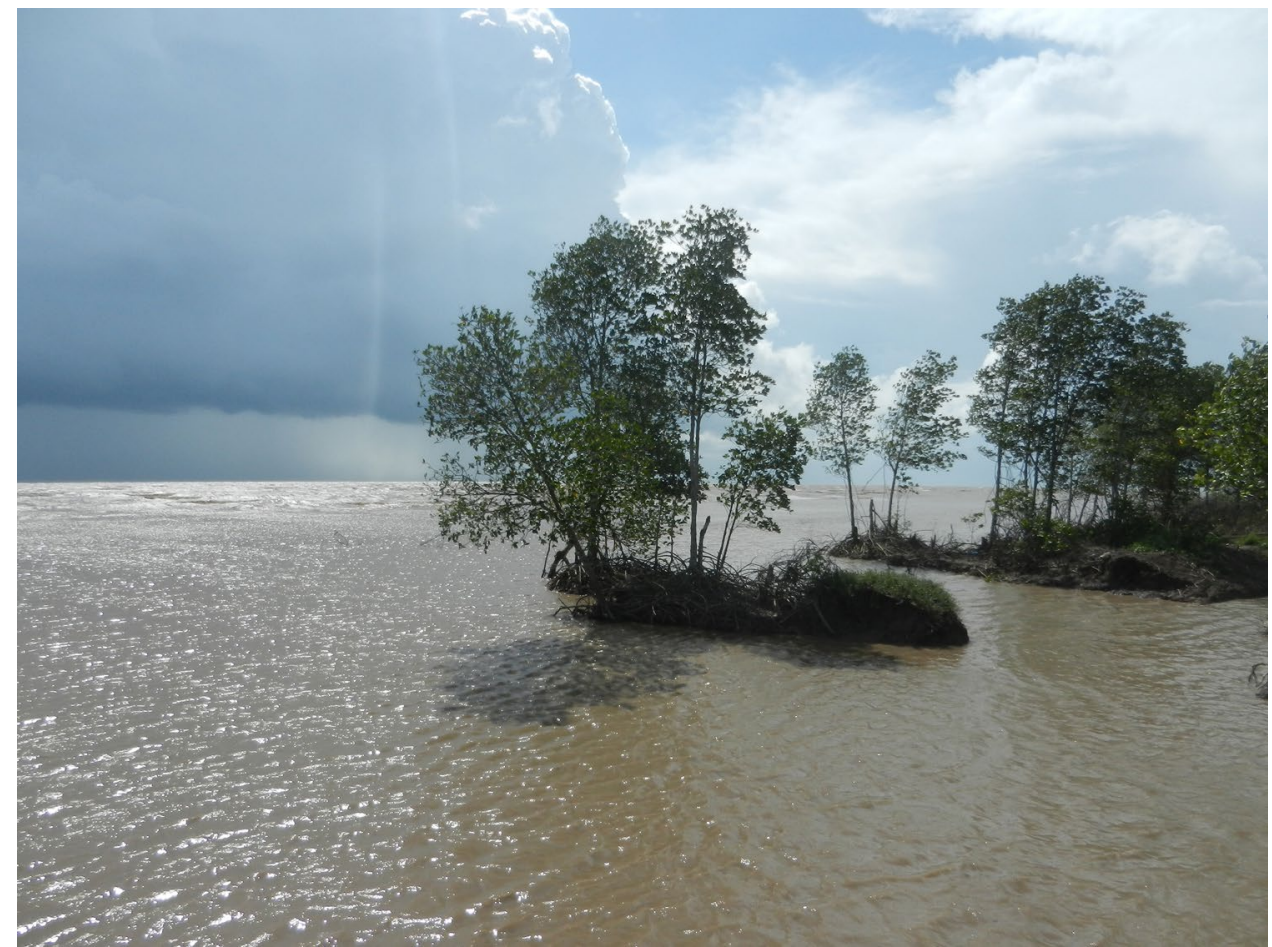

Coastal protection processes Mangroves have the potential of being an integral part of coastal protection systems. Especially since the Indian Ocean Tsunami in 2004, global interest in their role as a protective barrier against storm events and flooding, shielding coastal communities and property from the destructive impacts, has risen notably (Barbier et al. 2011). Based on Gedan et al. (2011), the processes which provide coastal protection can be divided into direct and indirect mechanisms. They reduce waves and currents, diminish the destructive forces of storms and tsunamis, and stabilise the coastline.

Mangroves have proven to be effective in attenuating wave energy and thus reducing wave heights reaching the shore (Chowdhury et al. 2019; Hassan et al. (Eds.) 2005; van Coppenolle et al. 2018). Wave-trunk interactions and wave breaking cause the dissipation of wave energy in mangrove forests (QuangBao 2011). Thus, waves are dampened directly by the mangroves' structural presence (Gedan et al. 2011). Even over a relatively small distance mangroves have the potential to significantly reduce waves (QuangBao 2011), since the largest reduction in wave heights in relation to distance travelled occurs near the mangroves seaward edge, declining exponentially with distance travelled through the mangrove belt (World Bank Group 2016). The processes underlying these protective effects are highly complex and dependent on a variety of indicators and characteristics regarding the vegetation, the topography and the initial wave or storm. Vegetation characteristics, such as tree density and structural complexity, mostly depend on the dominant species or the mix of species but also on the general mangrove forest structure features like forest width and density (World Bank Group 2016). Of course, these properties are interconnected. For example, with a smaller width of the mangrove belt but an increased density of vegetation and individual plants, the same wave attenuation can be achieved as with a larger width but lower density (QuangBao 2011). Key hydrological characteristics are initial wave height and the water depth. The water depth is of particular importance, as it influences the type of vegetation - aerial roots, trunks, branches or canopy - that the waves are passing through (World Bank Group 2016). Indirectly mangroves dampen waves through the increased bed roughness, stabilisation of the soil and sediment accretion (Gedan et al. 2011). As Narayan et al. (2016) concluded in his study, all these mechanisms within mangroves can reduce wave heights by $31 \%$ (95 \% CI: $25-37 \%$ ). Since the magnitude of energy absorbed strongly depends on vegetation structure and initial wave conditions, QuangBao (2011) developed a formula based on cross-shore distance, mangrove structure and initial wave height as major input values or determining influences. Derived from field investigations in two regions of coastal Vietnam, according to QuangBao (2011), the wave height behind a mangrove forest belt can be determined as

$W_{h}=a e^{b B_{w}}$, 
with $W_{h}[\mathrm{~cm}]$ being the wave height behind the mangrove habitat, $B_{w}[\mathrm{~m}]$ being the cross-shore mangrove forest band width. Intercept coefficient $a$ describes a function of the initial wave height $I_{w h}[\mathrm{~cm}]$,

$a=0.9899 I_{w h}+0.3526$,

and slope coefficient $b$ describes a function of the forest structure,

$b=0.048-0.0016 H-0.00178 \ln (N)-0.0077 \ln (C C)$,

with the average tree height $H[\mathrm{~m}]$, tree density $N\left[\right.$ tree $/ h a^{-1}$, and canopy closure $C C$ [\%]. Given an initial wave height $I_{w h}$ [cm] (cf. Eq. 7) and a targeted or 'safe' wave height $W_{h}[\mathrm{~cm}]$ behind the mangrove ecosystem, the necessary mangrove band width $B_{w}[\mathrm{~m}]$ depends on the forest structure (cf. Eq. 8) and can be determined as

$B_{w}=\frac{\ln \left(W_{h}\right)-\ln (a)}{b}$.

Another indirect effect on waves, besides wave attenuation, is the reduction of wind speeds over the water surface through the mangrove canopy, which decreases the likelihood of waves increasing in height within the mangrove area (World Bank Group 2016).

Current velocities can also be reduced significantly within mangrove forests by the sheer density of tree trunks, branches and aerial roots (Gutiérrez et al. 2011). The flow of water is resisted by drag forces due to the high number of vegetation obstacles, the bottom friction caused by the uneven sea bed as well as the eddy viscosity that originates from the turbulent flow of water though narrow openings between the mangroves' trunks and branches (Mazda et al. 2005).

The mangroves' ability to attenuate tsunamis or coastal storms and flooding largely depends on their ability to reduce the impact of waves and currents, as well as the factors and characteristics underlying these processes, as described above (Alongi et al. 2008; World Bank Group 2016; Hassan et al. (Eds.) 2005). Additional tsunami specific factors that influence the mangroves' effectiveness are size and speed of a tsunami and its angle of incursion relative to the coastline. Storm surges that are moving slowly are likely to be rather unaffected by mangroves, as they have time to flow through the vegetation. Fast-moving tsunamis however, can be reduced by mangrove presence. Naturally there are certain limits to the mangrove trees' ability to withstand the forces of a tsunami, but usually, even after severe damages and some resulting tree mortality, the forest's structural complexity is maintained and he mangrove band can recover and rebuild its protective function (World Bank Group 2016), if the initial conditions of the mangrove forest were sufficient.
Fringing mangroves also have a stabilising function and reduce shoreline erosion along sandy and muddy coasts (Alongi et al. 2008; Barbier et al. 2011; Gedan et al. 2011; Hassan et al. (Eds.) 2005). Direct mechanisms that benefit shoreline stabilisation are the stabilisation of sediments and the retention of soils through the mangroves root structure (Barbier et al. 2011). Furthermore, mangroves actively trap even fine sediments by slowing down the water movement and generating stagnation zones behind the plants, so that sediments can settle and accrete (Alongi et al. 2008; Gedan et al. 2011). Indirect mangrove effects are the increased rigidity and consolidation of the ground. The mangroves extensive underground rooting system increases the rigidity of the soils and through the extraction of water from the soil, it is compacted and consolidated (Augustinus 1995).

Ecological and societal value In the previously mentioned study by Costanza et al. (1998), mangroves were rated as equally valuable as salt marshes. Since mangroves are the primary source of nutrients and energy in the coastal environments where they thrive, they benefit nature and people with supporting ecosystem services of major significance (QuangBao 2011). Mangrove forests actively promote biodiversity, offering a unique habitat to a wide range of insects, fish, reptiles, birds and mammals (Atkinson et al. 2016; Cosslett and Cosslett 2014; GIZ 2014; Gutiérrez et al. 2011; Hassan et al. (Eds.) 2005). Mangroves provide habitat similar to that of terrestrial forests, with the difference or paradoxical feature being, that their relatively low tree species diversity enables a relatively high faunal biodiversity (Gutiérrez et al. 2011).

Mangroves offer a variety of provisioning services to coastal communities and wildlife. As they provide sheltered habitats with areas of limited accessibility for larger animals, mangroves play an important role as nursery grounds for marine organisms and other animals (GIZ 2014; Hassan et al. (Eds.) 2005). To coastal communities mangrove forests are an important food source, e.g. through the provision of fishery resources (Atkinson et al. 2016; World Bank Group 2016; GIZ 2014; Hassan et al. (Eds.) 2005), as well as a supplier of firewood and construction material (World Bank Group 2016; Cosslett and Cosslett 2014; Hassan et al. (Eds.) 2005). When handled sustainably and non-destructive, in balance with the natural mangrove ecosystem and the locations it provides, mangroves can even support agricultural activities like rice cultivation (Hassan et al. (Eds.) 2005).

As far as regulating services are concerned, mangroves are processing pollutants (Hassan et al. (Eds.) 2005) and sequester carbon (Atkinson et al. 2016; GIZ 2014). Similar to the value for salt marsh ecosystems, Chmura et al. (2003) estimates the carbon sequestration by mangroves at an average rate of $210 \mathrm{~g} \mathrm{~m}^{-2} \mathrm{yr}^{-1}$. 


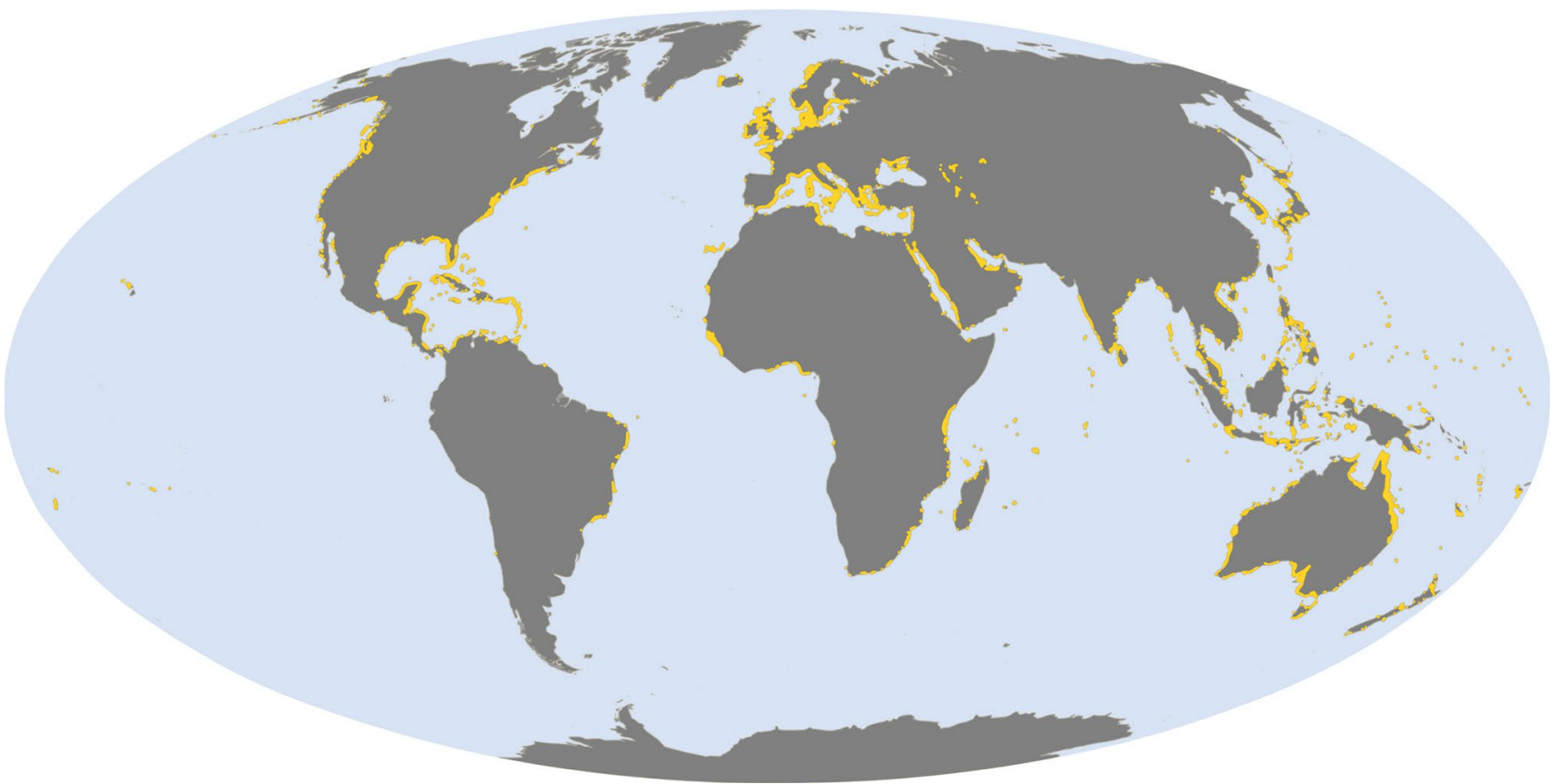

Fig. 9 Global distribution of seagrass in yellow after UNEP WCMC (2020)

The biodiversity supported by mangrove ecosystems is also of great cultural and aesthetic value. Coastal communities are often closely connected with the ecosystem and their cultural heritage and traditional knowledge is tied to its health and functioning (Walters et al. 2008). Furthermore, ecotourism activities are cultural services that can financially benefit and develop coastal communities whilst promoting the protection and conservation of mangroves (Friess 2017).

\section{Seagrass meadows}

Seagrasses are a group of about 60 different angiosperm species (Duarte et al. 2008; Green and Short 2003; Ondiviela et al. 2014), which grow in soft substrates preferably under wave-sheltered conditions in depths where at least approximately $11 \%$ of the surface light still reaches the sea floor (Barbier et al. 2011). Seagrass grows in the form of meadows. Seagrass meadows are usually monospecific - only meadows in the tropics or subtropics may contain several species, especially in the Indo-Pacific region where seagrass species diversity is greatest (Duarte et al. 2008). In the temperate zones in higher latitudes the eelgrass types (Zostera spp.) are most common and form large meadows in estuarine and near-shore coastal areas, while in the tropics and subtropics large areas are often covered with manatee (Syringodium filiforme) and turtle grass (Thalassia testudinum) (Hassan et al. (Eds.) 2005).
As angiosperms or flowering plants, seagrasses are seedbearing vascular plants. For reproduction purposes and habitat maintenance they pollinate on the water surface or under water and produce fruits and seeds. Their primary mode of reproduction or expansion, however, is clonal growth (Duarte et al. 2008). Clonal growth is of particular importance during the colonization of new habitats as well as during recovery from disturbances such as storm events. The spread of clones is facilitated via the rhizomes. New roots, shoots and branches typically form in the internodes of rhizomes (Marba et al. 2004).

Seagrasses occupy the soft-bottom areas of the world's oceans from the tropics to the temperate zones (Hassan et al. (Eds.) 2005), extending from the intertidal zone to depth of up to $40 \mathrm{~m}$ Gutiérrez et al. (2011). As can be seen in Fig. 9, which displays the global distribution of seagrass meadows, the ecosystem can be found along the coasts of all continents with the exception of Antarctica. The global aerial extend of seagrass is hard to estimate, since documentation is especially poor for the coasts of many developing countries. A conservative estimate of global seagrass areas compiled by Green and Short (2003) amounts to $177,000 \mathrm{~km}^{2}$, which is in general considered much too low (Duarte et al. 2008). More progressive estimations of global seagrass area range up to values of $600,000 \mathrm{~km}^{2}$ (Mcleod et al. 2011).

Seagrass meadows often occur in the proximity to other coastal ecosystems such as coral reefs, mangroves or salt marshes and are ecologically linked with them (Duarte et al. 
2008; Green and Short 2003). The different seagrass species have developed a number of adaptations and adaptation strategies to enable their survival in the niche where they thrive. They are able to grow whilst being completely submerged and can tolerate varying high salinities. To withstand stresses caused by water movement, their root system anchors them into the soft soil and to expand and reproduce under these harsh conditions, seagrasses developed a submarine pollination system as well as clonal growth, as explained above. Flattened and elongated, strap-like leaves as well as the extensive root and rhizome system are widespread characteristics among seagrass species, which have developed over tie due to these adaptation (Green and Short 2003). Furthermore, seagrass meadows can actively alter their environment to improve conditions for them and promote their growth and reproduction by reducing turbidity and in turn increasing light availability (van der Heide 2007).

Since seagrass meadows grow at the land-sea margin they are especially vulnerable to anthropogenic impacts and alterations to their environment. As estimated by Duarte et al. (2008), the global mean loss rate of seagrass meadows over the last decades is nearly twice as high as loss rates of mangroves or salt marshes and amounts to $2-5 \% \mathrm{yr}^{-1}$. Human activities in the coastal environment like boating and anchoring, coastal development and dredging (Duarte et al. 2008; Hassan et al. (Eds.) 2005) as well as habitat conversion for algae farming (Hassan et al. (Eds.) 2005) or oyster and mussel aquaculture (Green and Short 2003) pose direct threats to seagrass meadows and are partly responsible for their drastic decline, especially in proximity to urbanised areas. Negative indirect impacts are hypersalinisation and siltation, resulting from changes to inflows (Hassan et al. (Eds.) 2005), and, above all, reduced coastal water clarity (Duarte et al. 2008; Green and Short 2003). Seagrasses are vulnerable to reduced light penetration. Increased turbidity, caused by either the discharge of large amounts of sediments into coastal waters or by increased nutrient loading and subsequent eutrophication of coastal waters and algae blooming, thus is responsible for the destruction of many seagrass beds.

Climate change-induced sea level rise also threatens seagrass beds. Since they require a lot of light, which no longer reaches the seabed in sufficient strength with increasing water depth, seagrass meadows either have to migrate landwards to remain in shallower waters, or they eventually disappear. As projected by the IPCC (2019) with medium confidence for the sea level rise under the RCP8.5 emission scenario by the end of the century, coastal wetlands in general are under high risk of total local loss. The effects of the increase in global temperature on seagrass are hard to estimate, because nearly all aspects of seagrass metabolism and growth is affected by it. A moderate increase in temperatures may even pose chances for seagrass expansion, as pointed out by Duarte et al. (2008), since it could enhance species diversity in the subtropics and expand the distribution of cold-water seagrass species to higher latitudes.

Coastal protection processes Like other coastal wetlands, seagrass meadows influence certain hydrodynamic processes, through which they in turn provide regulating ecosystem services like wave energy attenuation or shoreline stabilisation.

Seagrass beds are known to dampen wave energy and, hence, wave height (Ondiviela et al. 2014; Schoonees et al. 2019). Waves are being attenuated directly through friction, caused by the structural presence of the vegetation in the water column (Gedan et al. 2011; Narayan et al. 2016). A variety of different factors, both biophysical-vegetational and hydrodynamic, influence the degree of wave attenuation. Standing biomass, plant flexibility, shoot density and leaf length or height of the canopy are decisive vegetation characteristics (Ondiviela et al. 2014; Rupprecht 2015). Incident energy flux (Ondiviela et al. 2014), wave height and even more so wave period (Maza and Lara 2012) as well as water depth represent influential hydrodynamic factors. The water depth, or in other words the proportion of the water column occupied by the seagrass meadow, is of particular importance. The larger the portion of water column occupied by the meadow, the more successful seagrass is in attenuating waves, because the interaction surface in vertical and horizontal dimension is the key to the degree of attenuation. Thus, in deeper coastal water attenuation abilities of seagrass meadows are more limited whereas in shallow areas seagrass are more effective in attenuating waves (Barbier et al. 2011; Gutiérrez et al. 2011; Ondiviela et al. 2014). Another influence factor regarding wave attenuation is seasonality (Ondiviela et al. 2014), which plays a particularly important role in temperate zones. During winter, when hydrodynamic forcing in coastal areas of the temperate zones is highest, most of the above-ground biomass of seagrass dies, resulting in wave attenuation capacity being at its lowest. According to the previously mentioned study by Narayan et al. 2016, wave heights can be reduced by an average of $36 \%$ (95\% CI: $25-45 \%$ ), as concluded from analysed studies for seagrass and kelp beds combined. After Bouma et al. 2014 the wave decay coefficient for seagrass meadows $k_{\text {seagrass }}\left[\mathrm{m}^{-1}\right]$ can be estimated between 0.001 and 0.01 , as derived from field measurements. Based on Eqs. 2 and 3 the wave height after maximum attenuation by a seagrass meadow (thus maximum coverage, $B=B_{\max }$, and $k_{\text {seagrass }}=k_{\text {seagrass, } \max }=0.01$ ) can be approximated by

$H_{L, \text { seagrass }}=0.3 h e^{-\left(0.01 e^{-d h}\right) L}$. 
Current flow and current velocity are also attenuated by seagrass meadows (Maza and Lara 2012; Ondiviela et al. 2014; Schoonees et al. 2019), which promotes sedimentation within the beds (Bouma et al. 2014; Ondiviela et al. 2014; Schoonees et al. 2019). The seagrasses extensive above- and below-ground biomass directly reduces erosion and traps sediment. While the canopy encourages the deposition of sediments and prevents its re-suspension, the extensive root and rhizome systems bind the deposited sediment over the longer term and secure the seagrass meadow's accretion (Duarte et al. 2008; Green and Short 2003). Furthermore, seagrass beds indirectly favour sedimentation as they dampen the effects of waves an currents on the sea floor and, thus, prevent scouring action of waves (Green and Short 2003).

Ecological and societal value Regarding the value of provided ecosystem services, Costanza et al. (1998) assessed seagrass meadows to be of even more value than other wetland ecosystems like salt marshes or mangroves. Many of the seagrass meadows' ecosystem services are based on the following two supporting services. Seagrass beds exhibit high primary production (Green and Short 2003) and provide crucial habitat for a large number of different species of fish and invertebrates (Duarte et al. 2008; Green and Short 2003; Hassan et al. (Eds.) 2005) as well as large herbivores like dugongs and sea turtles in the tropics and swans or geese in temperate zones (Duarte et al. 2008).

Concerning provisioning services, seagrass serves as a food source for many of these species and poses important nursery areas, especially for coral reef fishes in the tropics (Hassan et al. (Eds.) 2005).

Regulating services include the filtration of nutrients and contaminants from coastal waters as well as oxygen production from photosynthesis, which improves water quality and supports the existing fauna (Green and Short 2003). Furthermore, like the other wetland ecosystems featured before, seagrass meadows sequester carbon at a rate of 69-169 $\mathrm{g}$ $\mathrm{m}^{-2} \mathrm{yr}^{-1}$ (Duarte et al. 2010).

Important cultural services are linked with the habitat provision for certain species. Seagrass beds help safeguarding threatened species like sea horses, sea turtles or sirenians. Some of these animals are perceived by local communities as well as tourists and nature-enthusiasts as being of particular cultural or aesthetic value (Green and Short 2003).

\section{Beach ecosystems}

Beach ecosystems consist of often highly interacting beach and dune areas. Beaches and dunes by themselves and in combination with each other function as bulwarks as well as dynamic buffers for storms and extreme events on the coast. They also provide space for a variety of tourism and sporting related activities and serve as habitat, resting sites and nursery for a range of animal and plant species.

\section{Beaches and foreshore areas}

Beaches, which per definition describe shores that are covered with sand or shingle (Shepard 1973), represent the world's largest type of open shoreline (Defeo et al. 2009) and a physically dynamic ecosystem (IPCC 2019). The prevailing nature of a beach is strongly characterised by the acting hydrodynamics, tides, waves and currents as well as the extent of the near-shore, surf, and dry beach zones (Finkl 2004; Short 2006). Beaches can be classified as micro- $(<2$ $\mathrm{m})$, meso- (2-4 m) or macro-tidal ( $>4 \mathrm{~m}$ ) based on the existing tidal ranges as defined by Davies (1964). Other classifications like e.g. in Finkl (2004) state that, regarding the affects on beach morphology and hydrodynamics, the dissipation of incident wave energy is the decisive factor - especially in micro-tidal environments. However, with increasing tidal range this changes and tide-related processes begin to have stronger influences (Finkl 2004), meaning that the interaction of the two drivers need to be considered when classifying beach ecosystems. Based on the works of Wright and Short (1984) and Short (1991), Masselink and Short (1993) developed a conceptual classification approach which takes four variables into consideration - breaker height, wave period, high tide sediment fall velocity, and tidal range. From these values they distinguish between the three main beach type groups of reflective, intermediate and dissipative beaches. Reflective beaches are usually coarser in grain size and have no surf zone, intermediate beaches feature a surf zone with bars and rips, and dissipative beaches are finegrained and have extensive surf zones with multiple shoreparallel bars and troughs (Defeo et al. 2009; Finkl 2004).

Through long-shore and cross-shore sediment transport, storage and exchange beach ecosystems are closely linked to the surf zone on the seaward and to coastal dunes on the landward side (Defeo et al. 2009). Depending on the availability of sand three states of interacting beach-dune systems can be differentiated after Doody (2013). Focussing on the beach ecosystem these are

- Erosion: With little to no vegetation, bare sand areas are prevalent and sand movement on the beach is high. The sediment budget is deficitary with the amount of removed sand outweighing the amount of gained sand on the beach;

- Dynamic Equilibrium: The beaches in this state are highly mobile and react to changing weather conditions by moving landward or seaward. In equilibrium over the year, storms flatten the beach and move sand to the lower beach level (during winter in temperate regions, during 
monsoon season in the tropics) while in the storm-free season it gradually builds up on the upper beach;

- Accretion: With sediment availability in abundance the shoreline can move seaward, as the beach accumulates further sediment and allows vegetation and therefore foredune development.

Beach ecosystems form naturally at low-lying coastlines where sand is available and transported long-shore and cross-shore by waves and currents (Barbier et al. 2011). If there is sufficient mobilised sand in the foreshore, beaches can also form when sandbanks migrate towards the coast from the sea and gradually attach themselves to the island or mainland (Rabe et al. 2018) (e.g. Fig. 10). Nowadays, many beaches around the world are maintained or even widened and enlarged artificially through the practice of sand nourishments - either performed directly on the beach or in the foreshore area. During decades of practice this these techniques have proven to be very successful in counteracting coastal erosion and stabilising shorelines (Niemeyer et al. 1996; Sørensen et al. 1996; Wiegel and Saville 1996). Sand, of course, is an increasingly valuable resource (Bridges et al. 2018) that can only be removed from designated dredge sites. Possible sediment sources include e.g. navigational channels, that require excavation, terrestrial or riverine sand deposits, the intertidal area or offshore dredging sites and pits (Carley and Cox 2017; Hanley et al. 2014). If designed and constructed well, the artificial nature of such beaches may be undetectable to most people. To meet the local conditions and keep harmful environmental impacts as low as possible, however, the nourished sand should match the naturally prevalent sand in grain size, colour, shape, fall velocity, mineralogy and biogenic fraction. Physical impacts and the ecological disturbance of habitats is to be avoided (Carley and Cox 2017).

As can be seen in Fig. 11, beach ecosystems occur on all continents except Antarctica, with an increase in relative occurence in the lower mid-latitudes as well as the subtropics between $20^{\circ}$ to $40^{\circ}$ (Luijendijk et al. 2018). Regarding the total length of sandy beaches Australia ranks highest with $13,200 \mathrm{~km}$ total beach length, followed by the USA $(12,800 \mathrm{~km})$, Brazil $(6,100 \mathrm{~km})$, Denmark $(4,600 \mathrm{~km})$ and Mexico (4,900 km) (Hinkel et al. 2013). According to Hinkel et al. (2013) four of these countries (USA, Australia, Mexico, and Brazil) are also amongst the five countries most affected by land loss without nourishment under SRES scenario A1B (approximately equivalent to RCP6.0 IPCC (2019)) by 2100 . In terms of absolute costs they concluded that the USA, Japan, Germany, Denmark and the Netherlands rank highest. Looking at the big picture, several studies show that beaches worldwide are under threat of erosion and partly even extinction (e.g. Luijendijk et al. 2018; Morris et al. 2018; Vousdoukas et al. 2020).

Threats to beaches and the foreshore area are manifold. They range from pollution to overexploitation by sand mining or groundwater extraction and the harvesting of beach organisms (Brown et al. 2002). Excessive coastal developments in combination with coastal protection with passive
Fig. 10 Boardwalk towards the North Sea on the vast Kniepsand off Nebel on the island of Amrum, Germany

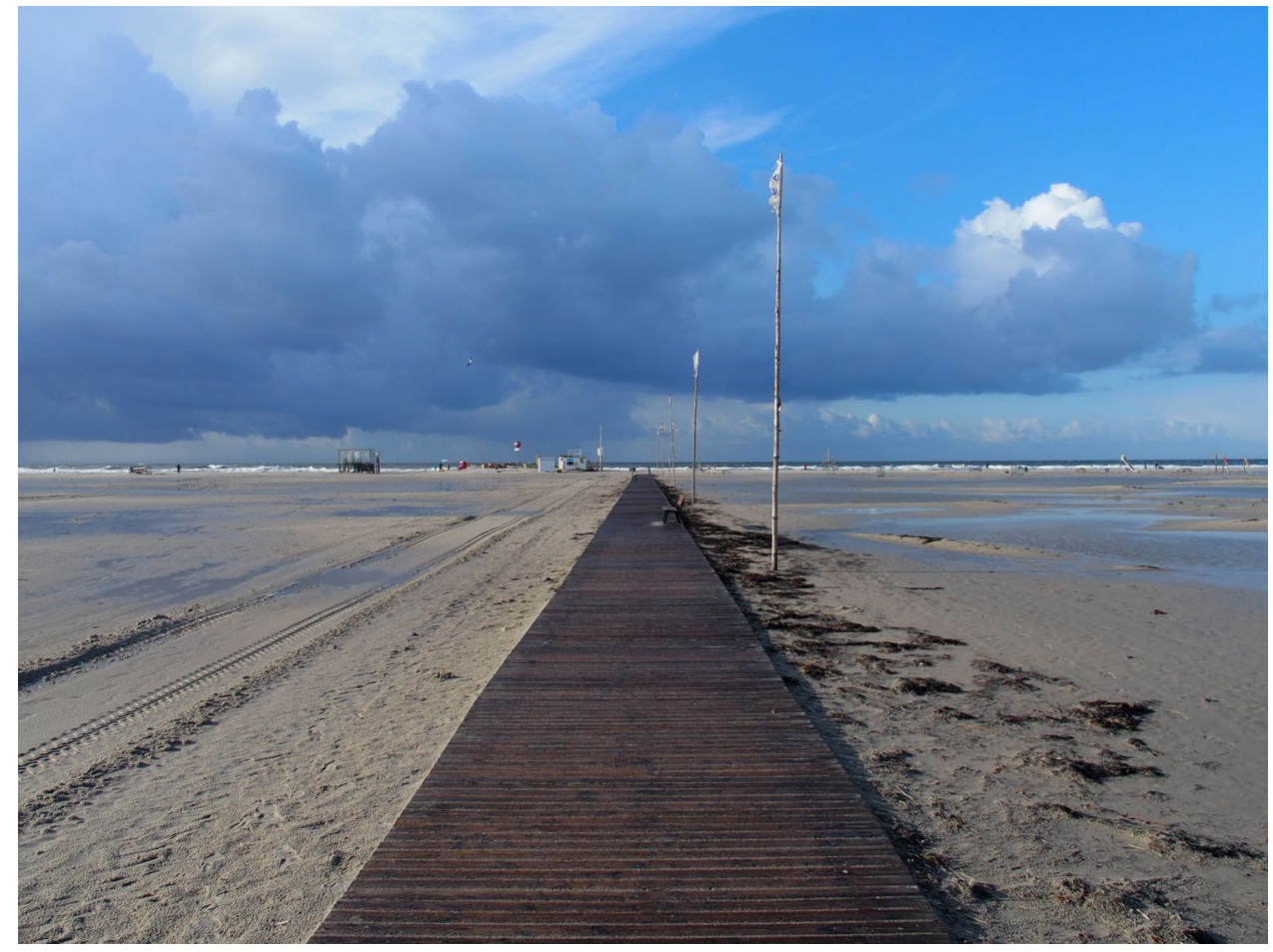




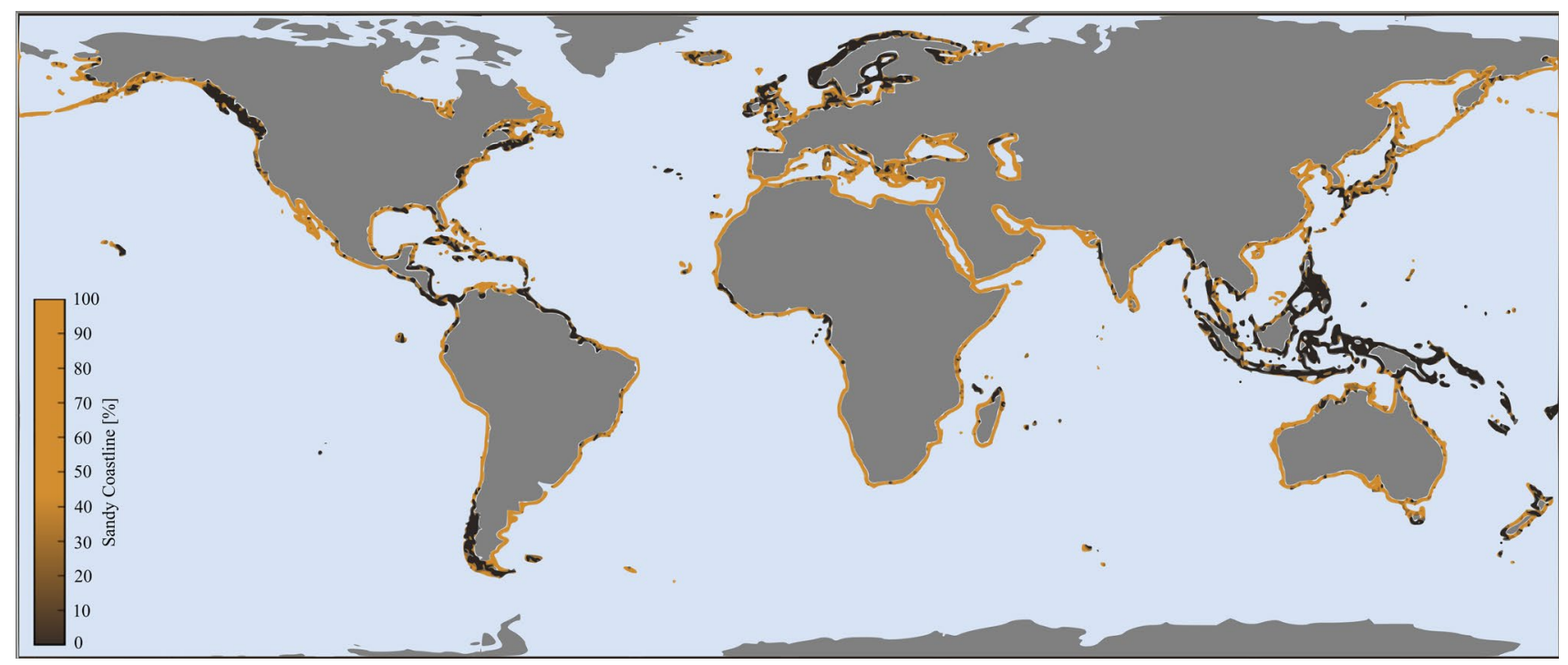

Fig. 11 Global distribution of sandy coastlines after Luijendijk et al. (2018)

Fig. 12 Scheme of wave attenuation over the cross-shore section of a foreshore-beachsystem, attenuation occurs over the sand bars in the foreshore area and on the beach; with $\mathrm{H}_{i}$ = initial wave height; areas of increased long-shore sediment transport are marked in yellow

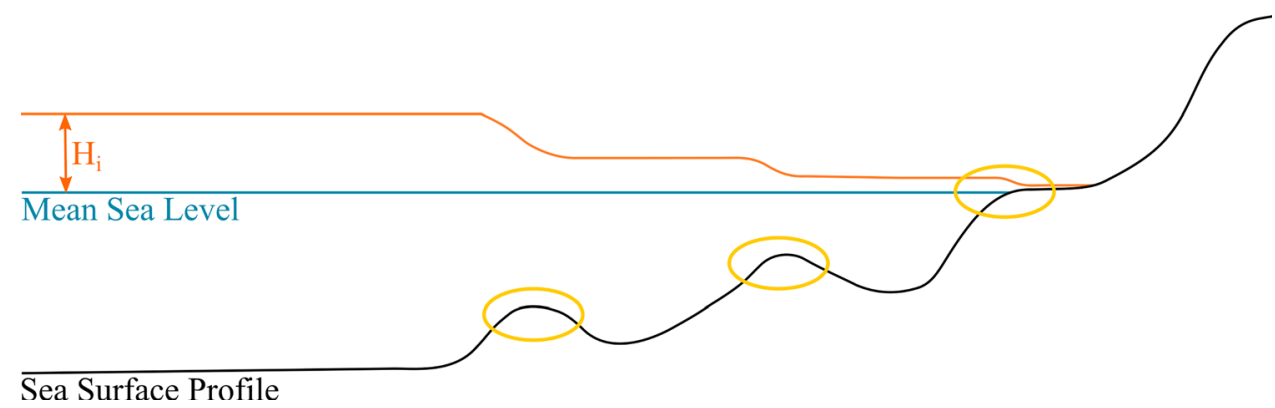

structures lead to a hardening or armouring of the coastal environment and therefore often to disruptions in the sand balance and dynamics (Brown et al. 2002; Hanley et al. 2014; Hassan et al. (Eds.) 2005). Urban expansion and touristic developments in combination with climate change related processes and events such as sea level rise, storm surges of increased frequency and intensity, and changes in offshore winds and weathering regimes (IPCC 2019) resulting in the phenomenon of coastal squeeze - are the major long-term threat to beach ecosystems worldwide (Defeo et al. 2009). Narrow sandy beaches are particularly threatened to disappear due to coastal squeeze (IPCC 2019). According to projections of medium confidence of the latest IPCC report (IPCC 2019) the aforementioned changes under the RCP8.5 scenario translate to a substantial risk for beach ecosystems by the end of the $21^{\text {st }}$ century.

Coastal protection processes In terms of coastal protection, beach ecosystems can be regarded as adaptive, resilient structures. They respond to changes in their environment in order to maximise their persistence and minimise harmful effects (Hanley et al. 2014). As displayed in the scheme in
Fig. 12, the energy of waves that reach the shore is directly attenuated or dissipated by the beach slope (Barbier et al. 2011; Doody 2013), which displays one of the most important processes affecting the beach morphology as well as beach hydrodynamics (Finkl 2004). Coastal erosion resulting from storms and waves interacting with the beach is a highly complex process and depends on various storm parameters such as air pressure, mean water level, wind speed and direction as well as wave height (Anthony 2013). But thanks to the beaches ever-changing character and the ecosystem's responsive nature, regeneration from erosion damages due to severe storm surges can take place within a few weeks (Niemeyer et al. 1996) - of course dependent on the sediment availability and hydrodynamic transport conditions.

In principle, natural and dynamic formation and shaping processes play an essential role in coastal protection. For example, in high energy environments with increased wave action, sandy beaches can respond by flattening their profile. The cross-shore sediment transport is increasingly shifted offshore into the sublittoral zone. This then shallowing foreshore, where multiple rows of submerged bars can 
form with the additional sediment - hence the development of a wider dissipative surf zone - causes wave breaking well offshore, so that wave impact on the beach and dunes is greatly reduced. In less energetic environments the beach is usually more permeable and less saturated with ocean water. Therefore, shorter and steeper waves arriving at the beach can transport sediments back onshore, causing an enhanced accretion and steepening of the beach, which in turn becomes more reflective. If inundation times are sufficiently low allowing the sand in the upper parts of the beach to dry out onshore winds can transport the sand back into adjacent dune ecosystems (Hanley et al. 2014).

Wave energy dissipation by beaches is a non-uniform process, that results from the complex interaction of various different forces. On the foreshore wave-bottom interactions are mainly responsible for energy dissipation, whereas in the surf zone turbulence due to wave breaking dominates energy dissipation. Even though wave bores that reach the swash zone only bear a small percentage of the wave's initial energy that has not been dissipated yet on its way onto the sandy coast, this wave run-up is often responsible for considerable damages on the beach, in the dunes or to property in the adjacent hinterland. Since waves continue to lose energy in the swash zone due to turbulence, bottom friction and percolation, wider beaches offer greater levels of protection than narrow, fringing beaches (Stutz et al. 1998). Through combination and alignment of these interactions, beach ecosystems are able to absorb up to $90 \%$ of the initial energy of waves when they arrive at the coast (Palmer and Limited 1996).

Furthermore, accounting for another regulating eco-system service of beach ecosystems beside the aforementioned storm surge protection and erosion control, beaches are often interlinked with adjacent dune ecosystems for which they store and with which they dynamically exchange sediments.

Ecological and societal value Beach ecosystems support a unique biodiversity, as they provide habitat for species of vegetation, benthic fauna and sea birds, that cannot be found in any other environment (Defeo et al. 2009; Hassan et al. (Eds.) 2005).

Beaches provide feeding grounds for migratory birds as well as nesting areas for sea birds and sea turtles (Defeo et al. 2009; Hassan et al. (Eds.) 2005), which are particularly dependent on these ecosystems for reproduction. They also provide an easily accessible source of sand as construction material, the extraction of which, though, is detrimental to almost all other ecosystem services (Doody 2013).

Regulating ecosystem services, aside from the dissipation of wave energy and the facilitation of sediment exchange, include the breakdown of organic materials and pollutants, water filtration and purification and the transport of terrestrial nutrients to the coastal system. Due to the discharge of nutrient-rich groundwater, beach ecosystems connect the land-based dune aquifers with the ocean (Defeo et al. 2009; Hassan et al. (Eds.) 2005).

Culturally, beaches provide a variety of ecosystem services. Above all, beaches are the main driver of coastal tourism in holiday destinations worldwide, since they offer opportunities for a wide range of recreational activities such as sunbathing, sports and games, ocean access or simply walking (Doody 2013; Hassan et al. (Eds.) 2005). Besides, beaches are places of great aesthetics, which, as holiday photographs and a variety of artworks illustrate, form a large part of the visual appeal of coastal landscapes (Doody 2013).

\section{Dunes}

Dunes are highly dynamic geomorphic structures and coastal ecosystems that continuously change their form both in the short and long term (Barbier et al. 2011; Hassan et al. (Eds.) 2005; Kollmann et al. 2019). They usually occur along extensive beaches where sediment is abundantly available and can extend for several kilometres along the coast reaching tens of metres up to $100 \mathrm{~m}$ in height. But coastal dunes may also form as non-dominant, narrow linear structures, interspersed by cliffs and rocks headlands or other coastal ecosystems such as salt marshes or mangroves (Doody 2013). Coastal dunes depend on waves to transport sand onshore and wind to drive the sand further inland. Therefore, the sediments that make up a dune need to be light enough to be transported by the wind whilst being heavy enough not to be in suspension in the air, which results in dunes consisting of a rather narrow grain size spectrum. The sand in dunes varies in the range of 0.06-4 mm in diameter (Doody 2013), is therefore easily movable, low in nutrients, initially mostly rich in lime and has a low water-holding capacity (Kollmann et al. 2019).

Sand dunes are closely linked with adjacent beach ecosystems and are interacting with them through various processes - mainly storage, transport and exchange of sand (Defeo et al. 2009) - acting as a sand reservoir for the beach and the surf zone (Wiegel and Saville 1996). As mentioned above with regard to beach ecosystems, there are three states of interacting beach-dune systems according to Doody (2013), depending on the availability of sand. Focussing on the dune ecosystem these are

- Erosion: Due to a deficitary sediment budget and little to no vegetation on the beach developed foredunes only survive until the next storm. Losses of inland dunes can hardly be prevented, therefore the dune front typically has a steep face;

- Dynamic Equilibrium: The foredunes in this state are highly mobile and react to changing weather conditions by moving landward or seaward, always in a semi-stable state or natural balance; 
Fig. 13 Incipient foredunes exposed to the sea on Amrum, Germany

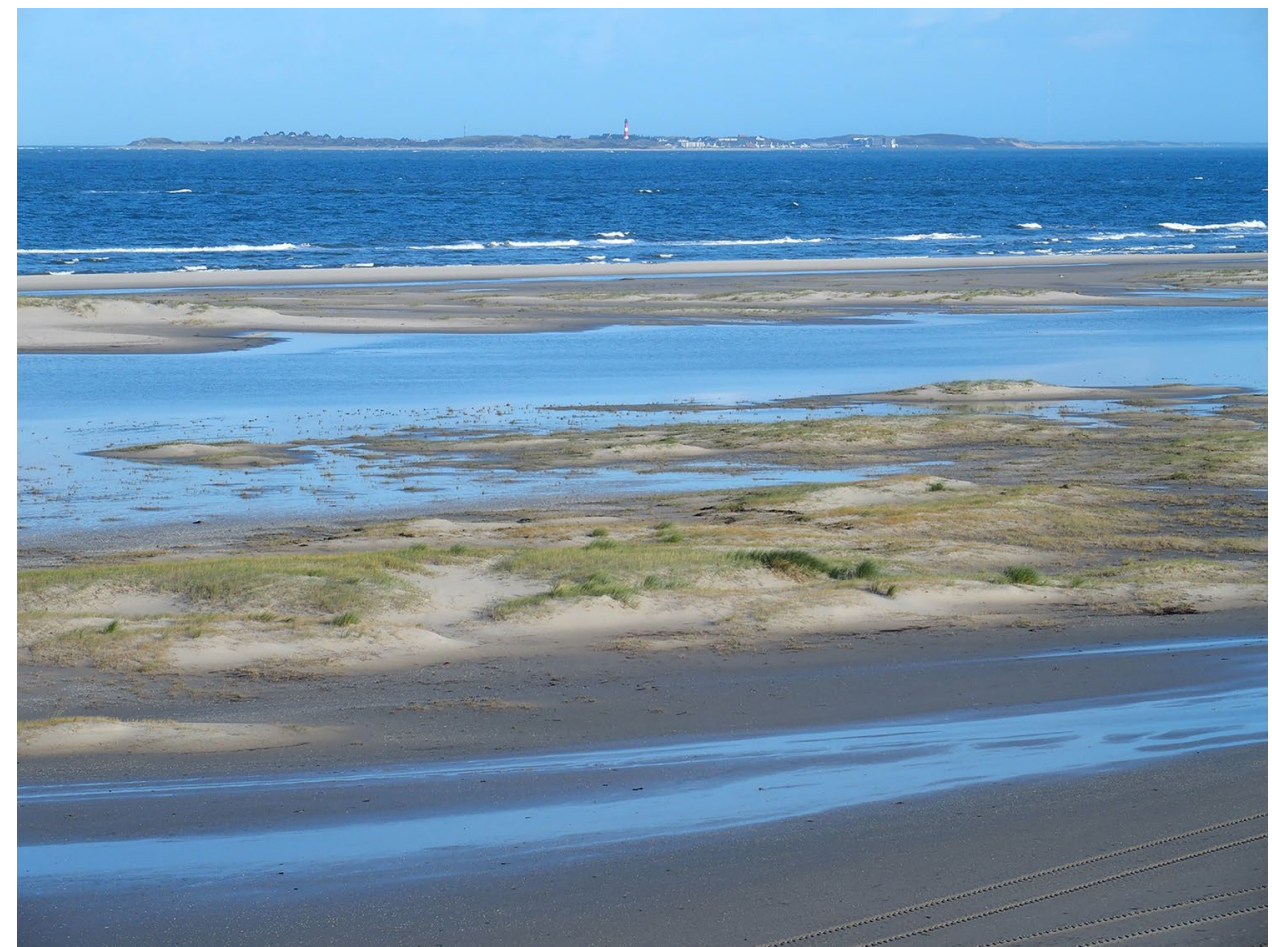

- Accretion: Foredunes can move seaward, as the beach accumulates further sediment and allows vegetation development. Former foredunes, now lying landward of the newly developed ones, can continue to accrete sediment and eventually become inland dunes.

Freshwater reservoirs or 'cushions' that float on the brackish water of the subsoil due to their lower density form under dunes. These freshwater cushions are vital for many dune plants, which reach down to the groundwater with their deep rooting systems (Kollmann et al. 2019). There are two broad vegetation types that can be distinguished - one associated with the temperate and cold regions and the other with the tropics (Doody 2013). In both cases though, the presence of vegetation in general is of significant importance for dune ecosystems, because dune vegetation is what stabilises and shapes an environment that would otherwise be highly unstable and shifting (Gutiérrez et al. 2011; Hanley et al. 2014).

Pioneer vegetation, thus early colonising species in sand dunes, all display similar mechanisms to cope with the harsh conditions of the environment they grow in. Since they are severely impacted by storms, broken up, transported elsewhere by waves or winds or buried under washed up sediments they all produce rhizomes, stolons and suckers to form new colonies when being relocated on the beach (Doody 2013). Dunes then begin to form naturally in such places, under the protection of this pioneer vegetation or also behind beach debris or mussel shingle (MELUR 2015), as can be seen in Fig. 13. A chain of processes must link together for dunes to develop (Doody 2013). The erosion of sand and water-driven transport through river flow or tidal currents represent the first processes. Next, sands need to be washed ashore a beach where the inundation or swash free time is long enough for the sand to dry out, and which is wide enough to guarantee sufficient wind exposure for the sand to be moved across the beach. Finally, when encountering obstacles such as pioneer vegetation, two different mechanism can cause the deposition of the sand and the beginning formation of an incipient foredune (Pethnick 1984). Either a boundary layer formed around the vegetation is dissipates the wind energy or sand grains actually hit the plants' surface and drop down. As can be derived from these interlinking processes, several factor have a significant impact on the formation of an incipient foredune. The most important are plant characteristics such as height, distribution or density, the present wind velocity and the rates of sediment transport (Hesp and Walker 2013). These, in combination with several other impact factors like storm erosion or occurrence of overwash, determine the success of the development of an incipient foredune. Established foredunes then develop from incipient foredunes over time. Under higher rates of sand supply foredunes become rather wide than tall, creating a series of ridges and expanding over a larger area, whereas when sand supply is negligible, single foredunes become taller as the deposition of the sand is not spread as widely as in the former case (Hanley et al. 2014; Hesp and Walker 2013). Over time, more and more sand can deposit in the vegetation's or obstacles' surrounding area, causing 


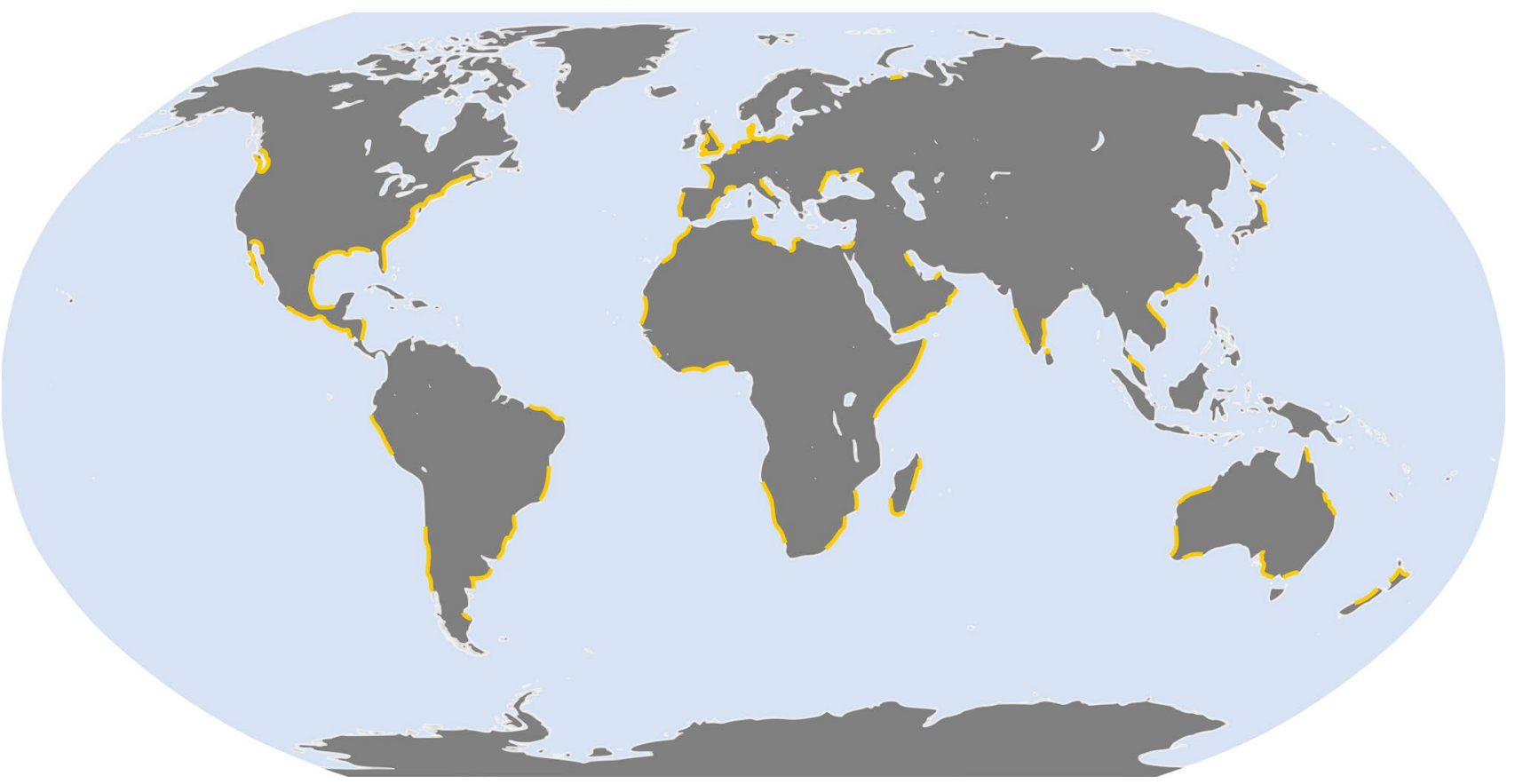

Fig. 14 Global distribution of well developed dune systems in yellow after Martínez et al. (2008)

the foredune to grow further and starting the successive process of dune development - from incipient and established foredunes to white or yellow, then grey and finally mature, fixed or brown dunes with shrubs and woodland.

Regarding human interventions in dune development and dune management there are two approaches that need to be distinguished. What is known today 'dynamic coastal management' implies little to no interference in the dune ecosystem whereas 'soft engineering' involves human interference to promote dune development or stabilise exiting dunes (Jong et al. 2014). The latter has been good practice for centuries in some dune ecosystems. Brushwood sand fences are constructed to reduce wind velocities and thus allow sediment accumulation and facilitate faster colonisation by pioneer dune vegetation. This technique is used to extend and strengthen existing dunes, close gaps or create new dunes. Furthermore, active planting of sand-binding dune vegetation or even forestation in established dunes is conducted to stabilise already existing dunes (Hanley et al. 2014; Wiegel and Saville 1996). Historically, dunes were fixed this way in many places to prevent their migration, as they threatened settlements, pasture and farmland (Ellenberg and Dierschke 2010; Müller and Fischer 1937).

Coastal dunes occur extensively around the world and can be found in the cold of the Antarctic as well as in the humidity and heat of the inner tropics (Doody 2013; Kelletat et al. 1999). The global distribution of well developed dune systems, areas where dunes are a significant or the dominant structure in the transition zone between land and ocean, is depicted in Fig. 14. The distribution of further small sand dune areas along the coasts, which are interspersed with sandy shore, rocky headlands or vegetation patches, e.g. in the Antarctica, Greenland, Northern Russia or Canada, can be found in the original figure by Martínez et al. (2008).

Coastal dunes can be classified geomorphologically according to their shape or on the basis of the vegetation present. According to their form, dunes are first divided into free dunes, i.e. dunes that develop freely on a surface, and bound dunes, i.e. those that are bound to relief or vegetation influences as sand accumulation on obstacles (Dikau et al. 2019; Zepp 2017). Different types of free dunes can occur on sandy coasts. Transverse dunes, which form at right angles to the dominant wind direction when there is a sufficient supply of sediment, are common and usually form straightline dune ridges. Parabolic dunes are also not uncommon on coasts and mainly emerge behind the first row of dunes. This curved dune form develops when sand transport is frequently impeded on the sides by increased roughness, e.g. by vegetation (Hesp and Walker 2013; Zepp 2017).

The classification of dunes based on the zonation of dune vegetation offers the advantage of being able to describe dunes as a habitat. The characteristic ecological differentiation of the site conditions and the associated vegetation zonation is caused by the increasingly weaker influences of wind, sand dynamics and salinity as the distance to the sea increases. Accordingly the five zones of vegetation and dune types are distinguished below and briefly described starting from the sea or beach moving inland corresponding to the 
Fig. 15 The transition of a grey dune to a mature dune with patches of both marram grass and common heather

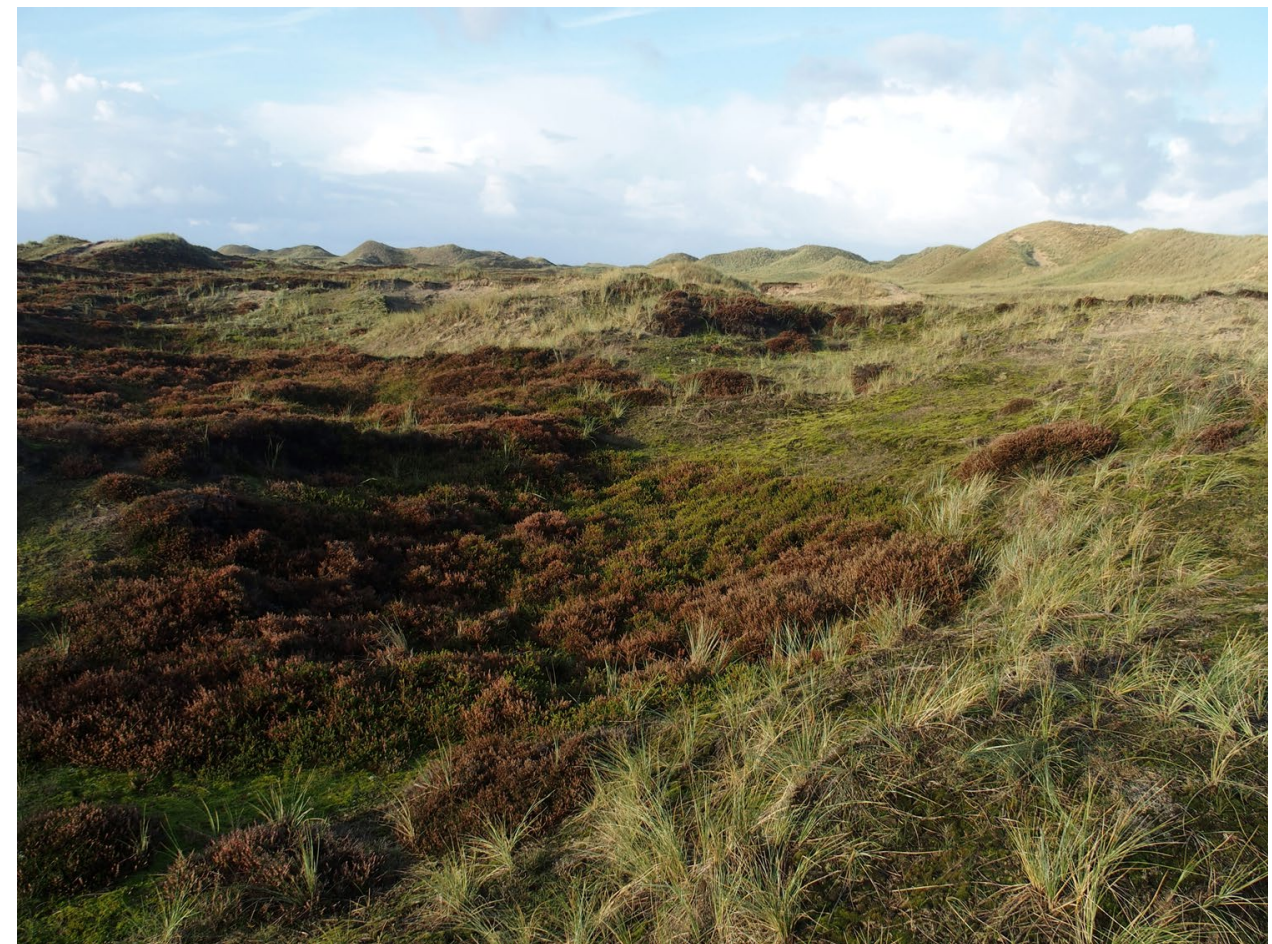

dune and vegetational succession Hesp and Walker (2013); Kollmann et al. (2019).

1. Incipient Foredune: Incipient foredunes or embryo dunes develop behind pioneer plants on the backshore of beaches (see Fig. 13). They can grow up to a few centimetres and are very rich in salt and nutrients.

2. Foredune: Foredunes or primary dunes are usually coherent, low dunes in front of the foot of a continuous chain of higher dunes. They are exposed to strong salinity and occasional flooding, but also to summer drought and nutrient deficiencies. They grow $10-30 \mathrm{~cm}$ per year, but rarely exceed 1-2 $\mathrm{m}$ in height.

3. Yellow Dune: Yellow or white dunes develop from foredunes and represent the first higher and coherent chain of dunes closest to the beach. They lie beyond the influence of the high tide, but are strongly exposed to winds that cause either sedimentation or erosion. Yellow dunes usually reach heights of 10-30 m and are covered with deep-rooted grasses.

4. Grey Dune: Grey dunes are flatter, older dunes that develop on the leeward side of the yellow dunes and can be several hundred metres wide. Compared to the yellow dunes, the micro-climate and soil properties change. The soil is more acidic, less nutritious and low-growing plant species dominate the area.

5. Mature Dune: Mature, fixed or brown dunes are found in the older areas with largely stabilised sands. They are also shallower than the dunes in the front rows and can extend inland for several kilometres. A closed vegetation cover of dwarf-shrub communities along with dune forest adds organic matter to the soil of the mature dunes, resulting in the development of a relatively thick layer of raw humus (see Fig. 15).

While, with certain site-specific differences, a white dune can develop from a foredune within a few years, the development into a grey dune takes another 10-20 years and the transformation into a mature dune about 60-70 years (Kollmann et al. 2019). In coastal dunes, dynamic phases usually alternate with phases of stability (Provoost et al. 2011). Vegetative succession can proceed more or less undisturbed as long as no external stressors influence the processes within the dune ecosystem.

In general, the concept of sediment budget is a useful tool to assess the likelihood of a dune ecosystem to extend, be stable or decline (Doody 2013). If there is a lack of sediment supply a dune is very likely to erode, which can lead to the loss of the dune or dune system, but does not necessarily have to. Coastal armouring, the hardening of coastlines through the construction of hard coastal protection assets such as breakwaters, groynes, revetments, or sea walls, generally poses a large threat to dune systems. Hydrodynamic regimes are changed on a local scale, thus sediment supply and subsequently the sediment budget of a beach-dune system is altered (Everard et al. 2010; Hanley et al. 2014; 
Fig. 16 Scheme of an initial cross-shore profile and erosion profile due to dune erosion during a storm surge

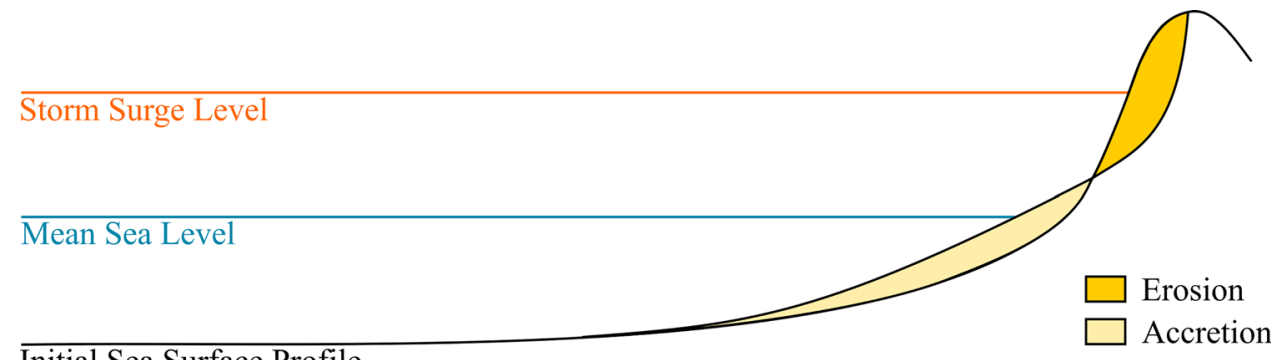

Initial Sea Surface Profile
Kollmann et al. 2019). Besides coastal armouring, dune systems are under threat and decline due to several further stressors. For example, since 1900 about $25 \%$ of the European dunes have been lost (Delbaere 1998) and Heslenfeld et al. (2008) estimate that $85 \%$ of the remainder are under threat of decline or disappearance.

Improved agricultural practices and urban development are major reasons for dune decline. Uncontrolled expansion of tourism and recreation also threaten dune ecosystems (Everard et al. 2010). Extensive summer house developments, such as in Denmark, create a multitude of trampling paths in the dunes, which damage the vegetation and thus create bare surfaces prone to the wind and blow-outs (Kollmann et al. 2019). Regular grooming of tourist beaches not only removes litter but also propagules of dune plants from the beach (Defeo et al. 2009), which prevents the establishment of pioneer plants and thus the formation of incipient foredunes. Increasing eutrophication, which can be exacerbated by agricultural or tourism practices, is another threat that permanently alters dune ecosystems (Kollmann et al. 2019).

Climate change related threats that will challenge coastal dunes in the future are locally predicted increases in storm intensities and frequencies (Everard et al. 2010; Hanley et al. 2014). If dunes are free to migrate landward, sea level rise as such does not represent a major problem for dune ecosystems. Unfortunately, many coastal areas are densely populated and population and tourism pressure continues to grow, which in turn causes coastal development for urban expansion, recreation and industry. Coastal dunes therefore suffer from coastal squeeze, being pressured by the rising ocean from one and spatial restrictions through development and construction from the other side (Everard et al. 2010; Hanley et al. 2014; Kollmann et al. 2019).

Coastal protection processes Coastal dunes form a natural form of coastal protection and play an important role in coastal defence along the world's sandy coastlines. Where dunes occur, they can take on the central flood protection function by acting as a physical barrier to protect the hinterland from flooding, and make other coastal protection structures superfluous (e.g. on typical barrier islands off the coast). Comparable to dykes, which determine the manmade, artificial coastal protection on many coasts, dunes provide effective natural protection of the hinterland from floods and inundation and contribute to coastal conservation. The coastal protection and sediment storage capacities represent two of the coastal dunes' most valued regulating ecosystem services. The higher dune ranges in the first row, in the area of the yellow dunes, play a particularly decisive role. These dunes form the natural barrier against high water levels and prevent flooding of the hinterland, reduce wave action, serve as a sediment reserve and stabilise the sandy coasts (Hassan et al. (Eds.) 2005; Palmer and Limited 1996; Rabe et al. 2018).

While dune vegetation plays a key role, if not the key role, in the formation and stabilisation of coastal dunes, the geomorphological characteristics of a dune are primarily responsible for and determine its coastal protection properties. Therefore, the dune morphology as well as sediment supply, accumulation and stabilisation are important factors for the dunes coastal defence capacities (Hanley et al. 2014). Unlike a dyke, the dune body actually erodes partially during storm surge events. Hence, dunes that serve as part of the coastal protection system need to be able to withstand a certain amount of erosion and storm surge damage (Roscoe and Diermanse 2011).

Hanley et al. (2014) describe coastal dune ecosystems very aptly as a 'moveable last line of defence'. Depending on the intensity of the storm event, sand is eroded from either the foredune or the seaward foot or face of the yellow dune and then moved by the water onto the beach or as far as the foreshore area (Bijker 1996; Doody 2013; Everard et al. 2010). In general, erosion only occurs at the peak of the storm surge during a relatively short time period, and the eroded sand stays within the breaker zone and is deposited in the so-called erosion profile (Bijker 1996) as depicted in Fig. 16. Hence, the material does not get lost during a storm event but is rather relocated within the dynamic dune-beach system. During the storm event the relocated sand helps to replenish the beach and foreshore area, thus improving wave dissipation in the are in front of the dunes (Doody 2013; Everard et al. 2010). The concept of the erosion profile has been analysed in several scientific works - two of the most 
widely recognised were the studies by Vellinga (1986) and van Gent et al. (2008). The remaining part of the dune that has not been relocated continues to provide a protective barrier and prevents the persistent swell from washing over the dune and thereby flooding the hinterland.

After the storm has passed, the sand is gradually transported back onto the beach by waves, dries out , and transported back to the dunes by wind. The formation or re-formation of the dunes starts anew. If the beach is sufficiently wide for enough sand to dry out and for enough wind transport capacity to be generated, dunes can regenerate within month after storm surge events (Niemeyer et al. 1996). This, of course, is highly site-specific.

Ecological and societal value A major supporting ecosystem service by coastal dunes is the provision of habitat for a variety of different species that are equipped to live in dynamic, nutrient-poor environments (Kollmann et al. 2019). Dune ecosystems support a high biodiversity, particularly including seabirds, invertebrate species and dune plants (Hanley et al. 2014; Hassan et al. (Eds.) 2005). Furthermore, as successional habitats, dunes facilitate other services through soil formation (Everard et al. 2010).

Provisioning services of dunes are limited. They provide breeding and feeding grounds to the aforementioned seabirds (Hassan et al. (Eds.) 2005) and are as such of particular importance for a variety of migratory birds. Traditionally, especially grey and mature dunes were used as grazing land for cattle and supplier of raw materials like timber (Hanley et al. 2014; Kollmann et al. 2019; Provoost et al. 2011). As with beach ecosystems, dunes provide the opportunity for sand extraction at relatively low effort, however, this is at the expense of most of the other ecosystem services (Doody 2013).

Regarding regulation, aside from coastal protection and sediment storage and exchange (Doody 2013), dunes are likely to purify groundwater and in some cases even drinking water from rivers is being infiltrated into dune systems for purification purposes (Everard et al. 2010). In addition, the fresh water cushion that is formed below the dunes serves the dune vegetation as a source of water (Kollmann et al. 2019) and is also occasionally being tapped by humans to obtain drinking water (Geelen et al. 2017).

Cultural services are amongst the most widely appreciated services by coastal dune ecosystems. Dune areas are highly valued as a source of recreation, allowing several sporting activities, walking, bird watching or simply offering a place of rest and relaxation (Doody 2013; Everard et al. 2010; Hanley et al. 2014; Hassan et al. (Eds.) 2005). Like the adjacent beaches, coastal dunes are areas of great aesthetic appeal and therefore play a significant role in the visual experience of low-lying coastal areas around the world (Doody 2013).

\section{Reef Ecosystems}

Corals, shellfish and oysters are ecosystem engineers that form reef ecosystems, which can protect coastlines from waves and storms by acting as a natural submerged breakwaters in the near-shore zone. Furthermore, supporting an abundance of fish and other marine species, they offer a large biodiversity.

\section{Coral reefs}

Corals are autogenic ecosystem engineers (Jones et al. 1994), changing their surrounding environment via their own physical structure. Thus, corals reefs are structurally complex limestone habitats formed by the corals themselves. The formation and construction of the reefs is not facilitated and driven by the soft corals, but only by the hard, reefbuilding corals - the so-called scleractinian corals (Allemand et al. 2019). While there are less than 10 reef-building coral species know in cold waters, several hundred warm-water scleractinian coral species exist (Gutiérrez et al. 2011). From here on, due to their greater relevance, warm-water coral reefs will be examined more closely, referred to simply as coral reefs.

Coral reef ecosystems occur in the shallow coastal waters of the tropics and subtropics (Barbier et al. 2011), on average in depth between 0 and $30 \mathrm{~m}$, as their distribution mainly depends on light availability and the water temperature (Allemand et al. 2019). While the majority of coral growth usually occurs in water depth between 10 to $20 \mathrm{~m}$, reefs can extend to depth of up to $50 \mathrm{~m}$ (World Bank Group 2016) or, as mesophotic reefs, reach areas that are more than $100 \mathrm{~m}$ under the surface of the ocean (Allemand et al. 2019).

Coral reefs can be distinguished by the main types of atolls, barrier reefs, fringing reefs, or patch reefs (World bank Group 2016; Hassan et al. (Eds.) 2005), illustrated in Fig. 17. For most reef types the typical zonation from offshore to inshore as shown in Fig. 18 includes a fore reef, usually with a steep slope in case of atolls and fringing reefs, the reef crest, a broader reef flat and back reef zones, which can vary in the extreme between several kilometres for barrier reefs and non-existence for near-shore fringing reefs (World Bank Group 2016; Quataert et al. 2015).

Calcium carbonate $\left(\mathrm{CaCO}_{3}\right)$ is the structural basis of coral reef ecosystems, being synthesised by reef-building corals to form a skeleton and accumulated over thousands or even millions of years (Allemand et al. 2019). These accumulated dead coral skeletons make up the majority of the coral reef structure (Barbier et al. 2011). Only the thin outer layer of the reef consists of live coral tissue that is still growing and accreting more calcium carbonate. In their study, for example, Smith and Kinsey (1976) discovered that the $\mathrm{CaCO}_{3}$ production rate in well-flushed seaward reef areas 
Fig. 17 The three main types of coral reefs after Probert (2017)
Fig. 18 Coral reef zonation including patch reefs in the back reef zone after Probert (2017)

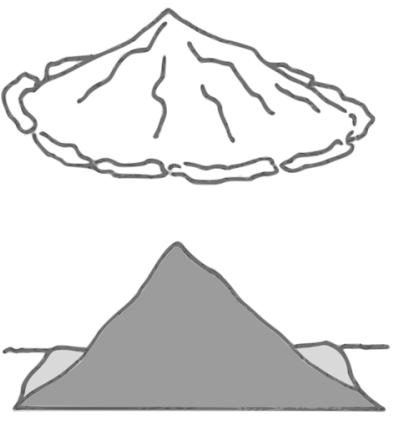

Fringing Reef
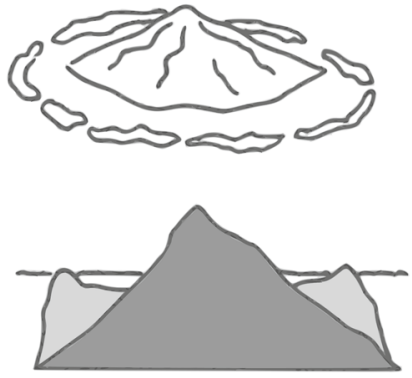

Barrier Reef
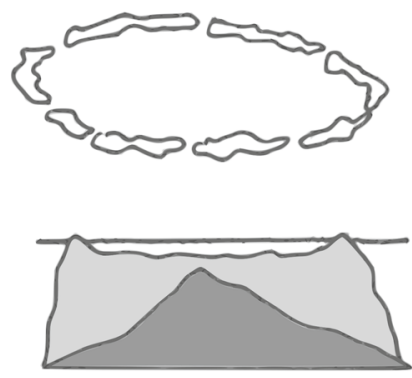

Atoll

Bedrock $\square$ Coral Limestone

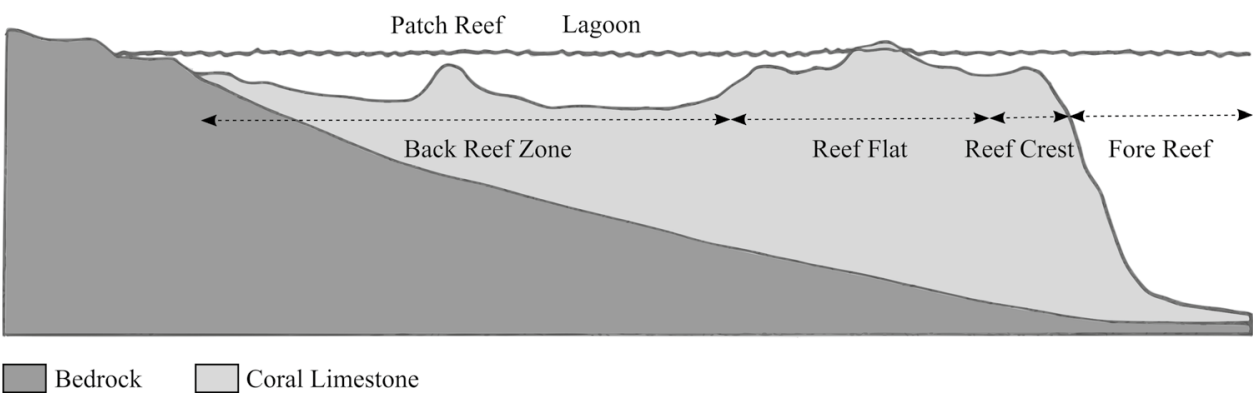

in the Pacific can be as high as $4 \mathrm{~kg} \mathrm{~m}^{-2} \mathrm{yr}^{-1}$. Putnam et al. (2017) even refer to values as high as $10 \mathrm{~kg} \mathrm{~m}^{-2} \mathrm{yr}^{-1}$.

Coral reef naturally occur in waters of the tropics and subtropics around the equatorial belt. Hence, they are mainly distributed between $30^{\circ} \mathrm{N}$ and $30^{\circ} \mathrm{S}$ (Allemand et al. 2019), as depicted in Fig. 19. In total they cover an estimated area of $285,000 \mathrm{~km}^{2}$ (World Bank Group 2016) to $620,000 \mathrm{~km}^{2}$ (Duarte et al. 2008). Around $25 \%$ of the world's coral reefs can be found in the Pacific Ocean and South-East Asia (World Bank Group 2016). Concerning countries, Australia and Indonesia are the countries with the largest coral area. Both are home to about $17 \%$ of the world's coral reefs each (Allemand et al. 2019). According to Burke et al. (2011), today $27 \%$ of the world's coral reefs are within marine protected areas, but there is considerable geographic variation to this value. Outside of Australia, where $75 \%$ of the reefs are protected, the share drops to an average of $17 \%$.

Corals can successfully thrive in the relatively nutrientpoor waters of the tropics (Hassan et al. (Eds.) 2005) thanks to a key biological process - a symbiotic life with a unicellular algae known as zooxanthellae (Allemand et al. 2019; Putnam et al. 2017). At a density of about 1 million algae per $\mathrm{cm}^{2}$ coral tissue, the zooxanthellae live inside the endodermal cells of the coral tissue. This symbiosis, or more specifically the exchange between the coral and the micro-algae, enables the coral to gain energy from sunlight. During photosynthesis, which the algae perform, they produce sugars (photosynthates) that serve as food for the corals. Furthermore, they provide the oxygen needed for coral respiration (Allemand et al. 2019). In return, the coral host provides the zooxanthellae with a safe and stable environment as well as inorganic nutrients, which are being recycled from the corals' metabolism (Putnam et al. 2017).

Coral reefs are very sensitive to anthropogenic stressors and can react quite drastically to changes in their environment with so-called disturbance-induced phase shifts, a process during which at a certain threshold, biologically diverse coral reef ecosystems irreversibly turn into impoverished wastelands (Bellwood et al. 2004). Global loss rates for coral reefs over the last decades are as high as 4-9 \% $\mathrm{yr}^{-1}$ (Duarte et al. 2008), i.e. twice as high as global loss rates of seagrass meadows.

Antropogenic stressors or threats causing coral reef degradation are manifold and can be categorised into local and global scale stressors. At the local level, the most common threats include overfishing and destructive fishing practices such as dynamite or cyanide fishing, coastal construction and development, mining for construction material or marine and ornamental trade, pollution and sedimentation, inadequate sanitation and poor run-off control leading to eutrophication as well as unsustainable tourism practices (Albert et al. 2015; Allemand et al. 2019; Barbier et al. 2011; World Bank Group 2016; Hassan et al. (Eds.) 2005).

Global threats are closely linked to climate change. When surface waters take up atmospheric $\mathrm{CO}_{2}$ a chemical 


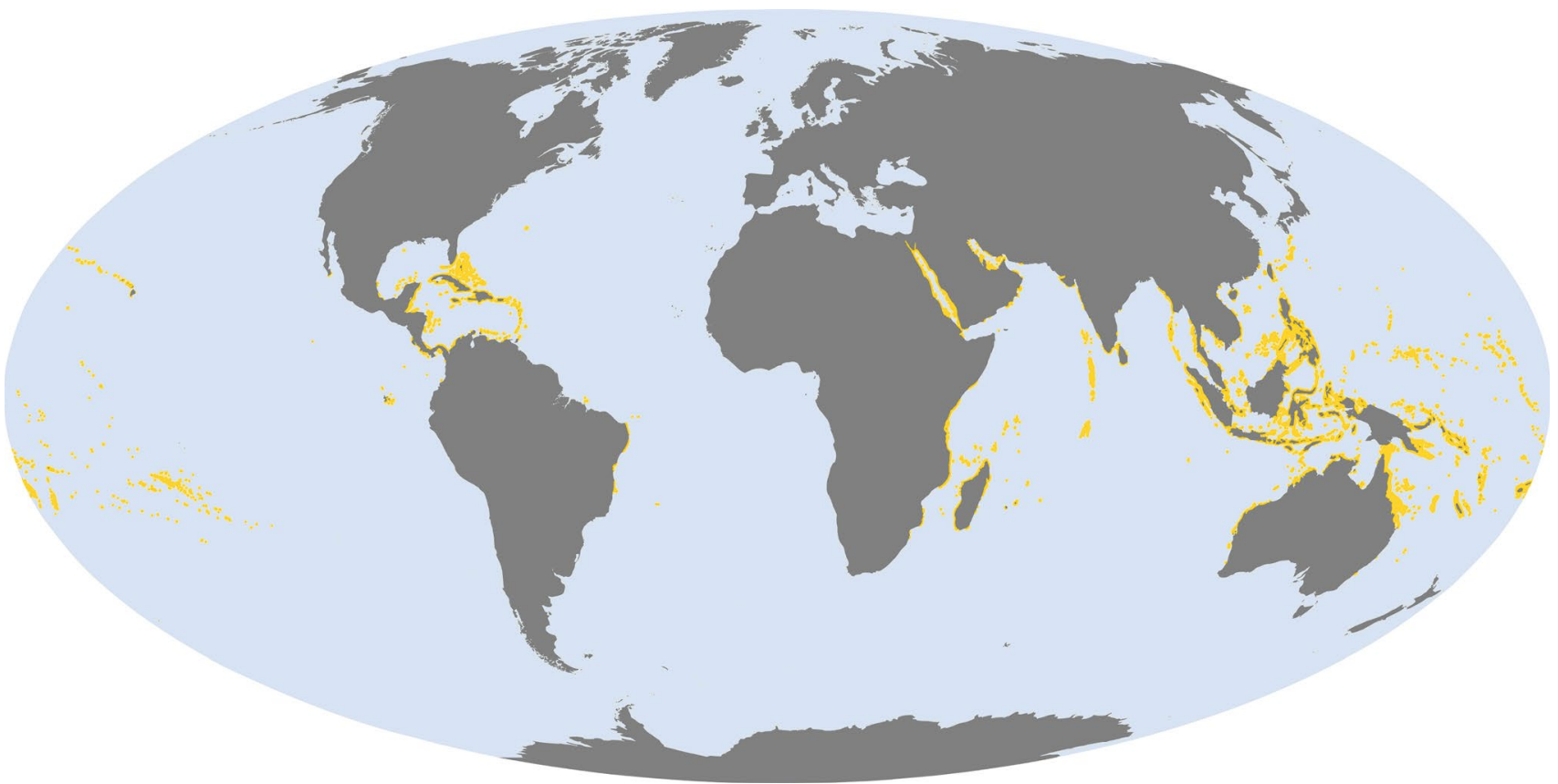

Fig. 19 Global distribution of warm-water coral reefs in yellow after UNEP WCMC (UNEPWCMC 2018)

modification of the coral reef environment occurs, resulting in a lower $\mathrm{pH}$ value (Allemand et al. 2019; Putnam et al. 2017). This process, called ocean acidification, is leading to a reduction in coral coverage and therefore to reef destruction and structural degradation (Barbier et al. 2011; Quataert et al. 2015). A harmful physical modification of the reef environment is the increase in water temperatures, which causes a process referred to as coral bleaching (Allemand et al. 2019; Hassan et al. (Eds.) 2005). An increase of $1{ }^{\circ} \mathrm{C}$ over long-term summer maxima can lead to a collapse of the vital symbiosis and a loss of the zooxanthellae (Putnam et al. 2017), which supply the corals with energy and oxygen. Thus, coral bleaching causes coral mortality and the degradation of coral reef ecosystems. According to highly confident estimations from the latest IPCC report (IPCC 2019), coral reefs will decline by a further $70-90 \%$ by the end of the century at $1.5{ }^{\circ} \mathrm{C}$ warming and vanish almost completely (>99\%) at a warming of $2{ }^{\circ} \mathrm{C}$.

Regarding sea level rise, healthy coral reefs are expected to be able to keep pace with rising waters, due to their ecosystem engineering ability to generate and accrete large amounts of calcium carbonate (World Bank Group 2016). Therefore, even in the face of accelerated sea level rise, many reefs can keep up the ecosystem services they provide, if not threatened and damaged by the anthropogenic stressors described above.

Coastal protection processes In comparison to wetland ecosystems with their flexible vegetation, coral reefs act as efficient breakwaters due to their rigid structure (Bouma et al. 2014) - also under exposure to higher and more powerful waves (Narayan et al. 2016) - and successfully protect low-lying coastal areas against natural hazards from the oceans (Quataert et al. 2015). Through the presence of coral reefsWorld Bank Group (2016) estimates that worldwide more than 200 million people benefit from the reduced coastal risks - for example coral reefs effectively attenuated up to $99 \%$ of the incident wave energy during hurricane Wilma in 2005, thus sheltering the coast of Puerto Morelos and adjacent areas in the state of Quintana Roo on the Yucatan peninsula (Blanchon et al. 2010).

The effect of the reef on waves is dependent on its physical geometry and its roughness, because wave reduction or wave energy dissipation either occurs via wave-breaking as a result of changes in water depth or bottom friction induced dissipation (Narayan et al. 2016; Quataert et al. 2015; Spalding and Ruffo 2014). Wave breaking usually occurs at the steep fore reef or its transition to the reef crest, as shown in the scheme in Fig. 20. For a simple estimation of whether or not wave breaking occurs in shallow water, given the water depth $h$ at the upper for reef or the reef crest, McCowan's breaking criterion (McCowan 1894),

$\frac{H_{b}}{h_{b}}=0.78$,

with $H_{b}$ as the height of the breaking wave and $h_{b}$ as the water depth at which the wave breaks, can be applied. In practice, when the sea state is irregular, 
Fig. 20 Scheme of wave attenuation over the cross-shore section of a coral reef, attenuation occurs at the steep fore reef or at the reef crest; with $\mathrm{H}_{i}=$ initial wave height

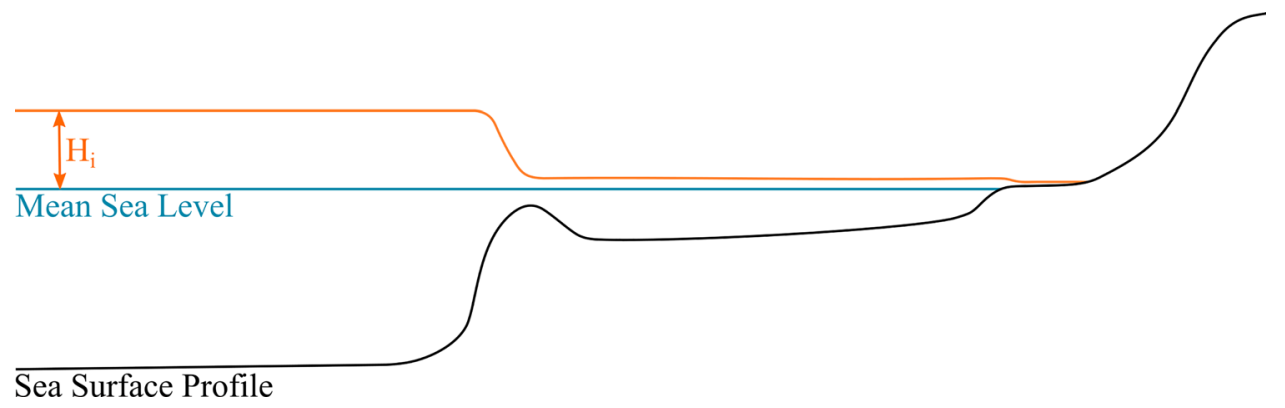

$0.6<\frac{H_{b}}{h_{b}}<1.2$,

and a surf zone establishes. Wave dissipation as a result of surface roughness, which creates frictional and drag forces, appears above the often wide reef flat. Hydrodynamic factors that influence the degree of wave attenuation are of course the initial wave length and height along with the depth of water above the reef surface. Significant coral reef characteristics are its cross-shore bathymetric profile, hence the fore reef slope and the reef flat width, as well as the bottom roughness of the reef surface (World Bank Group 2016; Narayan et al. 2016; Quataert et al. 2015). According to Narayan et al. (2016), coral reefs are able to reduce wave heights by an average of $70 \%$ (95\% CI: 54-81\%). In a metaanalysis of 27 different scientific studies on wave attenuation in coral reefs, Ferrario et al. (2014) even identified an average wave energy reduction rate of $97 \%$, in which $86 \%$ of the incident wave energy is already dissipated at the reef crest and a further $65 \%$ of the remaining energy dissipates above the reef flat.

Regarding the stabilisation of the shoreline, coral reef ecosystems play a more proactive role compared to coastal wetlands, as they do not only trap but rather generate sediments (World Bank Group 2016; Bouma et al. 2014). Hence, coral reefs contri-bute to the formation of beaches and sandy coasts in addition to securing and protecting them from erosion by calming wave conditions and providing a sheltered environment (Hassan et al. (Eds.) 2005).

Ecological and societal value In addition to the regulating ecosystem services of coastal protection and the generation of sand, which prevents erosion, coral reefs cater to the wellbeing of people and nature with several other ecosystem services. Coral reefs offer habitat to about $30 \%$ of known marine species, including $25 \%$ of marine fishes. They boast an enormous biodiversity, which is their main supporting service that underpins most others (Allemand et al. 2019; World Bank Group 2016; Woodhead et al. 2019).

As coral reefs are a major source of fisheries products, they provide tourists, export markets and above all coastal resident with diverse food (Albert et al. 2015; Allemand et al. 2019; Hassan et al. (Eds.) 2005). Furthermore, they deliver coral-based products such as sand, construction material, and curios and ornamentals for aquarium trade (Albert et al. 2015; Hassan et al. (Eds.) 2005; Woodhead et al. 2019). Since corals also provide pharmaceutical compounds, they can additionally be seen as suppliers of medicines, significantly contributing to human well-being and health (Allemand et al. 2019; Hassan et al. (Eds.) 2005).

Aside from the regulating services that help safeguard the coasts, coral reefs function as nitrogen fixers in the nutrient-poor coastal waters and provide certain water cleansing services, as they can transform, detoxify and sequester human-induced wastes up to certain limits (Moberg and Folke 1999).

Culturally, coral reef ecosystems support a variety of recreational activities and offer cultural and aesthetic value to coastal communities and numerous tourists alike (World Bank Group 2016). Apart from fisheries exports and aquarium trade, especially the reef tourism and diving industry is supporting the livelihoods of local communities (Moberg and Folke 1999). Reef tourism is of particular economic importance in the Small Island Developing States (Allemand et al. 2019) but also has a high economic value in other nations such as Egypt, Indonesia, Australia or the US (Spalding et al. 2017).

\section{Shellfish and oyster reefs}

Much like corals, reef- or bed-forming bivalves (Bivalvia) are ecosystem engineers which develop and form the underlying structure for their entire ecosystem themselves (Lenihan and Peterson 1998). Formed by individual organisms growing on top of each other, they can create stable, complex, three-dimensional hard structures, with effects on near-shore waves and sediment dynamics, which even persist after the organisms themselves die (Bouma et al. 2014; Chowdhury et al. 2019; EcoShape 2021 2021). As they are filter feeders, bivalves require long periods of submersion to ensure food availability. They thrive in sheltered intertidal flats in the intermediate elevation zones preferably in areas with lower impacts of waves and currents (Borsje et al. 2011; Folmer et al. 2017). 
Structured habitats are usually comprised of only one species (Beck et al. 2009). Less commonly, few species can coexist in mixed habitats (Folmer et al. 2017). There are three different kinds of structured habitats formed by epibenthic shellfish according to Beck et al. (2009).

- Reefs: Bivalves that form reefs represent the dominant structural component of the benthos and their build-up mass provides vertical relief greater than $0.5 \mathrm{~m}$. Prominent reef-forming species include the Pacific oyster (Crassostrea gigas) as well as the blue mussel (Mytilus edulis).

- Beds: In beds, bivalves represent the major structural component of the benthos and their accumulated mass provides vertical relief of up to $0.5 \mathrm{~m}$ on an otherwise unstructured sea floor. European flat oysters (Ostrea edulis) are an example of bed-forming epibenthic shellfish species.

- Aggregations: Secondary structures, that are build on top of existing physical features, are called aggregations. Prominent examples are species from the family of pen shells (Pinnidae).

Reef- or bed-forming bivalves can be found in the oceans around the globe. As oysters are the most prominently discussed reef-forming bivalve family with regard to $\mathrm{NbS}$ (e.g. Arkema et al. (2013); Bridges et al. (2018); Didderen et al. (2019); Spalding and Ruffo (2014)), Fig. 21 shows the global distribution of still functioning oyster reefs (Beck et al. 2009). With regard to the reefs historical abundance, Beck et al. (2009) rated their condition as either good, fair, poor or functionally extinct. European reefs were generally classified as poor or even functionally extinct in case of the North Sea and along the Atlantic coast of France and Spain. Australian reefs and the reefs along the West coast of North America are functionally extinct as well. Oyster reefs on the North American East coast and in Asia are mostly of poor condition, while the reefs in New Zealand, the Caribbean and South America were classified to be in fair condition. According to Beck et al. (2009), oyster reefs in good condition are only still present at the North coast of Brazil and along the Argentinian coast.

Unfortunately, while epibenthic shellfish reefs can take decades to develop, one single anthropogenic disturbance can be enough to destroy them entirely (Didderen et al. 2019). Since they pose an easily exploitable resource due to their proximity to human populations along the coasts, Beck et al. (2009) estimate that $85 \%$ of global oyster reefs have been lost in the course of the past century.

Man-made threats to shellfish reefs and beds are fisheries extraction and over-harvesting as well as destructive fishing practices, which directly damage or destroy the physical habitat structure. Coastal development and construction activities along with land reclamation projects and dredging of navigational channel on shipping routes also threaten shellfish reefs and cause their destruction and extinction (Beck et al. 2009).

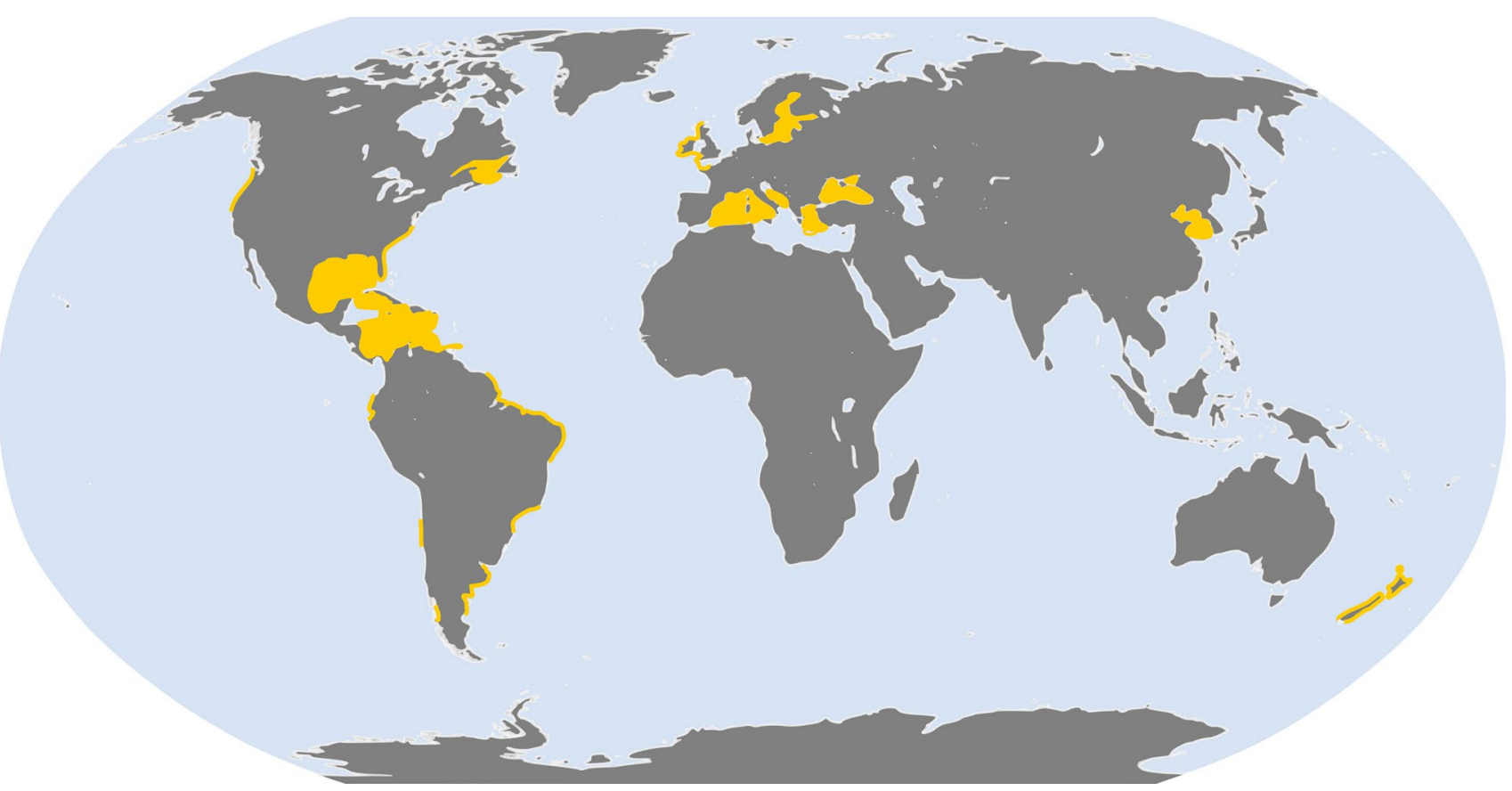

Fig. 21 Global distribution of oyster reefs in yellow after Beck et al. (2009); including reefs of good, fair and poor condition 
Natural threats are posed by waves and currents during storms, which have a destructive impact on the reefs. Ice-scouring during exceptionally cold winters also has the potential to permanently damage shellfish reefs in the intertidal zone (Folmer et al. 2017).

With respect to sea level rise, shellfish reefs increase in size over time and especially oyster reefs are expected to be resilient and grow with a rising sea level (Bridges et al. 2018; Chowdhury et al. 2019; Spalding and Ruffo 2014) - of course not unlimited in quantity and above all not limitlessly fast.

Coastal protection processes As reefs and beds reduce wave forcing and alter the physical environment, they provide structural barriers and sheltered areas, which trap sediments on the one hand (Bridges et al. 2018; Chowdhury et al. 2019) and reduce the loss of sediment from the tidal flats to the channels on the other hand (Beck et al. 2009; Schoonees et al. 2019). Hence, by eco-engineering their physical environment, reef- and bed-forming bivalves promote sediment accumulation and prevent erosion by fixing the seabed over a wide area.

Furthermore, bivalve species that do neither form reefs nor beds also contribute to the reduction of erosion and shoreline stabilisation (Carss et al. 2020). They increase the surface stability of the sea floor through the formation of a structural layer of shells within the sediment. The biodeposition of fine-grained material and the production of mucus factor into the increase in stability as well. A prominent example for such bivalve species is the common cockle (Cerastoderma edule), which is e.g. abundantly present throughout the North Sea.

In comparison to flexible vegetation, reefs - coral and shellfish alike - act as effective, natural breakwaters due to their rigidity and successfully attenuate waves in the nearshore zone (Bouma et al. 2014; Schoonees et al. 2019). The effectiveness of bivalve reefs in absorbing wave energy that is directed at shorelines has been analysed in various studies (e.g. Beck et al. 2009; Bridges et al. 2018; Chowdhury et al. 2019. Especially with regard to larger waves (Chowdhury et al. 2019), more specifically among the highest $10 \%$ of waves, reductions in wave height and wave energy are significant (Sutton-Grier et al. 2015).

Instead of wave breaking in reefs, dissipation caused by an increased bed friction is the main process behind wave energy reduction over mussel or oyster beds (Donker et al. 2013). On a much smaller scale, this also applies to aggregations of bivalves. When comparing natural oyster and mussel beds for the same physical wave forcing, oyster beds are found to be more effective in wave attenuation (Borsje et al. 2011). The measurement-based formula by Bouma et al. (2014) to estimate wave attenuation by intertidal habitats is also applicable to shellfish or mussel beds and oyster reefs. Derived from field measurements, Bouma et al.
(2014) estimate a wave decay coefficient for mussel beds $k_{\text {mussel }}\left[\mathrm{m}^{-1}\right]$ ranging between 0.05 to 0.15 , and a wave decay coefficient for oyster reefs $k_{\text {oyster }}\left[\mathrm{m}^{-1}\right]$ ranging between 0.15 to 0.3. Combining Eqs. 2 and 3 the wave height after maximum attenuation by a mussel bed (thus maximum coverage, $B=B_{\text {max }}$, and $k_{\text {mussel }}=k_{\text {mussel,max }}=0.15$ ) can be derived as

$H_{L, \text { mussel }}=0.3 h e^{-\left(0.15 e^{-d h}\right) L}$,

and the wave height after maximum attenuation by an oyster reef (thus maximum coverage, $B=B_{\max }$, and $k_{\text {oyster }}=k_{\text {oyster,max }}=0.3$ ) as

$H_{L, \text { oyster }}=0.3 h e^{-\left(0.3 e^{-d h}\right) L}$

respectively.

Ecological and societal value Shellfish reefs offer valuable habitat for fish and invertebrates (Chowdhury et al. 2019), which represents an important supporting service in addition to their high rate of primary production (Asmus and Asmus 1991).

By serving as a nursery habitat for fish they provide food and support recreational and commercial fisheries (Carss et al. 2020; Sutton-Grier et al. 2015) along with providing opportunities for aquaculture (Chowdhury et al. 2019). Furthermore shellfish are still and have long been used by humans for ornamentation, as a currency, in construction and as a mineral resource (Beck et al. 2009; Carss et al. 2020).

Regulating ecosystem services by shellfish reefs include the removal of excess nutrients (Beck et al. 2009; Carss et al. 2020) as well as nitrogen (Sutton-Grier et al. 2015) from near-shore waters. Coastal shellfish beds or reefs also actively promote water quality through the bivalves enormous filtering capacity. As filter feeders, bivalves remove suspended solids from the water column and improve water clarity, thus in turn promoting e.g. adjacent seagrass growth and reducing the likelihood of harmful algae blooms (Beck et al. 2009; Didderen et al. 2019).

Shellfish in general also provide cultural services, as there are countless images and references to shellfish in cultures around the globe (Carss et al. 2020) and the collecting of shells has made significant contributions to art, commerce and science since several centuries (Duncan and Ghys 2019).

\section{Discussion}

\section{Key features, occurrence and threats}

Coastal ecosystems thrive under various conditions and on all continents around the globe. Naturally, since they 
Table 3 Key features of the different coastal ecosystems

\begin{tabular}{ll}
\hline Coastal Ecosystem & Key Feature \\
\hline Salt Marshes & herbs \\
Mangroves & trees and shrubs \\
Seagrass Meadows & flowering plants \\
Beaches & physically dynamic sand or \\
& shingle environment \\
Dunes & dynamic geomorphic structures \\
Coral Reefs & structurally complex limestone \\
& habitats \\
Shellfish Reefs & reef- or bed-forming bivalves \\
\hline
\end{tabular}

differ from each other in their structure, their components and characteristics as well as their needs in terms of site conditions, not all coastal ecosystems examined above exist on every continent or occupy similar areas in the coastal environment. As described in the chapters beforehand, most coastal ecosystems are highly specified and perfectly adapted to their areas of distribution. The analysed ecosystems' key features, their distribution, and favourable conditions are summarised in Tables 3, 4, and 5 respectively.

Due to their very specific adaptations to the environment in which they thrive, coastal ecosystems are sometimes very sensitive to changes and threats in this very environment. Natural extremes, in coastal areas e.g. extreme storm events, can be harmful and destructive to all coastal ecosystems discussed above. Hence, changes in the hydrological and hydrodynamic conditions - caused by climate change or other modifications to the environment - and thus ultimately in the loads on the ecosystems pose one of the major threats to all of them. Further main threats to coastal ecosystems as analysed in this review paper, may they be climate change related, caused by direct or indirect human impacts, are summarised in Table 6.

\section{Coastal protection}

All coastal ecosystems examined in this review paper provide certain processes or support certain developments that directly or indirectly benefit the regulating ecosystem services 'storm protection' and 'erosion control' (cf. Table 2). The underlying system is always certain processes or services that have an effect on the prevailing hydrodynamic or morphological conditions.

- Limited water depth and the interaction with vegetation and structures cause a reduction of wave heights;

- the stabilisation of the sandy surface reduces the erosion potential;
- surface elevation and the absorption of hydrodynamic forces through sediment redistribution cause a reduction of flooding;

- and an increased bed roughness reduces shear stresses on the soft soil.

Table 4 Natural distribution of the different coastal ecosystems

\begin{tabular}{ll}
\hline Coastal Ecosystem & Distribution \\
\hline Salt Marshes & $\begin{array}{l}\text { mid-elevation coastal zones; } \\
\text { temperate climates } \\
\text { mid-elevation coastal zones; } \\
\text { tropics and subtropics } \\
\text { Mangroves }\end{array}$ \\
all continents except Antarctica; \\
tropics to temperate zones \\
all continents except Antarctica; \\
Beaches & $\begin{array}{l}\text { increased occurrence in lower mid- } \\
\text { latitudes and subtropics } \\
\text { worldwide } \\
\text { tropics and subtropics; }\end{array}$ \\
Dunes & around the equatorial belt \\
Coral Reefs & worldwide \\
\hline
\end{tabular}

Table 5 Favourable conditions for the different coastal ecosystems to thrive

\begin{tabular}{ll}
\hline Coastal Ecosystem & Favourable Conditions \\
\hline Salt Marshes & sandy or muddy coast; \\
& occasional submergence; \\
& shallow, low-energy shoreline \\
& loose and wet soils; \\
& periodic tidal submergence; \\
Mangroves & saline to brackish waters \\
& soft substrates; \\
& wave-sheltered environments; \\
Seagrass Meadows & light availability; \\
& depth up to 40 m; \\
& proximity to other coastal eco- \\
& systems \\
abundance of sediment; & close linkage to surf zone and \\
& coastal dunes \\
along extensive beaches; & abundance of sediment; \\
Beaches & close linkage with adjacent beaches \\
& shallow coastal waters; \\
light availability; & usually depth up to 30 m \\
sheltered, intertidal flats; & long periods of tidal submergence; \\
Dunes & low impacts of waves or currents \\
Coral Reefs & \\
&
\end{tabular}


Table 6 Main threats to the different coastal ecosystems; no mark does not imply that the threat is not harmful to the ecosystem, it is simply none of the major threats; $\mathrm{SM}=$ salt marshes, $\mathrm{M}=$ mangroves, SGM $=$ seagrass meadows, $\mathrm{B}$ = beaches, $\mathrm{D}=$ dunes, $\mathrm{CR}=$ coral reefs, $\mathrm{SOR}=$ shellfish/ oyster reefs; *causing ocean acidification, ${ }^{* *}$ in combination with landward spatial restrictions (coastal squeeze)

Table 7 Coastal protection processes provided by the different coastal ecosystems; $\mathrm{SM}=$ salt marshes, $\mathrm{M}=$ mangroves, $\mathrm{SGM}=$ seagrass meadows, $\mathrm{B}=$ beaches, $\mathrm{D}$ $=$ dunes, $\mathrm{CR}=$ coral reefs, $\mathrm{SOR}=$ shellfish/oyster reefs; * Terminology of the Millennium Ecosystem Assessment (Watson and Zakri (Eds.) 2003), see Table 2

\begin{tabular}{|c|c|c|c|c|c|c|c|c|}
\hline Threat & & SM & $\mathrm{M}$ & SGM & B & $\mathrm{D}$ & $\mathrm{CR}$ & SOR \\
\hline \multicolumn{9}{|l|}{ Climate change related impacts } \\
\hline \multicolumn{2}{|l|}{ Elevated atmospheric $\mathrm{CO}_{2}^{*}$} & $x$ & $x$ & & & & $x$ & \\
\hline \multicolumn{2}{|l|}{ Increased temperatures } & $x$ & $x$ & & & & $x$ & \\
\hline \multicolumn{2}{|l|}{ Accelerated sea level rise ${ }^{* *}$} & $x$ & $x$ & $x$ & $x$ & $x$ & & $(\boldsymbol{X})$ \\
\hline \multicolumn{9}{|l|}{ Indirect human impacts } \\
\hline \multicolumn{2}{|l|}{ Eutrophication } & $x$ & & $x$ & & $x$ & $x$ & \\
\hline \multicolumn{2}{|l|}{ Hypersalinisation } & & & $x$ & & & & \\
\hline \multicolumn{2}{|l|}{ Sedimentation } & & & & & & $x$ & \\
\hline \multicolumn{2}{|l|}{ Lack of sediment supply } & & & & $x$ & $x$ & & \\
\hline \multicolumn{2}{|l|}{ Reduced water clarity } & & & $x$ & & & & \\
\hline \multicolumn{9}{|l|}{ Direct human impacts } \\
\hline \multicolumn{2}{|l|}{ Shoreline development } & $x$ & $x$ & $x$ & $x$ & $x$ & $x$ & $x$ \\
\hline \multicolumn{2}{|c|}{ Industrial development and pollution } & & $x$ & & $x$ & & & \\
\hline \multicolumn{2}{|l|}{ Land reclamation } & & & & & & & $x$ \\
\hline \multicolumn{2}{|l|}{ Land-use changes } & & $x$ & $x$ & & $x$ & & \\
\hline \multicolumn{2}{|l|}{ Groundwater extraction } & & & & $x$ & & & \\
\hline \multicolumn{2}{|l|}{ Overexploitation } & & $x$ & & $x$ & $x$ & $x$ & \\
\hline \multicolumn{3}{|c|}{ Overfishing and destructive practices } & & & & & $x$ & $x$ \\
\hline \multicolumn{2}{|l|}{ Tourism pressure } & & $x$ & & $x$ & $x$ & $x$ & \\
\hline \multicolumn{2}{|l|}{ Boating/anchoring/dredging } & & & $x$ & & & & $x$ \\
\hline Coastal Protection Effect & SM & & M & SGM & $\mathrm{B}$ & $\mathrm{D}$ & $\mathrm{CR}$ & SOR \\
\hline \multicolumn{9}{|l|}{ Storm Protection* } \\
\hline \multirow{2}{*}{ Wave attenuation } & $\checkmark$ & & $\checkmark$ & $(\checkmark)$ & $\checkmark$ & $\checkmark$ & $\checkmark$ & $\checkmark$ \\
\hline & Wave breaking & & & & $\checkmark$ & $\checkmark$ & $\checkmark$ & \\
\hline \multicolumn{2}{|l|}{ Prevention of flooding } & & & & & $\checkmark$ & & \\
\hline & $\checkmark$ & & $\checkmark$ & $(\checkmark)$ & & & & \\
\hline \multirow{2}{*}{$\begin{array}{l}\text { Water retaining capacity } \\
\text { Wind speed reduction }\end{array}$} & $\checkmark$ & & & & & & & \\
\hline & & & $\checkmark$ & & & & & \\
\hline \multicolumn{9}{|l|}{ Erosion Control $^{*}$} \\
\hline Sediment accretion & $\checkmark$ & & $\checkmark$ & $\checkmark$ & & $\checkmark$ & $\checkmark$ & $\checkmark$ \\
\hline Ground soil stabilisation & $\checkmark$ & & $\checkmark$ & $\checkmark$ & & & & $\checkmark$ \\
\hline Reduction of shear stresses & $\checkmark$ & & $\checkmark$ & & & & $\checkmark$ & $\checkmark$ \\
\hline Sediment exchange and storage & & & & & $\checkmark$ & $\checkmark$ & & \\
\hline Sediment generation & & & & & & & $\checkmark$ & \\
\hline Build-up of humus & $\checkmark$ & & & & & & & \\
\hline
\end{tabular}

The most prominent effect regarding storm or coastal protection is the attenuation of wave energy and wave heights, which - to different degrees of course - is provided by wetland, beach and reef ecosystems alike. As for erosion control or shoreline stabilisation the promotion of sediment accretion is the major service provided by vegetation in wetland ecosystems or dunes as well as by reef structures. These are, of course, merely two examples of the different processes in favour of coastal protection provided by coastal ecosystems. A summary of the effects and developments which are described in this review paper is given in Table 7 . This overview underlines the high value that should be assigned to coastal ecosystems in terms of coastal protection and the fundamental role they can play in implementing and supporting coastal protection strategies and objectives. 
Table 8 Ecosystem services provided by the different coastal ecosystems; $\mathrm{SM}=$ salt marshes, $\mathrm{M}=$ mangroves, SGM $=$ seagrass meadows, $\mathrm{B}$ = beaches, $\mathrm{D}=$ dunes, $\mathrm{CR}=$ coral reefs, $\mathrm{SOR}=$ shellfish $/$ oyster reefs

\begin{tabular}{|c|c|c|c|c|c|c|c|}
\hline Ecosystem Service & SM & M & SGM & $\mathrm{B}$ & $\mathrm{D}$ & CR & SOR \\
\hline \multicolumn{8}{|l|}{ Supporting Ecosystem Services } \\
\hline Primary production & $\checkmark$ & & $\checkmark$ & & & & $\checkmark$ \\
\hline Habitat provision & $\checkmark$ & $\checkmark$ & $\checkmark$ & $\checkmark$ & $\checkmark$ & $\checkmark$ & $\checkmark$ \\
\hline Biodiversity & & $\checkmark$ & & $\checkmark$ & $\checkmark$ & $\checkmark$ & \\
\hline Soil formation & & & & & $\checkmark$ & & \\
\hline Nutrient cycling & $\checkmark$ & & $\checkmark$ & & & & $\checkmark$ \\
\hline \multicolumn{8}{|l|}{ Provisioning Ecosystem Services } \\
\hline Nursery for marine organisms & $\checkmark$ & $\checkmark$ & $\checkmark$ & & & & $\checkmark$ \\
\hline Breeding/foraging/resting for birds & $\checkmark$ & & & $\checkmark$ & $\checkmark$ & & \\
\hline Food source for communities & & $\checkmark$ & & & & $\checkmark$ & $\checkmark$ \\
\hline Food source for marine species & & & $\checkmark$ & & & & \\
\hline Freshwater source & & & & & $\checkmark$ & & \\
\hline Construction material & & $\checkmark$ & & $\checkmark$ & $\checkmark$ & $\checkmark$ & $\checkmark$ \\
\hline Fire wood & & $\checkmark$ & & & $(\checkmark)$ & & \\
\hline Agricultural activities & & $\checkmark$ & & & $(\checkmark)$ & & $\checkmark$ \\
\hline Curios and ornamentals & & & & & & $\checkmark$ & $\checkmark$ \\
\hline Pharmaceutical components & & & & & & $\checkmark$ & \\
\hline \multicolumn{8}{|l|}{ Regulating Ecosystem Services } \\
\hline Water quality improvement & $\checkmark$ & $\checkmark$ & $\checkmark$ & & & $\checkmark$ & $\checkmark$ \\
\hline Breakdown of organic materials & & & & $\checkmark$ & & & \\
\hline Carbon sequestration & $\checkmark$ & $\checkmark$ & $\checkmark$ & & & & \\
\hline Underwater oxygen production & & & $\checkmark$ & & & & \\
\hline Water filtration & & & & $\checkmark$ & $\checkmark$ & & $\checkmark$ \\
\hline Transport of terrestrial nutrients & & & & $\checkmark$ & & & \\
\hline Nitrogen fixation & & & & & & $\checkmark$ & $\checkmark$ \\
\hline \multicolumn{8}{|l|}{ Cultural Ecosystem Services } \\
\hline Aesthetic ecological value & $\checkmark$ & $\checkmark$ & $\checkmark$ & & & $\checkmark$ & \\
\hline Tourism and recreation & $\checkmark$ & $\checkmark$ & & $\checkmark$ & $\checkmark$ & $\checkmark$ & \\
\hline Cultural heritage and arts & & $\checkmark$ & & $\checkmark$ & $\checkmark$ & & $\checkmark$ \\
\hline Safeguard threatened species & & & $\checkmark$ & & & $\checkmark$ & \\
\hline Visual appeal of landscape & $\checkmark$ & $\checkmark$ & & $\checkmark$ & $\checkmark$ & & \\
\hline
\end{tabular}

\section{Ecology and society}

Aside form their significant contribution to coastal protection (cf. Section 3 - Water) coastal ecosystems also cater to the needs of Nature and People. Amongst a huge variety of different supporting, provisioning, regulating and cultural ecosystem services most of the coast-al ecosystems support a unique biodiversity and provide habitat to a highly specified flora and fauna above and under water, thus significantly benefiting nature. Several of the coastal ecosystems represent important nursery areas for marine organisms or breeding, foraging, and resting grounds for sea bird and sea turtles. From an ecological point of view, the improvement of water quality or carbon sequestration are also to be evaluated positively. The wide spectrum of recreational activities associated with coastal ecosystems such as beaches and dunes as well as the visual appeal or aesthetic ecological value of e.g. salt marshes or mangroves benefits people and human well-being. Tourism in ecosystems like mangroves or coral reefs strengthens local economies and therefore benefits society. Furthermore, several of the coastal ecosystems support fisheries, thus providing food for local coastal communities and visiting tourists alike. A summary of the ecosystem services which are described in this review paper is given in Table 8, stressing the high significance and astonishing diversity of services associated with these coastal ecosystems attending societal and ecological needs.

\section{Conclusion}

As depicted in this review paper, coastal ecosystems like salt marshes, mangroves, seagrass meadows, beaches, dunes, coral, and shellfish or oyster reefs bear the potential to bridge the gap between coastal engineering and nature conservation, since they provide benefits and support 
beneficial processes for Water, Nature and People alike. When for example using a salt marsh habitat as a $\mathrm{NbS}$ for an area, one does not have to choose between coastal protection and nature conservation or prioritise one over the other. By conserving and protecting a salt marsh, thus promoting its natural healthy state, one ensures that the salt marsh provides its greatest possible protection for the coast as well as supporting the greatest possible biodiversity.

Hence, in addition to the existing coastal protection structures and systems, which are currently working well and satisfactory in terms of protecting people and goods in the hinterland from flooding and related dangers and damages as well as shoreline preservation and erosion control, coastal ecosystems as Nature-based Solutions can be a promising, sustainable and multi-beneficial part of the coastal protection schemes along our coastlines. They offer a promising approach for the existing coastal protection to adapt to climate change related challenges, which coastal communities are already facing in the present day and which will most certainly intensify in the future (IPCC 2019), while incorporating ecological and societal needs.

The overriding premise when working with coastal ecosystems as Nature-based Solutions is, of course, to work within the given, natural boundary conditions and not to create artificial landscapes as foreign bodies in the coastal environment.

However, aside from a few very site specific results, the degree to which coastal ecosystems can support coastal protection in collaboration with nature conservation and protection is still hard to assess and to guarantee, especially regarding e.g. effects of seasonality or influences of changing natural boundary conditions. Furthermore, possible differences between naturally developed coastal ecosystems and those, whose development is triggered or facilitated by human intervention and actions, need to be considered and examined further. Do these newly developed ecosystems provide the same services? Are the desired ecosystem services provided by the same quality or to the same degree?

More research is required in order to answer these questions and investigate these uncertainties. Pilots, whose impact and success or failure is carefully monitored from a technical, ecological and societal point of view, are needed for all relevant coastal ecosystems and on different scales. Only then can we better understand the dynamics and interactions within and between the coastal ecosystems and their (anthropological) environment and fully capture and utilise their potential for the land-sea transition zone.

Acknowledgements The authors thank the Deutsche Forschungsgemeinschaft (DFG, German Research Foundation) for supporting this work under Germany's Excellence Strategy - EXC 2037 "CliCCS Climate, Climatic Change and Society" - project number: 390683824.
Funding Open Access funding enabled and organized by Projekt DEAL.

Declarations The authors have no relevant financial or non-financial interests to disclose. The authors have no conflicts of interest to declare that are relevant to the content of this article. All authors certify that they have no affiliations with or involvement in any organization or entity with any financial interest or non-financial interest in the subject matter or materials discussed in this manuscript. The authors have no financial or proprietary interests in any material discussed in this article.

Conflicts of interest The authors declare that they have no conflict of interest.

Open Access This article is licensed under a Creative Commons Attribution 4.0 International License, which permits use, sharing, adaptation, distribution and reproduction in any medium or format, as long as you give appropriate credit to the original author(s) and the source, provide a link to the Creative Commons licence, and indicate if changes were made. The images or other third party material in this article are included in the article's Creative Commons licence, unless indicated otherwise in a credit line to the material. If material is not included in the article's Creative Commons licence and your intended use is not permitted by statutory regulation or exceeds the permitted use, you will need to obtain permission directly from the copyright holder. To view a copy of this licence, visit http://creativecommons.org/licenses/by/4.0/.

\section{References}

Albert JA, Olds AD, Albert S, Cruz-Trinidad A, Schwarz AM (2015) Reaping the reef: Provisioning services from coral reefs in solomon islands. Marine Policy 62:244-251. https://doi.org/10. 1016/j.marpol.2015.09.023

Albert C, Schröter B, Haase D, Brillinger M, Henze J, Herrmann S, Gottwald S, Guerrero P, Nicolas C, Matzdorf B (2019) Addressing societal challenges through nature-based solutions: How can landscape planning and governance research contribute? Landscape and Urban Planning 182:12-21. https://doi.org/10.1016/j. landurbplan.2018.10.003

Allemand D, Osborn D (2019) Ocean acidification impacts on coral reefs: From sciences to solutions. Regional Studies in Marine Science 28:100558. https://doi.org/10.1016/j.rsma.2019.100558

Alongi DM (2008) Mangrove forests: Resilience, protection from tsunamis, and responses to global climate change. Estuarine, Coastal and Shelf Science 76(1):1-13. https://doi.org/10.1016/j. ecss.2007.08.024

Anderson ME, McKee Smith J, McKay SK (2011) Wave dissipation by vegetation

Anthony EJ (2013) Storms, shoreface morphodynamics, sand supply, and the accretion and erosion of coastal dune barriers in the southern north sea. Geomorphology 199(Special Issue 36):8-21. https://doi.org/10.1016/j.geomorph.2012.06.007

Arkema KK, Guannel G, Verutes G, Wood SA, Guerry A, Ruckelshaus M, Kareiva P, Lacayo M, Silver JM (2013) Coastal habitats shield people and property from sea-level rise and storms. Nature Climate Change 3(10):913-918. https://doi.org/10.1038/nclim ate 1944

Asmus RM, Asmus H (1991) Mussel beds: limiting or promoting phytoplankton? Journal of Experimental Marine Biology and Ecology 148(2):215-232. https://doi.org/10.1016/0022-0981(91) 90083-9 
Atkinson SC, Jupiter SD, Adams VM, Ingram JC, Narayan S, Klein CJ, Possingham HP (2016) Prioritising mangrove ecosystem services results in spatially variable management priorities. PloS one 11(3):e0151992. https://doi.org/10.1371/journal.pone.0151992

Augustinus PG (1995) Geomorphology and sedimentology of mangroves. In: Perillo GME (ed) Geomorphology and sedimentology of estuaries, developments in sedimentology. Elsevier, Amsterdam

Balke T, Bouma TJ, Horstman EM, Webb EL, Erftemeijer PL, Herman PM (2011) Windows of opportunity: thresholds to mangrove seedling establishment on tidal flats. Marine Ecology Progress Series 440:1-9. https://doi.org/10.3354/meps09364

Baptist MJ, Gerkema T, van Prooijen BC, van Maren DS, van Regteren M, Schulz K, Colosimo I, Vroom J, van Kessel T, Grasmeijer B, Willemsen P, Elschot K, de Groot AV, Cleveringa J, van Eekelen E, Schuurman F, de Lange HJ, van Puijenbroek M (2019) Beneficial use of dredged sediment to enhance salt marsh development by applying a 'mud motor'. Ecological Engineering 127:312-323. https://doi.org/10.1016/j.ecoleng.2018.11.019

Barbier EB, Hacker SD, Kennedy C, Koch EW, Stier AC, Silliman BR (2011) The value of estuarine and coastal ecosystem services. Ecological Monographs 81(2):169-193

Beck MW, Brumbaugh RD, Airoldi L, Carranza A, Coen LD, Crawford C, Defeo O, Edgar GJ, Hancock B, Kay M, Lenihan H, Luckenbach MW, Toropova CL, Zhang G (2009) Shellfish reefs at risk: A global analysis of problems and solutions

Bellwood DR, Hughes TP, Folke C, Nyström M (2004) Confronting the coral reef crisis. Nature 429(6994):827-833. https://doi.org/ 10.1038 /nature 02691

Benedict MA, McMahon E (2006) Green infrastructure: Linking landscapes and communities. Island Press, Washington, DC

Best S, van der Wegen M, Dijkstra J, Willemsen P, Borsje BW, Roelvink DJ (2018) Do salt marshes survive sea level rise? modelling wave action, morphodynamics and vegetation dynamics. Environmental Modelling \& Software 109:152-166. https://doi.org/ 10.1016/j.envsoft.2018.08.004

Bijker EW (1996) History and heritage in coastal engineering in the netherlands. In: Kraus NC (ed) History and Heritage of Coastal Engineering. American Society of Civil Engineers, Reston, pp 390-412

Blanchon P, Iglesias-Prieto R, Jordán Dahlgren E, Richards S (2010) Arrecifes de coral y cambio climático: vulnerabilidad de la zona costera del estado de quintana roo. In: Botello AV, VillanuevaFragoso S, Gutiérrez J, Rojas Galaviz J (eds) Vulnerabilidad de la zonas costeras mexicanas ante el cambio climático. Campeche, Mexico, pp 229-248

Borsje BW, van Wesenbeeck BK, Dekker F, Paalvast P, Bouma TJ, van Katwijk MM, de Vries MB (2011) How ecological engineering can serve in coastal protection. Ecological Engineering 37(2):113-122. https://doi.org/10.1016/j.ecoleng.2010.11.027

Böse M, Ehlers J, Lehmkuhl F (2018) Deutschlands Norden. Springer, Heidelberg. https://doi.org/10.1007/978-3-662-55373-2

Bouma TJ, van Belzen J, Balke T, Zhu Z, Airoldi L, Blight AJ, Davies AJ, Galvan C, Hawkins SJ, Hoggart SP, Lara JL, Losada IJ, Maza M, Ondiviela B, Skov MW, Strain EM, Thompson RC, Yang S, Zanuttigh B, Zhang L, Herman PM (2014) Identifying knowledge gaps hampering application of intertidal habitats in coastal protection: Opportunities \& steps to take. Coastal Engineering 87:147-157. https://doi.org/10.1016/j.coastaleng.2013.11.014

Bridges TS, Bourne EM, King J, Kuzmitski H, Moynihan E, Suedel B (2018) Engineering with nature : An Atlas. U.S. army engineer research and development center. https://doi.org/10.21079/ $11681 / 27929$

Bridges TS, Wagner PW, Burks-Copes KA, Bates ME, Collier ZA, Fischenich JC, Gailani JZ, Leuck LD, Piercy CD, Rosati JD, Russo EJ, Shafer DJ, Suedel BC, Vuxton EA, Wamsley TW (2015) Use of natural and nature-based features (nnbf) for coastal resilience: Final report

Brière C, Janssen SKH, Oost AP, Taal M, Tonnon PK (2018) Usability of the climate-resilient nature-based sand motor pilot, the netherlands. Journal of Coastal Conservation 22(3):491-502. https://doi.org/10. 1007/s11852-017-0527-3

Brown AC, McLachlan A (2002) Sandy shore ecosystems and the threats facing them: some predictions for the year 2025. Environmental Conservation 29(1):62-77. https://doi.org/10.1017/ S037689290200005X

Burke L, Reytar K, Spadling M, Perry A, Cooper E, Kushner B, Selig E, Starkhouse B, Teleki K, Waite R, Wilkinson C, Young T (2011) Reefs at risk: Revisited. World Resource Institute report, World Resources Institute, Washington, D.C

Carley JT, Cox RJ (2017) Guidelines for sand nourishment: Science and synthesis for nsw

Carss DN, Brito AC, Chainho P, Ciutat A, de Montaudouin X, Fernández Otero RM, Filgueira MI, Garbutt A, Goedknegt MA, Lynch SA, Mahony KE, Maire O, Malham SK, Orvain F, van der Schatte Olivier A, Jones L (2020) Ecosystem services provided by a non-cultured shellfish species: The common cockle cerastoderma edule. Marine Environmental Research 158:104931. https://doi.org/10.1016/j.marenvres.2020.104931

CBD (2009) Connecting biodiversity and climate change mitigation and adaptation: Report of the 2 nd ad hoc technical expert group (ahteg) on biodiversity and climate change

CBD (2010) X/33 biodiversity and climate change: Decision adopted by the conference of the parties to the convention on biological diversity at its tenth meeting

Chmura GL, Anisfeld SC, Cahoon DR, Lynch JC (2003) Global carbon sequestration in tidal, saline wetland soils. Global Biogeochemical Cycles 17(4), n/a-n/a. https://doi.org/10.1029/2002GB0019 17

Chowdhury MSN, Walles B, Sharifuzzaman SM, Shahadat Hossain M, Ysebaert T, Smaal AC (2019) Oyster breakwater reefs promote adjacent mudflat stability and salt marsh growth in a monsoon dominated subtropical coast. Scientific reports 9(1):8549. https:// doi.org/10.1038/s41598-019-44925-6

Cohen-Shacham E, Walters G, Janzen C, Maginnis S (2016) Naturebased solutions to address global societal challenges. IUCN International Union for Conservation of Nature. https://doi.org/ 10.2305/IUCN.CH.2016.13.en

Cosslett TL, Cosslett PD (2014) The mekong delta. In: Cosslett TL, Cosslett PD (eds.) Water resources and food security in the vietnam mekong delta, pp 3-21. Springer International Publishing, Cham. https://doi.org/10.1007/978-3-319-02198-0_1

Costanza R, d'Arge R, de Groot R, Farber S, Grasso M, Hannon B, Limburg K, Naeem S, O'Neill RV, Paruelo J, Raskin RG, Sutton $P$, van den Belt M (1998) The value of the world's ecosystem services and natural capital. Ecological Economics 25(1):3-15. https://doi.org/10.1016/S0921-8009(98)00020-2

Dalrymple RA, Kirby JT, Hwang PA (1984) Wave diffraction due to areas of energy dissipation. Journal of Waterway, Port, Coastal, and Ocean Engineering 110(1):67-79. https://doi.org/10.1061/ (ASCE)0733-950X(1984)110:1(67)

Davies JL (1964) A morphogenic approach to world shorelines. Zeitschrift für Geomorphologie 8(5):127-142. https://doi. org/10.1127/zfg/mortensen/8/1964/127

de Jong, B., Keijsers, J.G., Riksen, M.J., Krol, J., Slim, P.A.: Soft engineering vs. a dynamic approach in coastal dune management: A case study on the north sea barrier island of ameland, the netherlands. Journal of Coastal Research 30(4), 670 (2014). https:// doi.org/10.2112/JCOASTRES-D-13-00125.1

Dean RG (1978) Effects of vegetation on shoreline erosional processes. In: Clark JR, Clark JE (eds) Wetland functions and values: 
Processing of the national symposium on wetlands. Cambridge, pp 415-426

Defeo O, McLachlan A, Schoeman DS, Schlacher TA, Dugan J, Jones A, Lastra M, Scapini F (2009) Threats to sandy beach ecosystems: A review. Estuarine, Coastal and Shelf Science 81(1):1-12. https://doi.org/10.1016/j.ecss.2008.09.022

Delbaere BCW (ed) (1998) Facts \& figures on Europe's biodiversity: State and trends 1998-1999. Technical report series, European Centre for Nature Conservation, Tilburg

Didderen K, Lengkeek W, Kamermans P, Deden B, Reuchlin-Hugenholtz E, Bergsma JH, van Gool A, van der Have TM, Sas H (2019) Pilot to actively restore native oyster reefs in the north sea: Comrehensive report to share lessons lerned in 2018

Dikau R, Eibisch K, Eichel J, Meßenzehl K, Schlummer-Held M (2019) Geomorphologie. Springer, Berlin. https://doi.org/10. 1007/978-3-662-59402-5

Donker J, van der Vegt M, Hoekstra P (2013) Wave forcing over an intertidal mussel bed. Journal of Sea Research 82:54-66. https:// doi.org/10.1016/j.seares.2012.08.010

Doody JP (2013) Sand Dune Conservation, Management and Restoration, Coastal Research Library, vol 4. Springer, Dordrecht. https://doi.org/10.1007/978-94-007-4731-9

Duarte CM, Borum J, Short FT, Walker DI (2008) Seagrass ecosystems: their global status and prospects. In: Polunin NVC (ed.) Aquatic Ecosystems, pp 281-294. Cambridge University Press, Cambridge . https://doi.org/10.1017/CBO9780511751790.025

Duarte CM, Marbá N, Gacia E, Fourqurean JW, Beggins J, Barrón C, Apostolaki ET (2010) Seagrass community metabolism: Assessing the carbon sink capacity of seagrass meadows. Global Biogeochemical Cycles 24(4), n/a-n/a (2010). https://doi.org/10. 1029/2010GB003793

Duarte CM, Dennison WC, Orth RJW, Carruthers TJB (2008) The charisma of coastal ecosystems: Addressing the imbalance. Estuaries and Coasts 31(2):233-238. https://doi.org/10.1007/ s12237-008-9038-7

Duncan PF, Ghys A (2019) Shells as collector's items. In: Smaal A, Ferreira J, Grant J, Petersen J, Strand (eds.) Goods and Services of Marine Bivalves, pp. 381-411. Springer, Cham (2019). https:// doi.org/10.1007/978-3-319-96776-9_20

EcoShape (2021) Oyster reefs and the pacific oyster. https://www.ecosh ape.org/en/oyster-reefs-and-the-pacific-oyster/

Ellenberg H, Dierschke H (2010) Vegetation mitteleuropas mit den alpen: In: ökologischer, dynamischer und historischer Sicht ; 203 Tabellen, UTB Botanik, Ökologie, Agrar- und Forstwissenschaften, Geographie, vol 8104, 6, vollständig neu bearbeitete und stark erweiterte auflage edn. Verlag Eugen Ulmer, Stuttgart

Erchinger HF (1985) Ostfrieslands Naturlandschaften Dünen, Watt und Salzwiesen: Schutz und Erhaltung von Küste und Inseln. Tierund Pflanzenwelt, Soltau-Kurier, Norden

European Commission (2013) Green infrastructure (gi) - enhancing europe's natural capital: Communication from the commission to the european parliament, the council, the european economic and social committee and the committee of the regions

European Commission (2015) Towards an eu research and innovation policy agenda for nature-based solutions \& re-naturing cities: Final report of the horizon 2020 expert group on 'nature-based solutions and re-naturing cities'

European Commission (2016) The eu and nature-based solutions. https://ec.europa.eu/info/research-and-innovation/research-area/ environment/nature-based-solutions_en

Everard M, Jones L, Watts B (2010) Have we neglected the societal importance of sand dunes? an ecosystem services perspective. Aquatic Conservation: Marine and Freshwater Ecosystems 20(4):476-487. https://doi.org/10.1002/aqc.1114
FAO (2007) The world's mangroves 1980-2005: A thematic study prepared in the framework of the global forest resources assessment 2005

Feagin RA, Smith WK, Psuty NP, Young DR, Martínez ML, Carter GA, Lucas KL, Gibeaut JC, Gemma JN, Koske RE (2010) Barrier islands: Coupling anthropogenic stability with ecological sustainability. Journal of Coastal Research 26:987-992. https:// doi.org/10.2112/09-1185.1

Ferrario F, Beck MW, Storlazzi CD, Micheli F, Shepard CC, Airoldi L (2014) The effectiveness of coral reefs for coastal hazard risk reduction and adaptation. Nature Communications 5:3794. https://doi.org/10.1038/ncomms4794

Finkl CW (2004) Coastal classification: Systematic approaches to consider in the development of a comprehensive scheme. Journal of Coastal Research 201:166-213

Folmer E, Büttger H, Herlyn M, Markert A, Millat G, Troost K, Wehrmann A (2017) Beds of blue mussels and pacific oysters. In: Kloepper S, Baptist MJ, Bostelmann A, Busch JA, Buschbaum C, Gutow L, Janssen G, Jensen K, Jørgensen HP, de Jong F, Lüerßen G, Schwarzer K, Strempel R, Thieltges D (eds) Wadden Sea Quality Status Report 2017. Wilhelmshaven, Germany

Friess DA (2017) Ecotourism as a tool for mangrove conservation. Sumatra Journal of Disaster, Geography and Geography Education 1(1):24-35

Fröhlich J, Rösner HU (2015) Klimaanpassung an weichen küsten: Fallbeispiele aus europa und den usa für das schleswig-holsteinische wattenmeer

Gedan KB, Kirwan ML, Wolanski E, Barbier EB, Silliman BR (2011) The present and future role of coastal wetland vegetation in protecting shorelines: answering recent challenges to the paradigm. Climatic Change 106(1):7-29. https://doi.org/10.1007/ s10584-010-0003-7

Geelen LHWT, Kamps PTWJ, Olsthoorn TN (2017) From overexploitation to sustainable use, an overview of 160 years of water extraction in the amsterdam dunes, the netherlands. Journal of Coastal Conservation 21(5):657-668. https://doi.org/10.1007/ s11852-016-0452-x

Giri C, Ochieng E, Tieszen LL, Zhu Z, Singh A, Loveland T, Masek J, Duke N (2011) Status and distribution of mangrove forests of the world using earth observation satellite data. Global Ecology and Biogeography 20(1):154-159. https://doi.org/10.1111/j. 1466-8238.2010.00584.x

GIZ (2014) Mangrove management: A manual to appropriate mangrove conservation and planting in the mekong delta

Green EP, Short FT (eds) (2003) World Atlas of Seagrasses. University of California Press, Berkeley, USA

Gutiérrez JL, Jones CG, Byers JE, Arkema KK, Berkenbusch K, Commito JA, Duarte CM, Hacker SD, Lambrinos JG, Hendriks IE, Hogarth PJ, Palomo MG, Wild C (2011)Physical ecosystem engineers and the functioning of estuaries and coasts. In: Treatise on estuarine and coastal science, pp 53-81. Elsevier. https://doi.org/ 10.1016/B978-0-12-374711-2.00705-1

Hanley ME, Hoggart S, Simmonds DJ, Bichot A, Colangelo MA, Bozzeda F, Heurtefeux H, Ondiviela B, Ostrowski R, Recio M, Trude R, Zawadzka-Kahlau E, Thompson RC (2014) Shifting sands? coastal protection by sand banks, beaches and dunes. Coastal Engineering 87(S1):136-146. https://doi.org/10.1016/j. coastaleng.2013.10.020

Hassan R, Scholes R, Ash N (Eds.) (2005) Ecosystems and human well-being: Current state and trends, volume 1: Findings of the condition and trends working group of the millennium ecosystem assessment

Heslenfeld P, Jungerius PD, Klijn JA (2008) European coastal dunes: Ecological values, threats, opportunities and policy development. In: Martínez ML, Psuty NP (eds.) Coastal Dunes, Ecological studies, vol 171, pp 335-351. Springer-Verlag Berlin Heidelberg, 
Berlin, Heidelberg (2008). https://doi.org/10.1007/978-3-54074002-5_20

Hesp PA, Walker IJ (2013) Coastal dunes. In: Shroder JF (ed.) Treatise on Geomorphology, vol 17, pp 328-355. Elsevier. https://doi.org/ 10.1016/B978-0-12-374739-6.00310-9

Hinkel J, Nicholls RJ, Tol RS, Wang ZB, Hamilton JM, Boot G, Vafeidis AT, McFadden L, Ganopolski A, Klein RJ (2013) A global analysis of erosion of sandy beaches and sea-level rise: An application of diva. Global and Planetary Change 111:150-158. https://doi.org/10.1016/j.gloplacha.2013.09.002

Hofstede JLA (2019) On the feasibility of managed retreat in the wadden sea of schleswig-holstein. Journal of Coastal Conservation 13(4):185. https://doi.org/10.1007/s11852-019-00714-x

IPCC (2019) Ipcc special report on the ocean and cryosphere in a changing climate

IUCN (2012) The iucn programme 2013-2016. adopted by the iucn world conservation congress, september 2012

Jones CG, Lawton JH, Shachak M (1994) Organisms as ecosystem engineers. Oikos 69(3):373. https://doi.org/10.2307/3545850

Kelletat D (1999) Physische Geographie der Meere und Küsten: Eine Einführung, 2., lneubearb. und erw. aufl. edn. Teubner-Studienbücher der Geographie. Teubner, Stuttgart. http://www.bsz-bw. de/cgi-bin/ekz.cgi?SWB07476643

Kirwan ML, Guntenspergen GR, D'Alpaos A, Morris JT, Mudd SM, Temmerman S (2010) Limits on the adaptability of coastal marshes to rising sea level. Geophysical Research Letters 37(23), n/a-n/a. https://doi.org/10.1029/2010GL045489

Kirwan ML, Megonigal JP (2013) Tidal wetland stability in the face of human impacts and sea-level rise. Nature 504(7478):53-60. https://doi.org/10.1038/nature12856

Kirwan ML, Temmerman S, Skeehan EE, Guntenspergen GR, Fagherazzi S (2016) Overestimation of marsh vulnerability to sea level rise. Nature Climate Change 6(3):253-260. https://doi.org/10. 1038/nclimate2909

Knutson PL, Brochu RA, Seelig WN, Inskeep M (1982) Wave damping inspartina alterniflora marshes. Wetlands 2(1):87-104. https:// doi.org/10.1007/BF03160548

Kollmann J, Kirmer A, Tischew S, Hölzel N, Kiehl K (2019) Renaturierungsökologie. Springer, Berlin. https://doi.org/10.1007/ 978-3-662-54913-1

Küster H (2015) Nordsee: Die Geschichte einer Landschaft. Wissen im Norden. Wachholtz Murmann Publishers, Kiel and Hamburg. http://www.wachholtz-verlag.de

WWF Deutschland (Ed.) (2018) Land unter im Wattenmeer - Auswirkungen des Meeresspiegelanstiegs auf die Natur der Halligen und Möglichkeiten zur Anpassung. Husum and Berlin

Lenihan HS, Peterson CH (1998) How habitat degradation through fishery disturbance enhances impacts of hypoxia on oyster reefs. Ecological Applications 8(1):128-140

Luijendijk A, Hagenaars G, Ranasinghe R, Baart F, Donchyts G, Aarninkhof S (2018) The state of the world's beaches. Scientific reports 8(1). https://doi.org/10.1038/s41598-018-24630-6

Marbá N, Duarte CM, Alexandra A, Cabaço S (2004) How do seagrasses grow and spread? In: Borum J, Duarte CM, KrauseJensen D, Greve TM (eds) European seagrasses: an introduction to monitoring and management. The M\&MS project, S. 1, pp $11-18$

Marchand M (2008) Mangrove restoration in vietnam: Key considerations and a practical guide

Marijnissen R, Esselink P, Kok M, Kroeze C, van Loon-Steensma JM (2020) How natural processes contribute to flood protection - a sustainable adaptation scheme for a wide green dike. The Science of the total environment 739:139698. https://doi.org/10.1016/j. scitotenv.2020.139698

Martínez ML, Psuty NP, Lubke RA (2008) A perspective on coastal dunes. In: Martínez ML, Psuty NP (eds.) Coastal Dunes,
Ecological studies, vol 171, pp 3-10. Springer-Verlag Berlin Heidelberg, Berlin, Heidelberg. https://doi.org/10.1007/978-3540-74002-5_1

Masselink G, Short AD (1993) The effect of tide range on beach morphodynamics and morphology: A conceptual beach model. Journal of Coastal Research 9(3):785-800

Maza M, Lara JL, Ondiviela B, Losada IJ (2012) Wave attenuation modelling by submerged vegetation: Ecological and engineering analysis. Coastal Engineering Proceedings 1(33). https://doi.org/ 10.9753/icce.v33.management.62

Mazda Y, Kobashi D, Okada S (2005) Tidal-scale hydrodynamics within mangrove swamps. Wetlands Ecology and Management 13(6):647-655. https://doi.org/10.1007/s11273-005-0613-4

McCowan J (1894) On the highest wave of permanent type. The London, Edinburgh, and Dublin Philosophical Magazine and Journal of Science 38(233):351-358. https://doi.org/10.1080/14786 449408620643

Mcleod E, Chmura GL, Bouillon S, Salm R, Björk M, Duarte CM, Lovelock CE, Schlesinger WH, Silliman BR (2011) A blueprint for blue carbon: toward an improved understanding of the role of vegetated coastal habitats in sequestering co 2 . Frontiers in Ecology and the Environment 9(10):552-560. https://doi.org/ $10.1890 / 110004$

Mcowen C, Weatherdon LV, van Bochove JW, Sullivan E, Blyth S, Zockler C, Stanwell-Smith D, Kingston N, Martin C, Spalding M, Fletcher S(2017) Global distribution of saltmarsh (v6). In: Biodiversity data journal, united nations environment programme world conservation monitoring centre (UNEP-WCMC), vol 5.https://doi.org/10.34892/07VK-WS51

MELUR (2015) Strategie für das Wattenmeer 2100. Ministerium für Energiewende,Landwirtschaft, Umwelt und ländliche Räume des Landes Schleswig-Holstein (Ed.), Kiel

Mendez FJ, Losada IJ (2004) An empirical model to estimate the propagation of random breaking and nonbreaking waves over vegetation fields. Coastal Engineering 51(2):103-118. https:// doi.org/10.1016/j.coastaleng.2003.11.003

Mitsch WJ, Jørgensen SE (2003) Ecological engineering: A field whose time has come. Ecological Engineering 20(5):363-377. https:// doi.org/10.1016/j.ecoleng.2003.05.001

Moberg F, Folke C (1999) Ecological goods and services of coral reef ecosystems. Ecological Economics 29:215-233

Möller I, Kudella M, Rupprecht F, Spencer T, Paul M, van Wesenbeeck BK, Wolters G, Jensen K, Bouma TJ, Miranda-Lange M, Schimmels S (2014) Wave attenuation over coastal salt marshes under storm surge conditions. Nature Geoscience 7(10):727-731. https://doi.org/10.1038/ngeo2251

Morris RL, Konlechner TM, Ghisalberti M, Swearer SE (2018) From grey to green: Efficacy of eco-engineering solutions for naturebased coastal defence. Global change biology 24(5):1827-1842. https://doi.org/10.1111/gcb.14063

Müller F, Fischer O (1937) Die Inseln. 5: Amrum, Das Wasserwesen an der schleswig-holsteinischen Nordseeküste, vol 2:5, 1984 reprint der ausgabe berlin 1937 edn. Dietrich Reimer Verlag, Berlin

Narayan S, Beck MW, Reguero BG, Losada IJ, van Wesenbeeck B, Pontee N, Sanchirico JN, Ingram JC, Lange GM, BurksCopes KA (2016) The effectiveness, costs and coastal protection benefits of natural and nature-based defences. PloS one 11(5):e0154735. https://doi.org/10.1371/journal.pone.0154735

Narayan S, Beck MW, Wilson P, Thomas C, Guerrero A, Shepard C, Reguero BG, Franco G, Ingram JC, Trespalacios D (2016) Coastal wetlands and flood damage reduction: Using risk industry-based models to assess natural defenses in the northeastern usa

Nguyen HH, McAlpine C, Pullar D, Leisz SJ, Galina G (2015) Drivers of coastal shoreline change: Case study of hon dat coast, kien 
giang, vietnam. Environmental management 55(5):1093-1108. https://doi.org/10.1007/s00267-015-0455-7

Niemeyer HD, Eiben H, Rhode H (1996) History and heritage of german coastal engineering. In: Kraus NC (ed) History and heritage of coastal engineering. American Society of Civil Engineers, Reston, pp 169-213

Nolte S, Koppenaal EC, Esselink P, Dijkema KS, Schuerch M, de Groot AV, Bakker JP, Temmerman S (2013) Measuring sedimentation in tidal marshes: a review on methods and their applicability in biogeomorphological studies. Journal of Coastal Conservation 17(3):301-325. https://doi.org/10.1007/s11852-013-0238-3

Ondiviela B, Losada IJ, Lara JL, Maza M, Galván C, Bouma TJ, van Belzen J (2014) The role of seagrasses in coastal protection in a changing climate. Coastal Engineering 87:158-168. https://doi. org/10.1016/j.coastaleng.2013.11.005

Palmer R, Limited T (1996) History of coastal engineering in great britain. In: Kraus NC (ed) History and heritage of coastal engineering. American Society of Civil Engineers, Reston, pp 214-274

Palmer MA, Liu J, Matthews JH, Mumba M, D’Odorico P (2015) Manage water in a green way. Science (New York, N.Y.) 349(6248):584-585. https://doi.org/10.1126/science.aac7778

Pethick J, Burd F (1993) Coastal defence and the environment: A guide to good practice

Pethnick J (1984) An introduction to coastal geomorphology. Arnold, London

PIANC (2011) Working with nature: Pianc position paper

Probert PK (2017) Coral reefs. In: Probert PK (ed.) Marine conservation, pp 338-371. Cambridge University Press, Cambridge. https://doi.org/10.1017/9781139043588.014

Provoost S, Jones MLM, Edmondson SE (2011) Changes in landscape and vegetation of coastal dunes in northwest europe: a review. Journal of Coastal Conservation 15(1):207-226. https://doi.org/ 10.1007/s11852-009-0068-5

Putnam HM, Barott KL, Ainsworth TD, Gates RD (2017) The vulnerability and resilience of reef-building corals. Current biology : $\mathrm{CB}$ 27(11):R528-R540. https://doi.org/10.1016/j.cub.2017.04.047

Quang Bao T (2011) Effect of mangrove forest structures on wave attenuation in coastal vietnam. Oceanologia 53(3):807-818. https://doi.org/10.5697/oc.53-3.807

Quataert E, Storlazzi C, van Rooijen A, Cheriton O, van Dongeren A (2015) The influence of coral reefs and climate change on wavedriven flooding of tropical coastlines. Geophysical Research Letters 42(15):6407-6415. https://doi.org/10.1002/2015GL064861

Rabe S, Stokman A, Schulz J, Raupach P, Reise K (2018) Weiche kante: ein konzeptioneller beitrag zu einem naturfreundlichen küstenschutz in der wattenmeer-region

Roscoe KL, Diermanse F (2011) Effect of surge uncertainty on probabilistically computed dune erosion. Coastal Engineering 58(11):1023-1033. https://doi.org/10.1016/j.coastaleng.2011. 05.014

Rupprecht F (2015) Vegetation succession and coastal protection by wave dissipation in salt marshes of north-west europe. Phd thesis, Universität Hamburg, Hamburg, Germany. https://ediss.sub.unihamburg.de/volltexte/2015/7576/pdf/Dissertation.pdf

SAGE (2015) Natural and structural measures for shoreline stabilization. www.SAGEcoast.org

Schoonees T, Gijón Mancheño A, Scheres B, Bouma TJ, Silva R, Schlurmann T, Schüttrumpf H (2019) Hard structures for coastal protection, towards greener designs. Estuaries and Coasts 42(7):1709-1729. https://doi.org/10.1007/s12237-019-00551-z

Shepard FP (1973) Submarine Geology, 3, ed. Harper \& Row, New York, USA

Shepard CC, Crain CM, Beck MW (2011) The protective role of coastal marshes: a systematic review and meta-analysis. PloS one 6(11):e27374. https://doi.org/10.1371/journal.pone.0027374
Short AD (1991) Macro-meso tidal beach morphodynamics: An overview. Journal of Coastal Research 7(2):417-436

Short AD (2006) Australian beach systems-nature and distribution. Journal of Coastal Research 221:11-27. https://doi.org/10.2112/ 05A-0002.1

Siemes RWA, Borsje BW, Daggenvoorde RJ, Hulscher SJMH (2020) Artificial structures steer morphological development of salt marshes: A model study. Journal of Marine Science and Engineering 8(5):326. https://doi.org/10.3390/jmse8050326

Smith SV, Kinsey DW (1976) Calcium carbonate production, coral reef growth, and sea level change. Science (New York, N.Y.) 194(4268):937-939. https://doi.org/10.1126/science.194.4268. 937

Sørensen T, Fredsøe J, Jakobsen PR (1996) History of coastal engineering in denmark. In: Kraus NC (ed) History and Heritage of Coastal Engineering. American Society of Civil Engineers, Reston, pp 103-141

Spalding, M., Kainuma, M., Collins, L.: World atlas of mangroves (version 3): A collaborative project of itto, isme, fao, unep-wcmc, unesco-mab, unu-inweh and tnc (2010). 10.34892/W2EW-M835

Spalding MD, Ruffo S, Lacambra C, Meliane I, Hale LZ, Shepard CC, Beck MW (2014) The role of ecosystems in coastal protection: Adapting to climate change and coastal hazards. Ocean \& Coastal Management 90:50-57. https://doi.org/10.1016/j.oceco aman.2013.09.007

Spalding M, Burke L, Wood SA, Ashpole J, Hutchison J, zu Ermgassen P (2017) Mapping the global value and distribution of coral reef tourism. Marine Policy 82(1):104-113. https://doi.org/10.1016/j. marpol.2017.05.014

Stock M, Bergmann HH, Zucchi H (2012) Watt: Lebensraum zwischen Land und Meer, 3rd edn. Boyens, Heide

Stutz ML, Smith AS, Pilkey OH (1998)Differing mechanisms of wave energy dissipation in the wave shoaling zone, surf zone, and swash zone. Journal of Coastal Research (Special Issue No. 26, Proceedings of the Palm Beach International Coastal Symposium 19-23 May 1998), 214-218

Sutton-Grier AE, Wowk K, Bamford H (2015) Future of our coasts: The potential for natural and hybrid infrastructure to enhance the resilience of our coastal communities, economies and ecosystems. Environmental Science \& Policy 51:137-148. https:// doi.org/10.1016/j.envsci.2015.04.006

Sutton-Grier AE, Gittman RK, Arkema KK, Bennett RO, Benoit J, Blitch S, Burks-Copes KA, Colden A, Dausman A, DeAngelis BM, Hughes AR, Scyphers SB, Grabowski JH (2018) Investing in natural and nature-based infrastructure: Building better along our coasts. Sustainability 10(2):523. https://doi.org/10.3390/ su10020523

Thorenz F (2014) Die entwicklung des küstenschutzes an der nordsee. In: Gesellschaft Hafentechnische, E.V. (eds) Jahrbuch der Hafentechnischen Gesellschaft, Jahrbuch der Hafentechnischen Gesellschaft, vol 57, pp 135-155. Schiffahrts-Verlag Hansa, Hamburg

Tzoulas K, Korpela K, Venn S, Yli-Pelkonen V, Kaźmierczak A, Niemela J, James P (2007) Promoting ecosystem and human health in urban areas using green infrastructure: A literature review. Landscape and Urban Planning 81(3):167-178. https://doi.org/ 10.1016/j.landurbplan.2007.02.001

UNEP-WCMC, Short FT (2020) Global distribution of seagrasses (version 7.0): Seventh update to the data layer used in green and short (2003). https://doi.org/10.34892/X6R3-D211

UNEP-WCMC, WorldFish Centre, World Resources Institute, The Nature Conservancy (2018) Global distribution of warm-water coral reefs, compiled from multiple sources including the millennium coral reef mapping project (version 4.0). https://doi.org/ 10.34892/T2WK-5T34 
United Nations (2016) The first global integrated marine assessment: World ocean assessment $\mathrm{i}$

USACE (2012) Engineering with nature. https://ewn.el.erdc.dren.mil/ pub/EWNFactSheet_Final.pdf

van Coppenolle R, Schwarz C, Temmerman S (2018) Contribution of mangroves and salt marshes to nature-based mitigation of coastal flood risks in major deltas of the world. Estuaries and Coasts 41(6):1699-1711. https://doi.org/10.1007/s12237-018-0394-7

van der Heide T, van Nes EH, Geerling GW, Smolders AJP, Bouma TJ, van Katwijk MM (2007) Positive feedbacks in seagrass ecosystems: Implications for success in conservation and restoration. Ecosystems 10(8):1311-1322. https://doi.org/10.1007/ s10021-007-9099-7

van Gent M, van Thiel de Vries J, Coeveld EM, de Vroeg JH, van de Graaff J (2008) Large-scale dune erosion tests to study the influence of wave periods. Coastal Engineering 55(12):1041-1051. https://doi.org/10.1016/j.coastaleng.2008.04.003

Vellinga P (1986) Beach and dune erosion during storm surges. Phd thesis, Delft University of Technology, Delft, The Netherlands

Vousdoukas MI, Ranasinghe R, Mentaschi L, Plomaritis TA, Athanasiou P, Luijendijk A, Feyen L (2020) Sandy coastlines under threat of erosion. Nature Climate Change 10(3):260-263. https:// doi.org/10.1038/s41558-020-0697-0

Vriend HD, van Koningsveld M (2012) Building with nature: Thinking, acting and interacting differently. EcoShape, Building with Nature, Dordrecht

Walters BB, Rönnbáck P, Kovacs JM, Crona B, Hussain SA, Badola R, Primavera JH, Barbier E, Dahdouh-Guebas F (2008) Ethnobiology, socio-economics and management of mangrove forests: A review. Aquatic Botany 89(2):220-236. https://doi.org/10.1016/j. aquabot.2008.02.009

Watson RT, Zakri AH (Eds.) (2003) Ecosystems and human wellbeing: A framework for assessment: Millennium ecosystem assessment

Wiegel RL, Saville T Jr (1996) History of coastal engineering in the usa. In: Kraus NC (ed) History and heritage of coastal engineering. American Society of Civil Engineers, Reston, pp 513-600

Woodhead AJ, Hicks CC, Norström AV, Williams GJ, Graham NAJ (2019) Coral reef ecosystem services in the anthropocene. Funct Ecol:1 https://doi.org/10.1111/1365-2435.13331

World Bank Group (2016) Managing coasts with natural solutions: Guidelines for measuring and valuing the coastal protection services of mangroves and coral reefs. Beck MW and Lange G-M (Eds.), Waves technical report

Wright LD, Short AD (1984) Morphodynamic variability of surf zones and beaches: A synthesis. Marine Geology 56:93-118

Zepp H (2017) Geomorphologie: eine einführung, grundriss allgemeine geographie, vol 2164, 7, überarbeitete auflage edn. Ferdinand Schöningh and UTB, Paderborn and Stuttgart. http://www. utb-studi-e-book.de/9783838547404

Zerbe S, Wiegleb G (2009) Renaturierung von Ökosystemen in Mitteleuropa. Spektrum Akademischer Verlag, Heidelberg. https:// doi.org/10.1007/978-3-8274-2161-6

Zhang X, Lin P, Gong Z, Li B, Chen X (2020) Wave attenuation by spartina alterniflora under macro-tidal and storm surge conditions. Wetlands 40(6):2151-2162. https://doi.org/10.1007/ s13157-020-01346-w 